Supporting Information for

\title{
The Tunable Photophysical Properties of Enamine Intermediates Involved in Light-Driven Aminocatalysis
}

\author{
Katrina Bergmann and Rebecca L. Davis* \\ Department of Chemistry, University of Manitoba, Winnipeg, Manitoba R3T 2N2, Canada
}
A. General information
B. Experimental details for in situ enamine and dienamine formation
C. Optical absorption spectra
D. Benchmarking of density functionals and basis sets for TD-DFT calculations
S13
E. Summary of TD-DFT analysis for enamines and dienamines
S20
F. Select examples of enamine $Z$ isomers
$\mathrm{S} 23$
G. Application of different functionals
S24
H. Fluorescence and optical gap of enamines
S30
I. TD-DFT analysis and optical gap of isolable enamine
S31
J. Ground state geometry optimized structures
S33
K. TD-DFT analysis
S48
L. References
S86 


\section{A. General information}

Materials. All reagents and solvents were purchased from Sigma Aldrich and Alfa Aeser and used as received, without further purification.

Optical absorption spectra. The Biochrom WPA Biowave II spectrophotometer was used for all UV-vis measurements, collecting from 200 to $700 \mathrm{~nm}$, with a $1.00 \mathrm{~mm}$ Hellma Quartz Glass High Performance cuvette.

Computational details. All calculations were conducted using Gaussian 16 software unless otherwise stated. ${ }^{1}$ The IEFPCM(acetonitrile) solvent model was used for all calculations. ${ }^{2}$ Conformational searches were performed with Avogadro 1.2.0 using MMFF94s. ${ }^{3,4}$ The lowest energy structures from the conformational search were optimized at the M06-2X/6-31+G(d,p) level in order to determine the ground state geometries to be used for TD-DFT.5,6 For benchmarking, the first 50 vertical excitations from these ground state geometries of $\mathbf{I}, \mathbf{A}$, and I + A were analyzed using TD-DFT with the hybrid functionals B3LYP, ${ }^{7}$ PBE0, ${ }^{8}$ M06-2X, M06HF, ${ }^{9}$ CAM-B3LYP,10 LC-wHPBE, 11 wB97X-D, ${ }^{12}$ whPBE0, ${ }^{13}$ and the basis sets 6-31+G(d,p), aug-cc-pVDZ, ${ }^{14}$ and aug-cc-pVTZ. ${ }^{15}$ For the remainder of the TD-DFT studies, PBE0/aug-ccpVDZ was used, unless explicitly stated. The molecular orbitals and their energies were calculated using ground state DFT at this same level of theory. To display the calculated vertical excitations as UV-vis spectra, GaussView 6 was used and the peak half-width at half height was set to $0.333 \mathrm{eV} .{ }^{16}$ VESTA was used to visualize the molecular orbitals, with an isovalue of $0.02 .{ }^{17}$ 


\section{B. Experimental details for in situ enamine and dienamine formation}

Hexanal measurements. $\quad 98.3 \mu \mathrm{L}(0.800 \mathrm{mmol})$ of hexanal (A) in $1.000 \mathrm{~mL}$ of acetonitrile produced an $800 \mathrm{mM}$ solution, which was serial diluted to 400, 200, 100, and 50 $\mathrm{mM}$.

E-2-Hexenal measurements. $92.8 \mu \mathrm{L}(0.800 \mathrm{mmol})$ of $E$-2-Hexenal $(\mathbf{B})$ in $1.000 \mathrm{~mL}$ of acetonitrile produced an $800 \mathrm{mM}$ solution, which was then serial diluted to 400, 200, 100, 50, 25, $12.5,6.25,3.13,1.56 \mathrm{mM}$.

Pyrrolidine measurements. $24.6 \mu \mathrm{L}(0.300 \mathrm{mmol})$ of pyrrolidine (I) in $3.000 \mathrm{~mL}$ of acetonitrile produced a $100 \mathrm{mM}$ solution, which was diluted to $50 \mathrm{mM}$. Synthesis of the enamine was achieved by combining $24.6 \mu \mathrm{L}(0.300 \mathrm{mmol})$ of $\mathbf{I}$ and $36.9 \mu \mathrm{L}(0.300 \mathrm{mmol})$ of $\mathbf{A}$ in $3.000 \mathrm{~mL}$ of acetonitrile to produce a $100 \mathrm{mM}$ solution of $\mathbf{I}+\mathbf{A}$, which was stirred at room temperature for ten minutes with $4 \AA$ molecular sieves present in the vial, and then serial diluted to $50,25,12.5$, and $6.25 \mathrm{mM}$. Synthesis of the dienamine was achieved by combining $24.6 \mu \mathrm{L}$ $(0.300 \mathrm{mmol})$ of $\mathbf{I}$ and $34.8 \mu \mathrm{L}(0.300 \mathrm{mmol})$ of $\mathbf{B}$ in $3.000 \mathrm{~mL}$ of acetonitrile to produce a 100 $\mathrm{mM}$ solution of $\mathbf{I}+\mathbf{B}$, which was stirred at room temperature for ten minutes with $4 \AA$ molecular sieves present in the vial, and then serial diluted to 50, 25, 12.5, 6.25, 3.13, 1.56, and $0.78 \mathrm{mM}$.

Methyl prolinate measurements. $16.56 \mathrm{mg}(0.100 \mathrm{mmol})$ of L-proline methyl ester hydrochloride (II) in $2.000 \mathrm{~mL}$ acetonitrile produced a $50 \mathrm{mM}$ solution, which was serial diluted to $25,12.5,6.25,3.13$, and $1.56 \mathrm{mM}$. Synthesis of the enamine was achieved by mixing 33.12 $\mathrm{mg}(0.200 \mathrm{mmol})$ of $\mathbf{I I}$ and $24.6 \mu \mathrm{L}(0.200 \mathrm{mmol})$ of $\mathbf{A}$ in $4.000 \mathrm{~mL}$ of acetonitrile produced a 50 $\mathrm{mM}$ solution of $\mathbf{I I}+\mathbf{A}$, which was stirred at room temperature for ten minutes with $4 \AA$ molecular sieves present in the vial, and then serial diluted to 25, 12.5, 6.25, 3.13, and 1.56 mM. Since the enamine results indicated that the HOMO to LUMO gap for II + A was even larger than for I + A, the dienamine of II was not investigated.

Jorgensen's catalyst measurements. $29.9 \mathrm{mg}(0.050 \mathrm{mmol})$ of $(R)-\alpha, \alpha$-Bis[3,5bis(trifluoromethyl) phenyl]-2-pyrrolidinemethanol trimethylsilyl ether (III) in $0.500 \mathrm{~mL}$ acetonitrile produced a $100 \mathrm{mM}$ solution, which was serial diluted to 50, 25, 12.5, 6.25, 3.13, $1.56,0.78$, and $0.39 \mathrm{mM}$. Synthesis of the enamine was achieved by combining $29.9 \mathrm{mg}(0.050$ $\mathrm{mmol})$ of III and $6.2 \mu \mathrm{L}(0.050 \mathrm{mmol})$ of $\mathbf{A}$ in $0.500 \mathrm{~mL}$ acetonitrile to produce a $100 \mathrm{mM}$ solution of III $+\mathbf{A}$, which was stirred at room temperature for ten minutes with $4 \AA$ molecular sieves present in the vial, and then serial diluted to $50,25,12.5,6.25,3.13,1.56,0.78$, and 0.39 $\mathrm{mM}$. Synthesis of the dienamine was achieved by combining $44.9 \mathrm{mg}(0.075 \mathrm{mmol})$ of III and $8.8 \mu \mathrm{L}(0.075 \mathrm{mmol})$ of $\mathbf{B}$ in $0.750 \mathrm{~mL}$ acetonitrile to produce a $100 \mathrm{mM}$ solution of $\mathbf{I I I}+\mathbf{B}$, which was stirred at room temperature for ten minutes with $4 \AA$ molecular sieves present in the vial, and then serial diluted to 50, 25, 12.5, 6.25, 3.13, 1.56, and $0.78 \mathrm{mM}$.

MacMillan's catalyst (HCl salt) measurements. $6.37 \mathrm{mg}(0.025 \mathrm{mmol})((5 S)-(-)-2,2,3-$ Trimethyl-5-benzyl-4-imidazolidinone monohydrochloride (IV salt) in $1.000 \mathrm{~mL}$ acetonitrile produced a $25 \mathrm{mM}$ solution, which was serial diluted to $12.5,6.25,3.13$, and $1.56 \mathrm{mM}$. Synthesis of the enamine was achieved by combining $6.37 \mathrm{mg}(0.025 \mathrm{mmol})$ of IV salt and $3.1 \mu \mathrm{L}(0.025 \mathrm{mmol})$ of $\mathbf{A}$ in $1.000 \mathrm{~mL}$ acetonitrile produced a $25 \mathrm{mM}$ solution of $\mathbf{I V}$ salt $+\mathbf{A}$, which was stirred at room temperature for ten minutes with $4 \AA$ molecular sieves present in the vial, and serial diluted to $12.5,6.25,3.13$, and $1.56 \mathrm{mM}$. Synthesis of the dienamine was achieved by combining $6.4 \mathrm{mg}(0.025 \mathrm{mmol}) \mathbf{I V}$ salt and $2.9 \mu \mathrm{L}(0.025 \mathrm{mmol})$ of $\mathbf{B}$ in $1.000 \mathrm{~mL}$ acetonitrile to produce a $25 \mathrm{mM}$ solution of IV salt $+\mathbf{B}$, which was stirred at room temperature 
for ten minutes with $4 \AA$ molecular sieves present in the vial, and serial diluted to $12.5,6.25$, $3.13,1.56$, and $0.78 \mathrm{mM}$.

MacMillan's catalyst (freebase) measurements. Due to peaks in the IV salt $+\mathbf{A}$ experimental spectra that could not be explained computationally (Figure S12), it was hypothesized that the presence of hydrochloride in the $((5 S)-(-)-2,2,3$-Trimethyl-5-benzyl-4imidazolidinone monohydrochloride was interfering with the enamine spectra. To remove this interference, $15.0 \mathrm{~mL}$ saturated solution of $\mathrm{NaHCO}_{3}$ was added to $150.0 \mathrm{mg}((5 S)-(-)-2,2,3-$ Trimethyl-5-benzyl-4-imidazolidinone monohydrochloride. This solution was extracted three times with $15.0 \mathrm{~mL}$ dichloromethane, and the combined organic layers were dried over $\mathrm{NaSO}_{4}$. Solvent was removed by rotary evaporation providing a clear, colourless liquid. $21.8 \mathrm{mg}(0.100$ mmol) of this liquid (IV) in $1.000 \mathrm{~mL}$ acetonitrile produced a $100 \mathrm{mM}$ solution, which was serial diluted to $50,25,12.5,6.25,3.13$, and $1.56 \mathrm{mM}$. Synthesis of the enamine was achieved by combining $21.8 \mathrm{mg}(0.100 \mathrm{mmol})$ of IV and $12.3 \mu \mathrm{L}(0.100 \mathrm{mmol})$ of $\mathbf{A}$ in $1.000 \mathrm{~mL}$ acetonitrile produced a $100 \mathrm{mM}$ solution of $\mathbf{I V}+\mathbf{A}$, which was stirred at room temperature for ten minutes with $4 \AA$ molecular sieves present in the vial, and serial diluted to 50, 25, 12.5, 6.25, 3.13, and $1.56 \mathrm{mM}$. Synthesis of the dienamine was achieved by combining $21.8 \mathrm{mg}(0.100 \mathrm{mmol}) \mathbf{I V}$ and $11.7 \mu \mathrm{L}(0.100 \mathrm{mmol})$ of $\mathbf{B}$ in $1.000 \mathrm{~mL}$ acetonitrile produced a $25 \mathrm{mM}$ solution of $\mathbf{I V}+\mathbf{B}$, which was stirred at room temperature for ten minutes with $4 \AA$ molecular sieves present in the vial, and serial diluted to $12.5,6.25,3.13,1.56$, and $0.78 \mathrm{mM}$. 


\section{Optical absorption spectra}

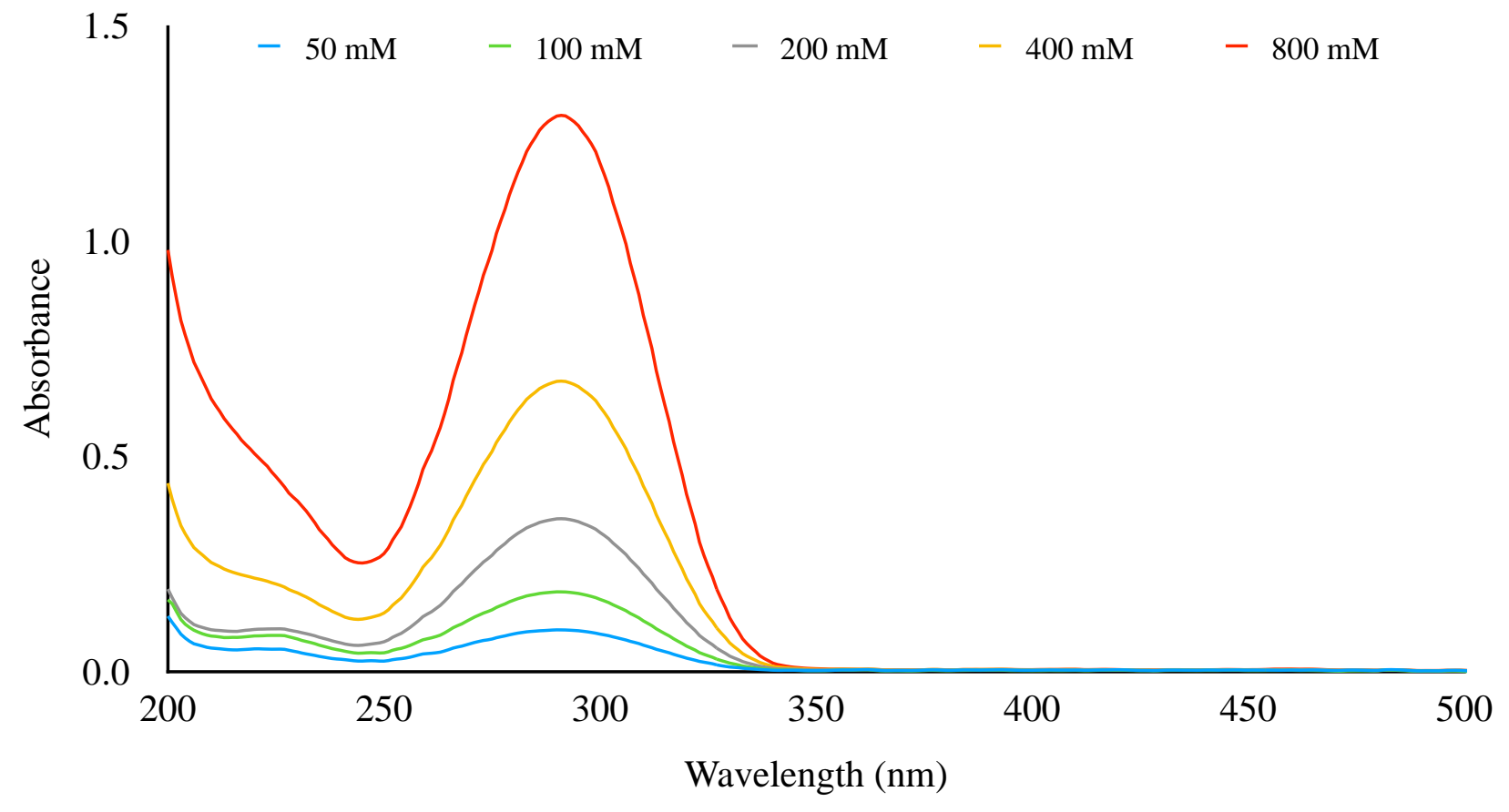

Figure S1. UV-vis absorption spectra of $\mathbf{A}$.

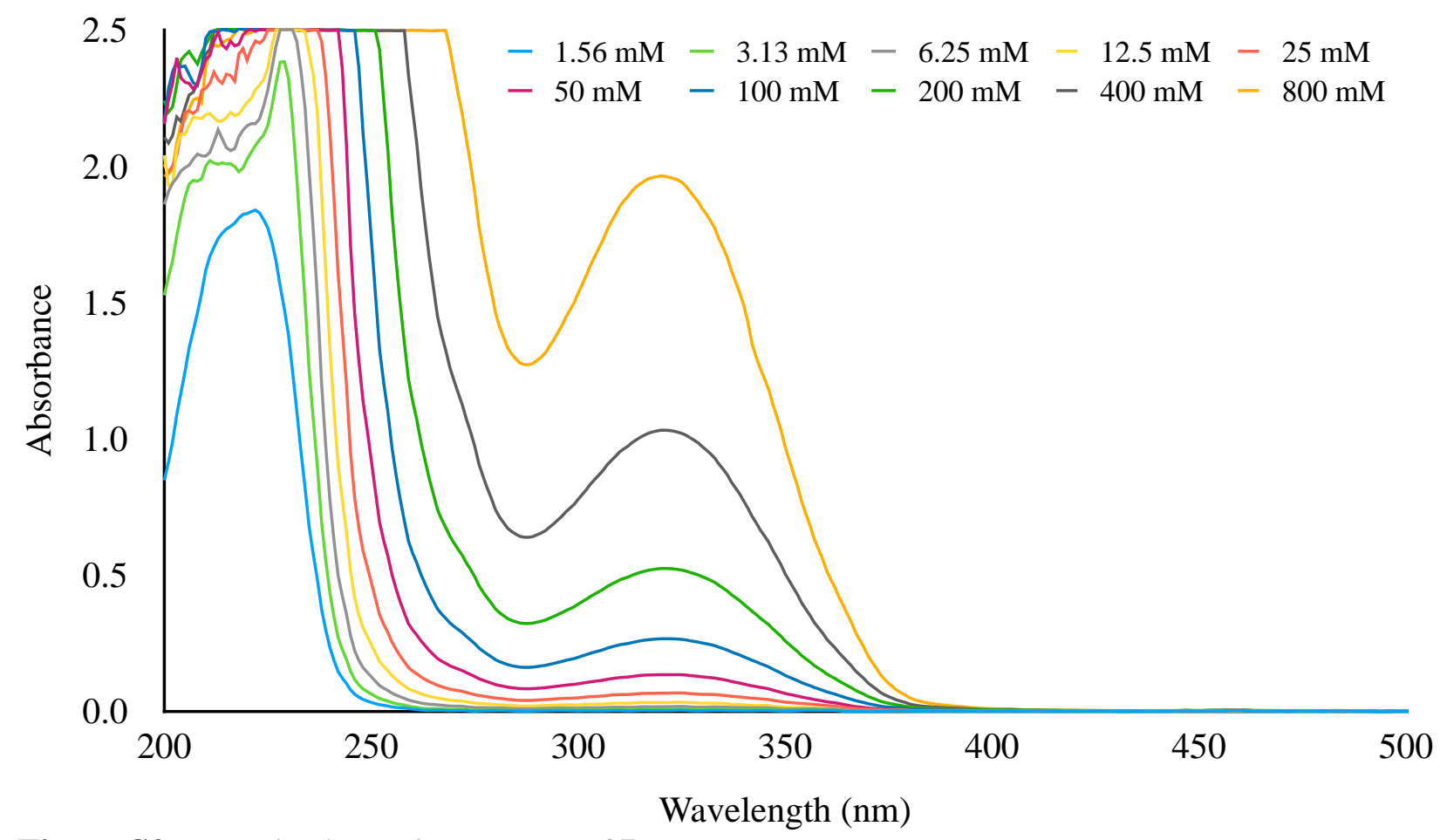

Figure S2. UV-vis absorption spectra of $\mathbf{B}$. 


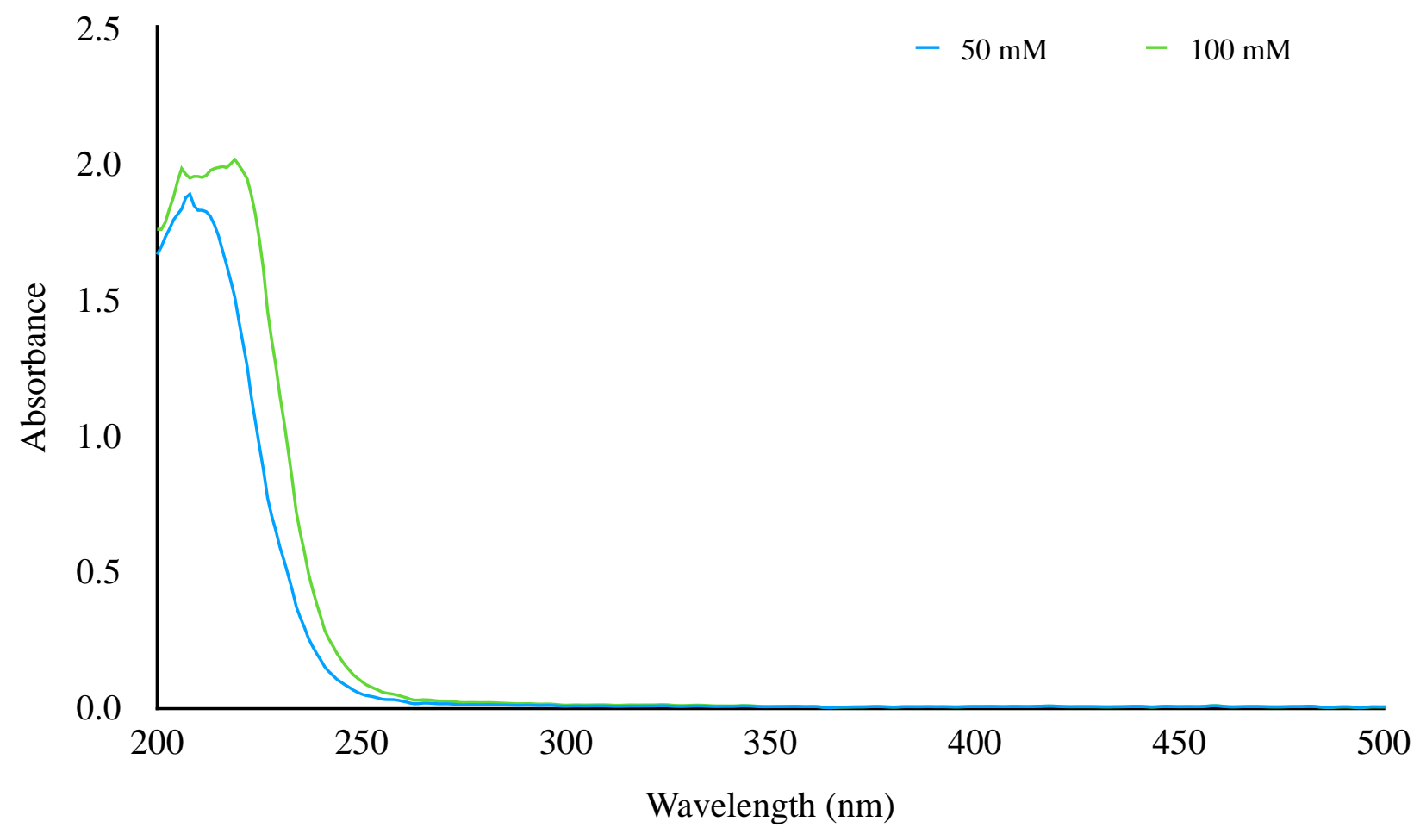

Figure S3. UV-vis absorption spectra of $\mathbf{I}$.

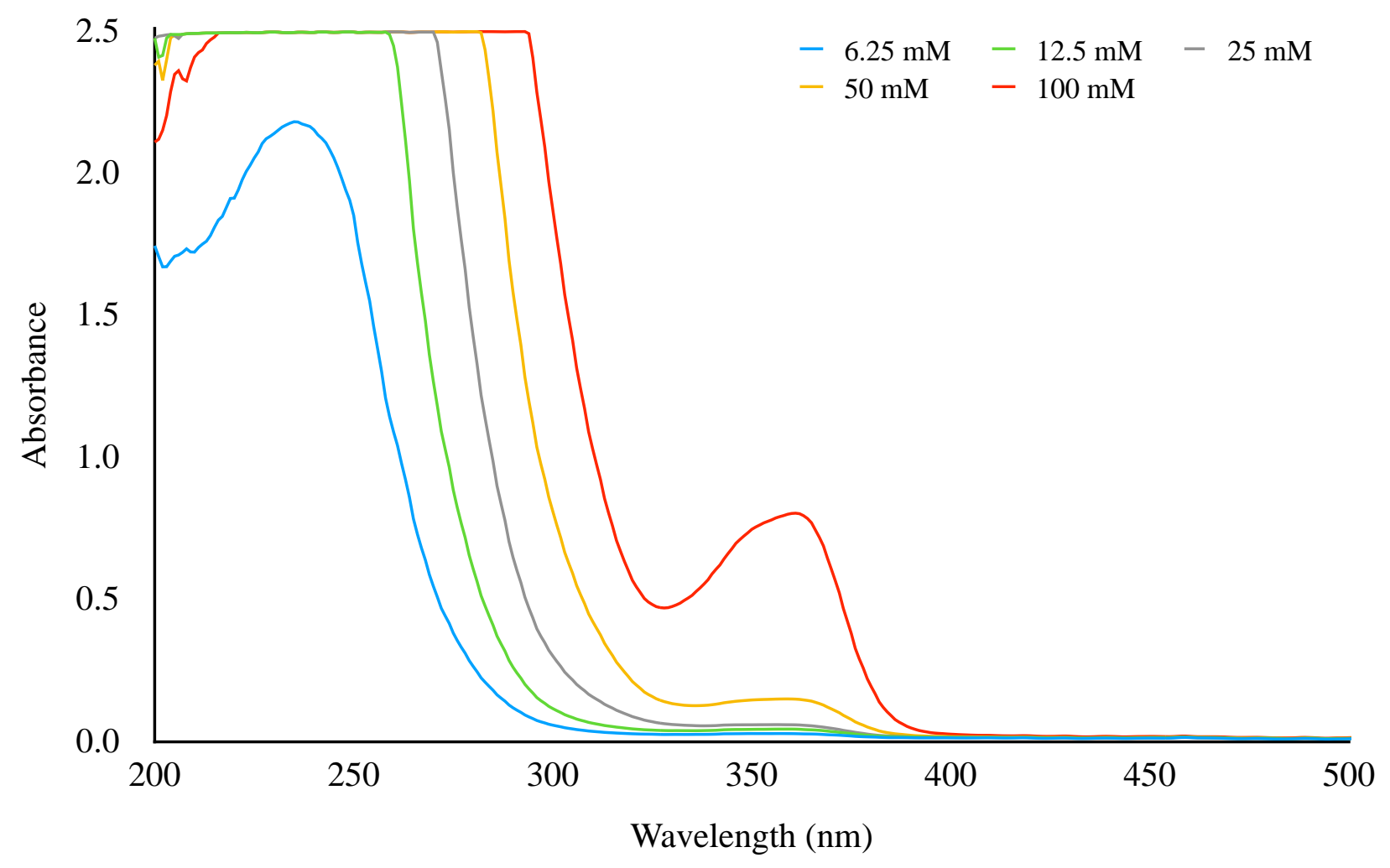

Figure S4. UV-vis absorption spectra of $\mathbf{I}+\mathbf{A}$. 


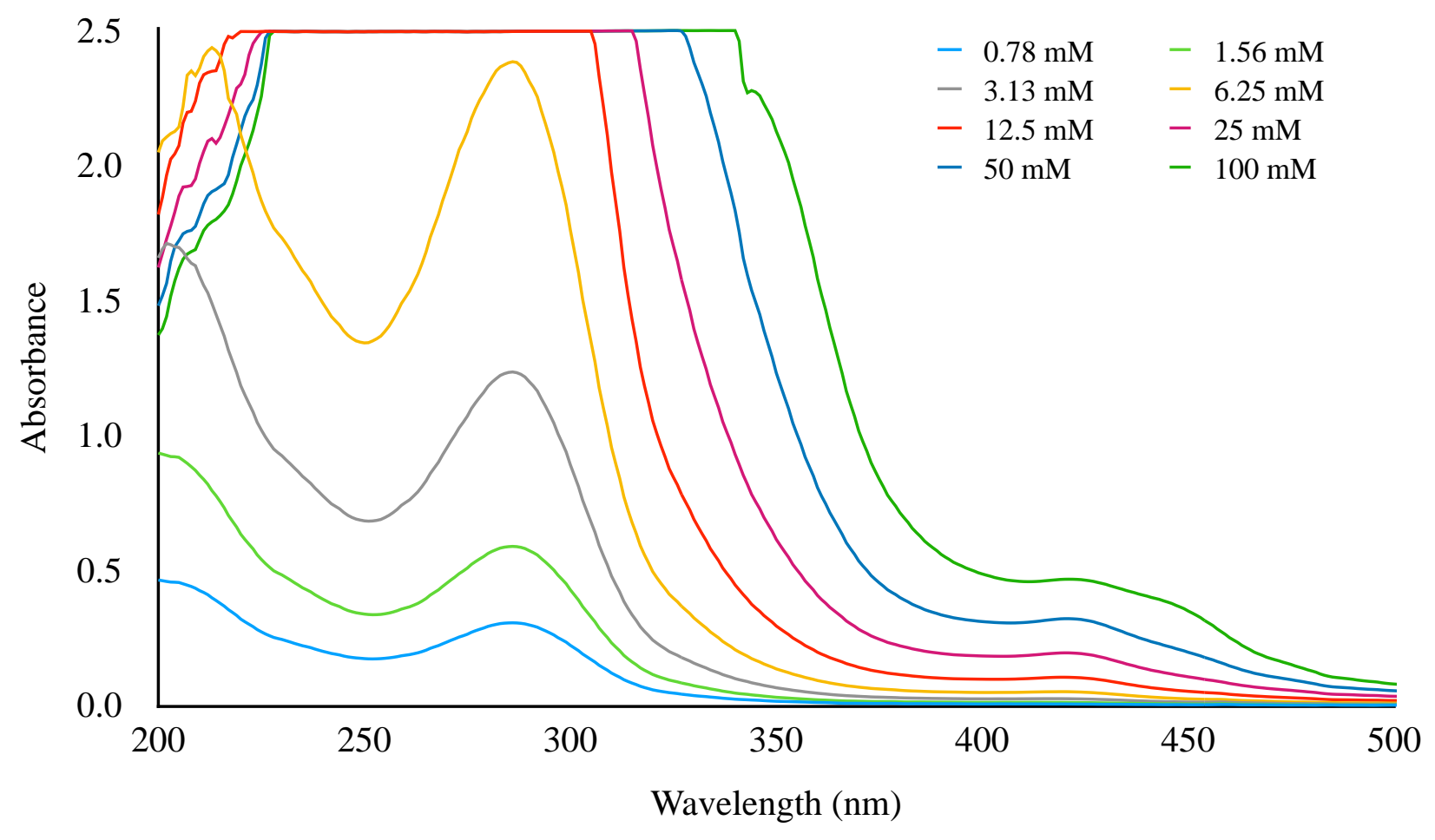

Figure S5. UV-vis absorption spectra of $\mathbf{I}+\mathbf{B}$.

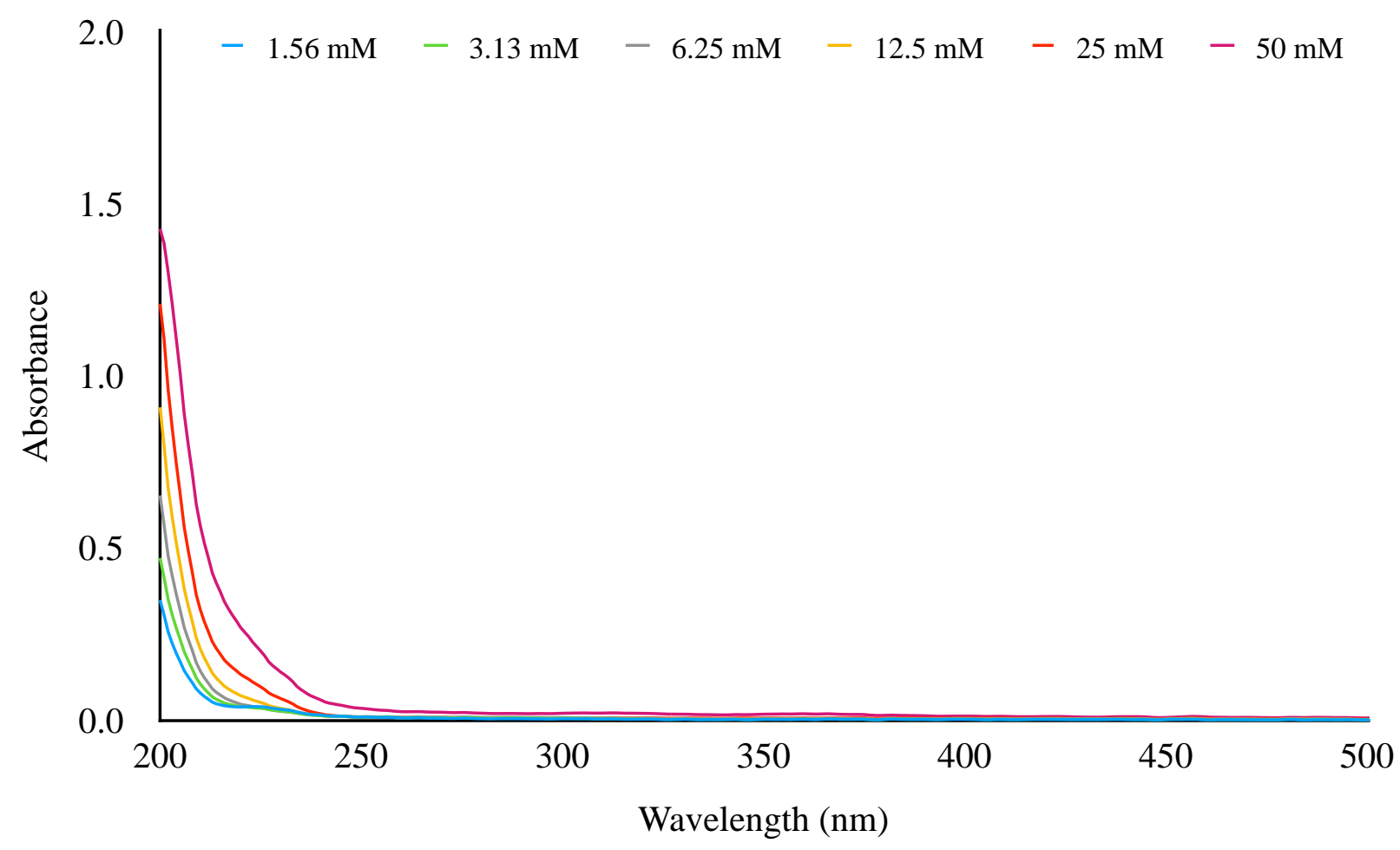

Figure S6. UV-vis absorption spectra of II. 


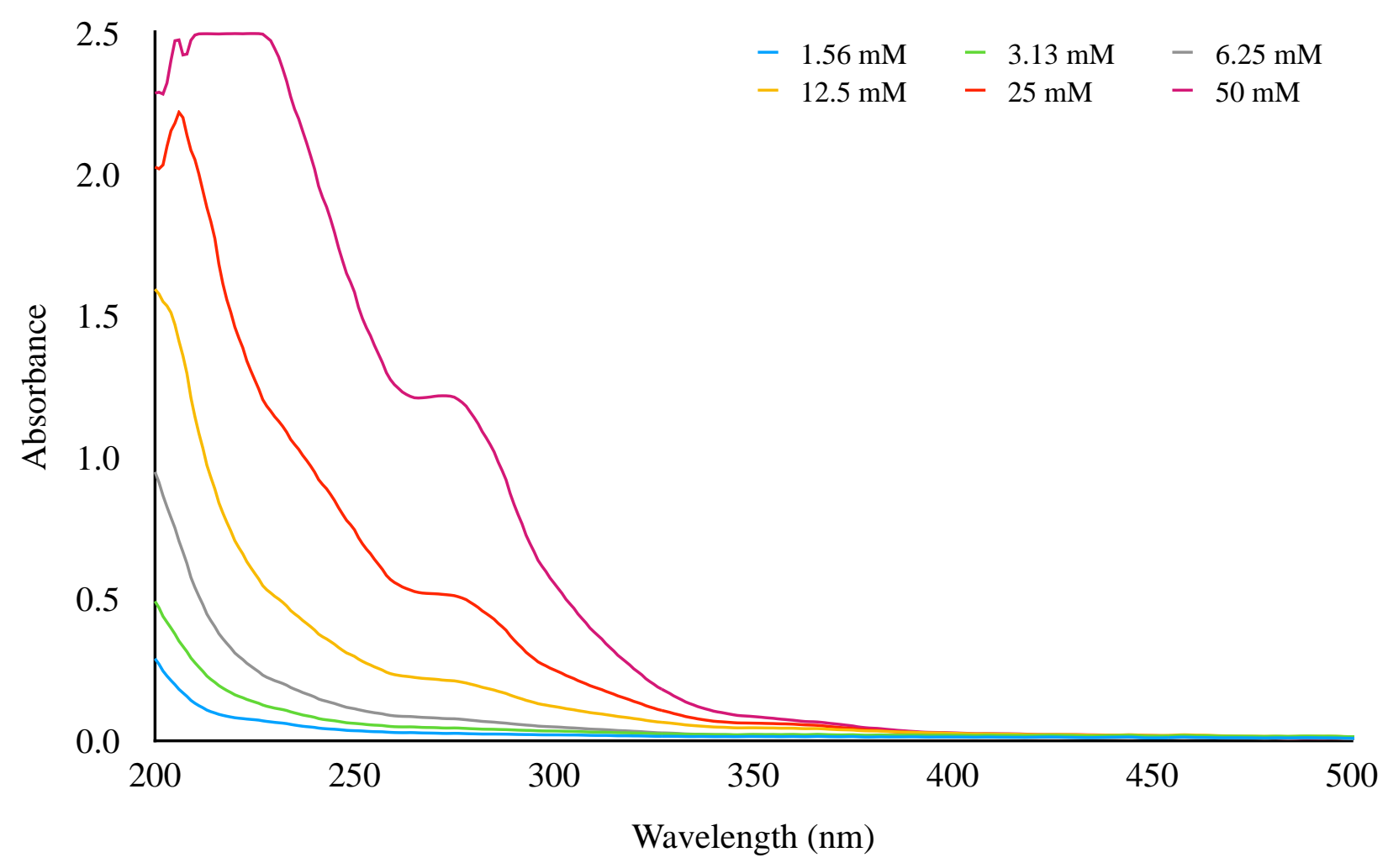

Figure S7. UV-vis absorption spectra of $\mathbf{I I}+\mathbf{A}$.

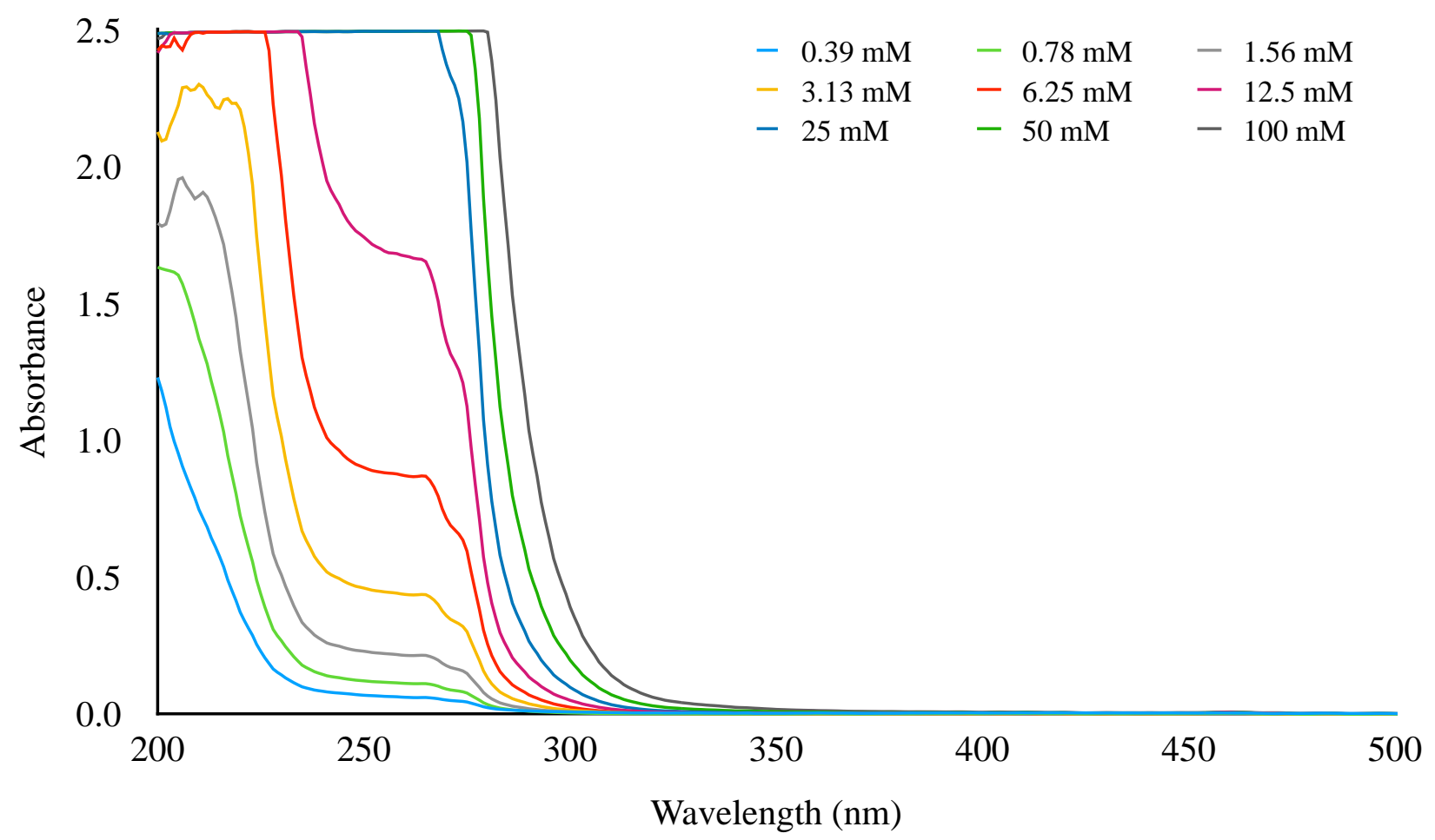

Figure S8. UV-vis absorption spectra of III. 


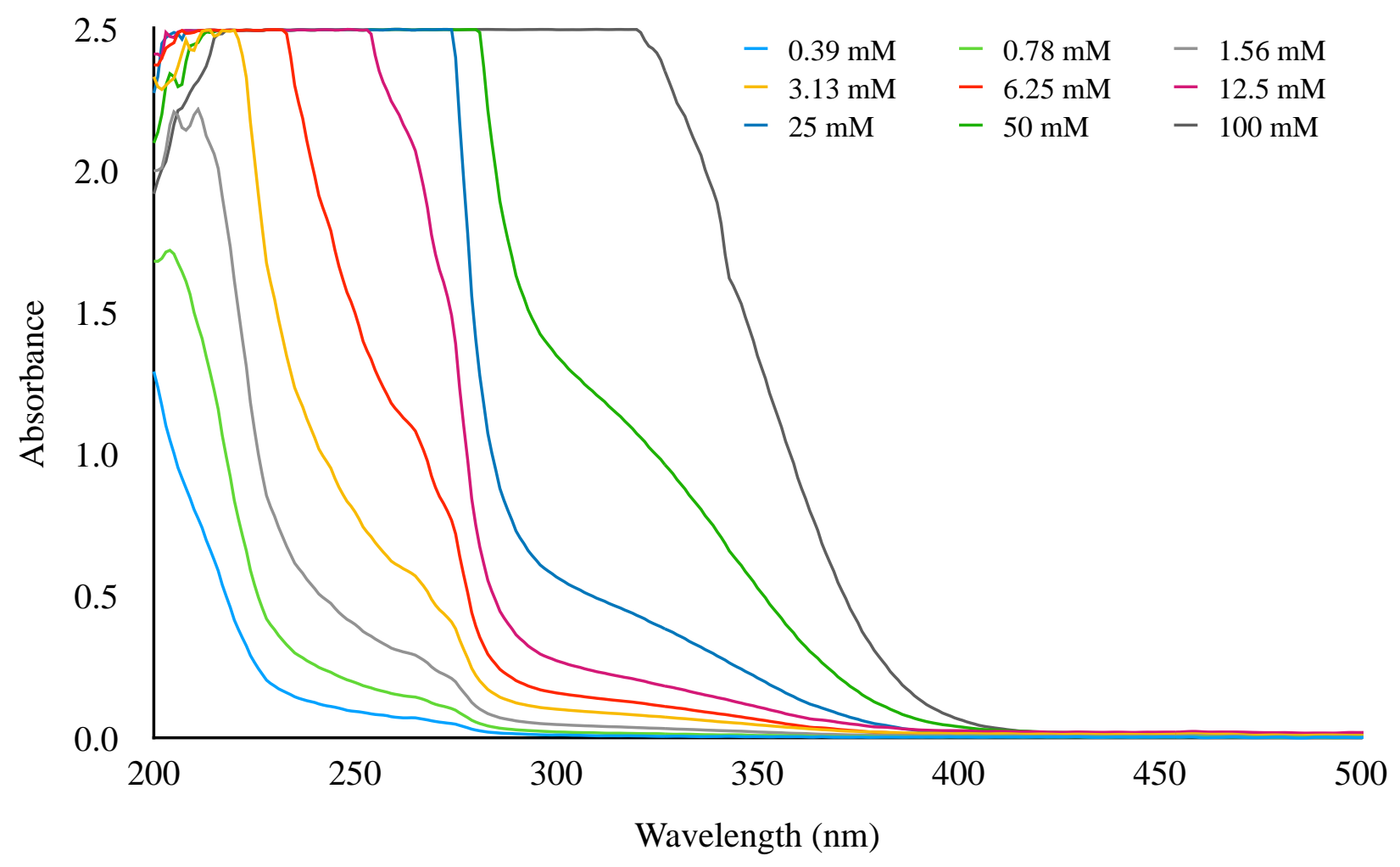

Figure S9. UV-vis absorption spectra of III + A.

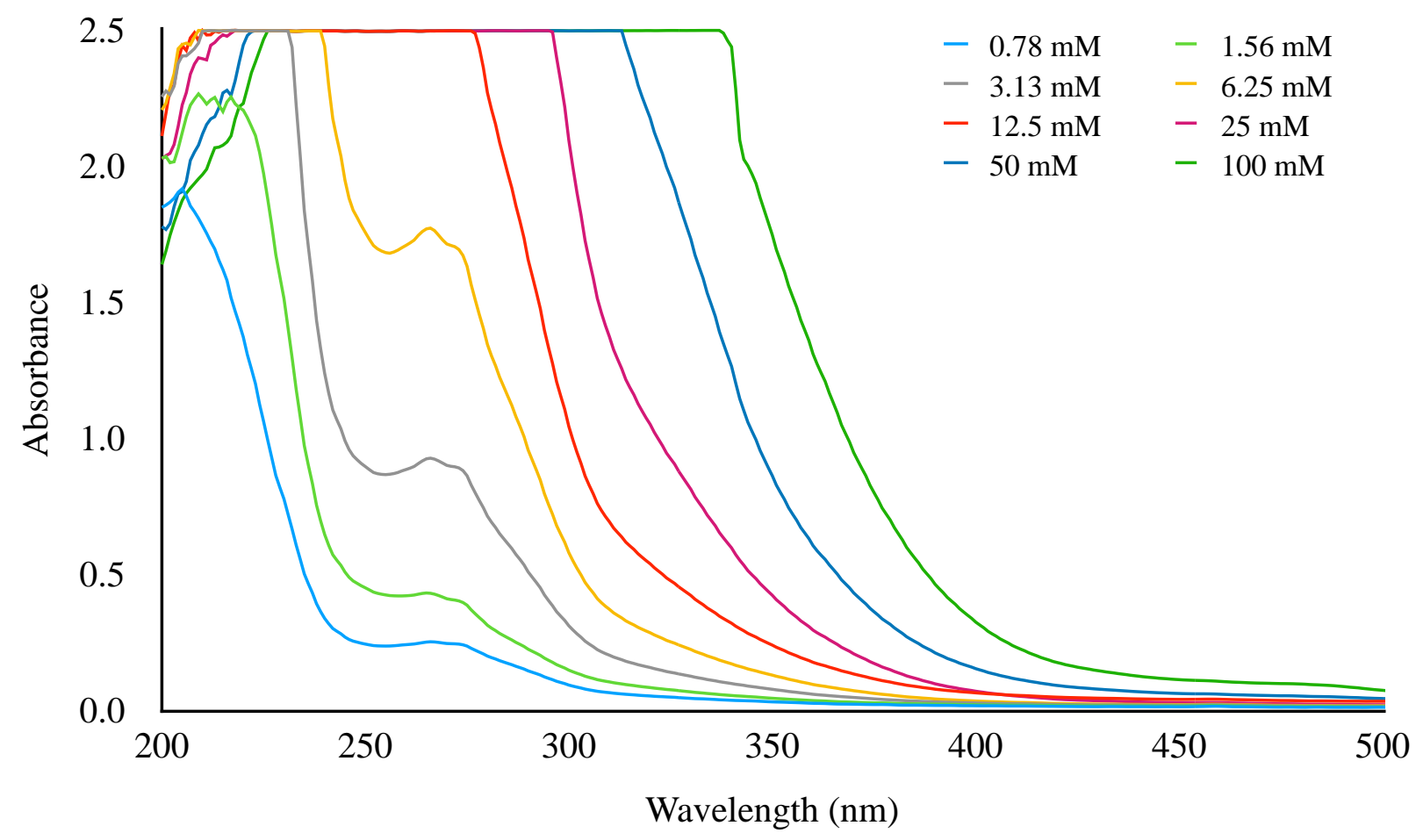

Figure S10. UV-vis absorption spectra of III + B. 


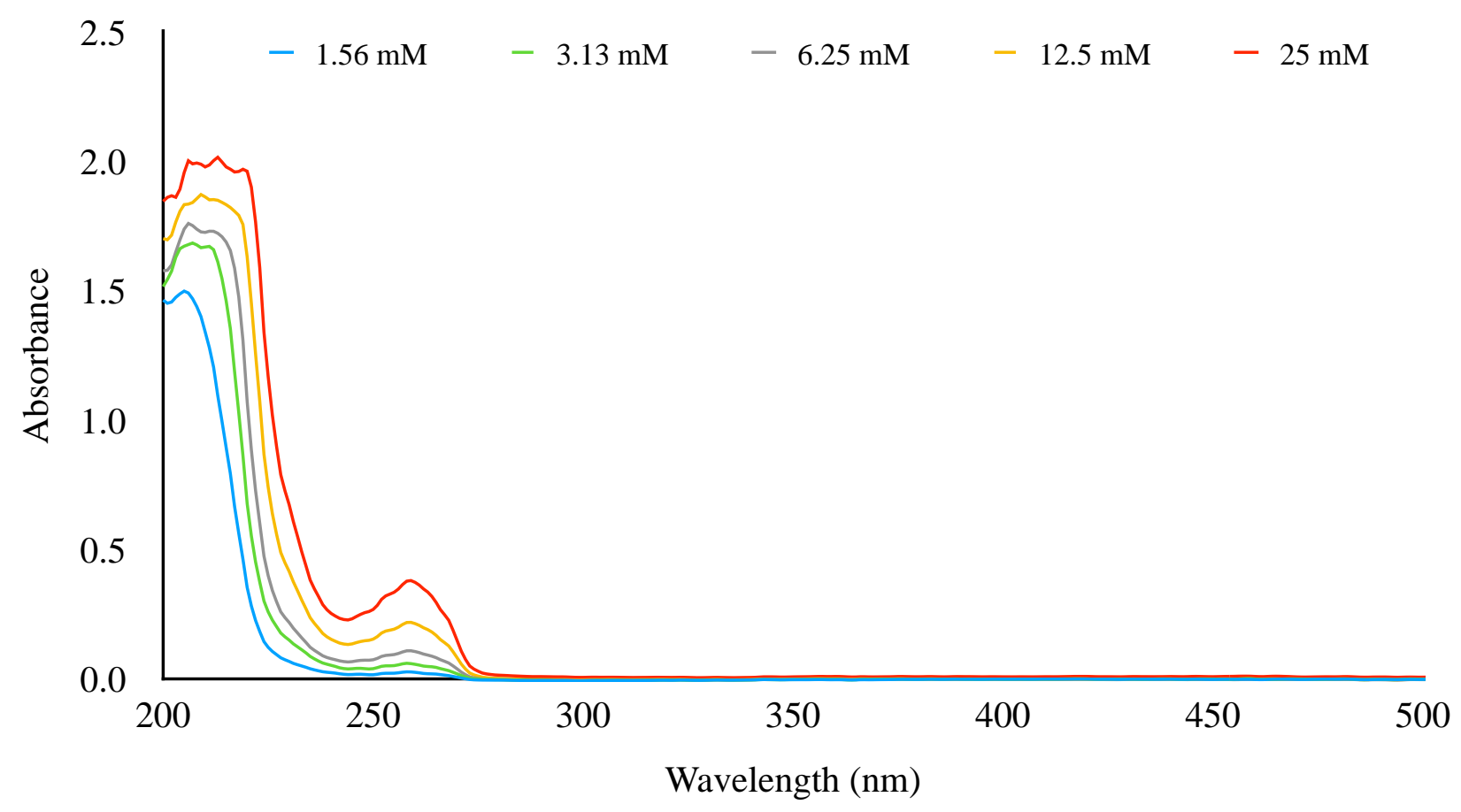

Figure S11. UV-vis absorption spectra of IV salt.

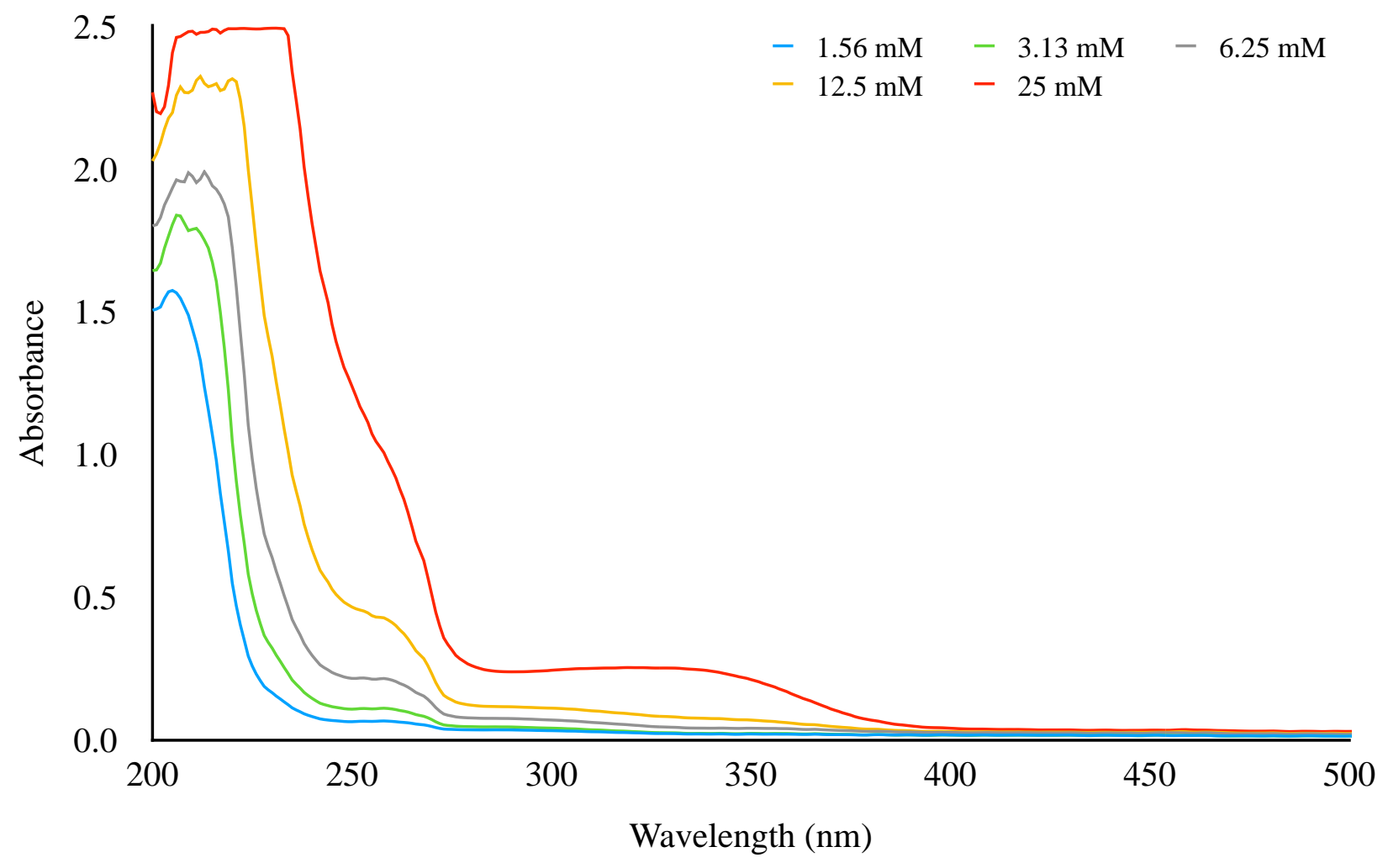

Figure S12. UV-vis absorption spectra of IV salt $+\mathbf{A}$. 


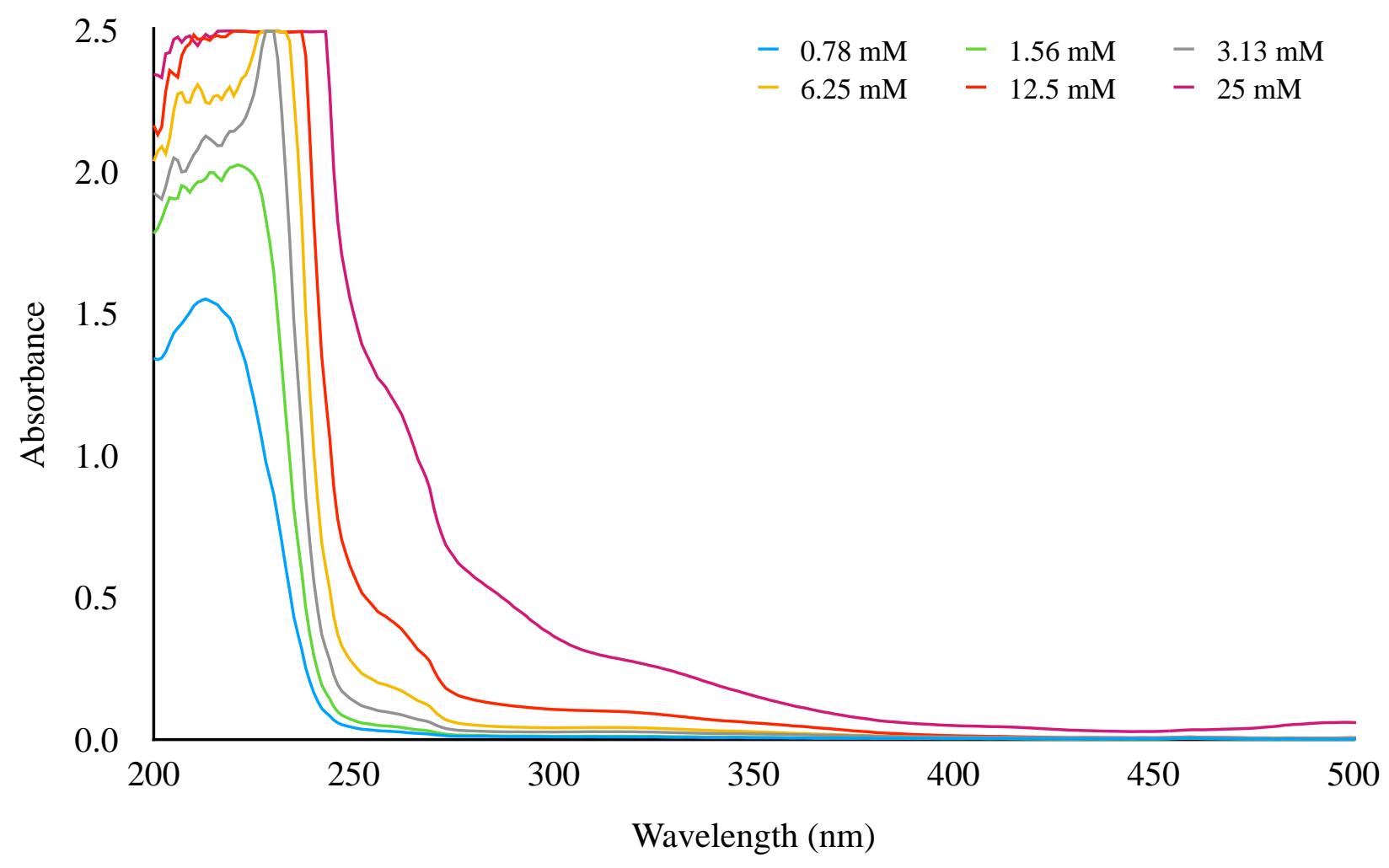

Figure S13. UV-vis absorption spectra of IV salt + B.

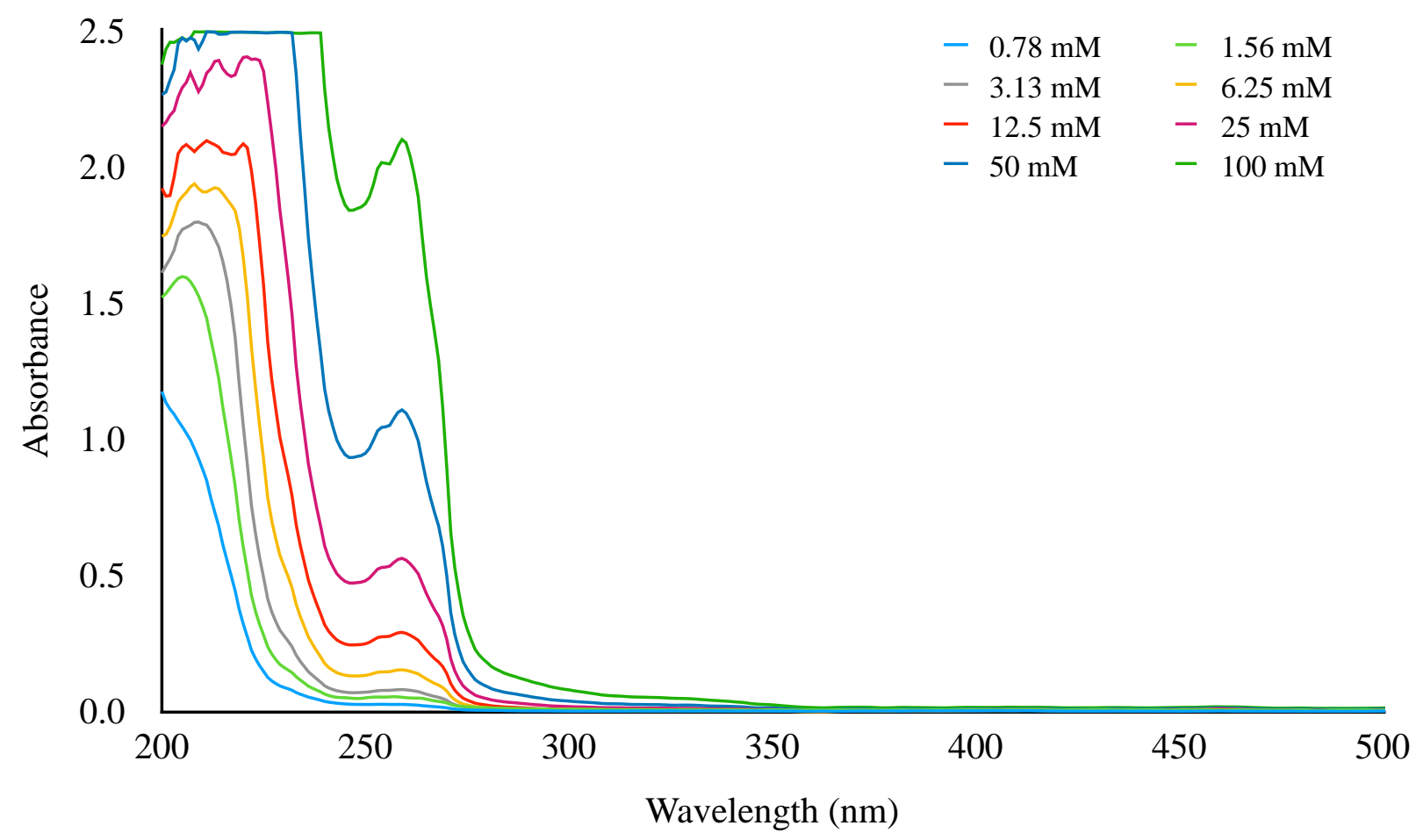

Figure S14. UV-vis absorption spectra of IV. 


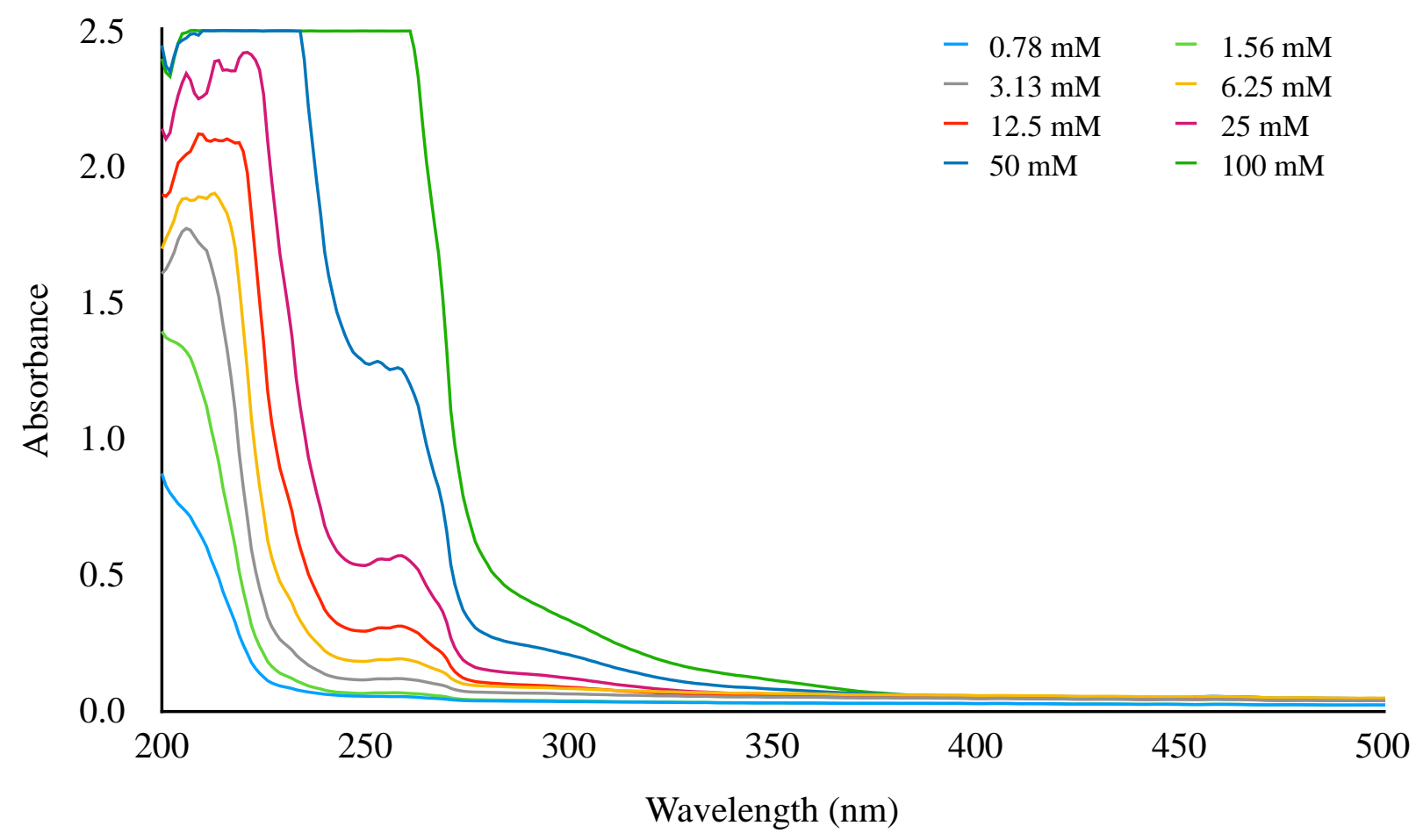

Figure S15. UV-vis absorption spectra of IV + A.

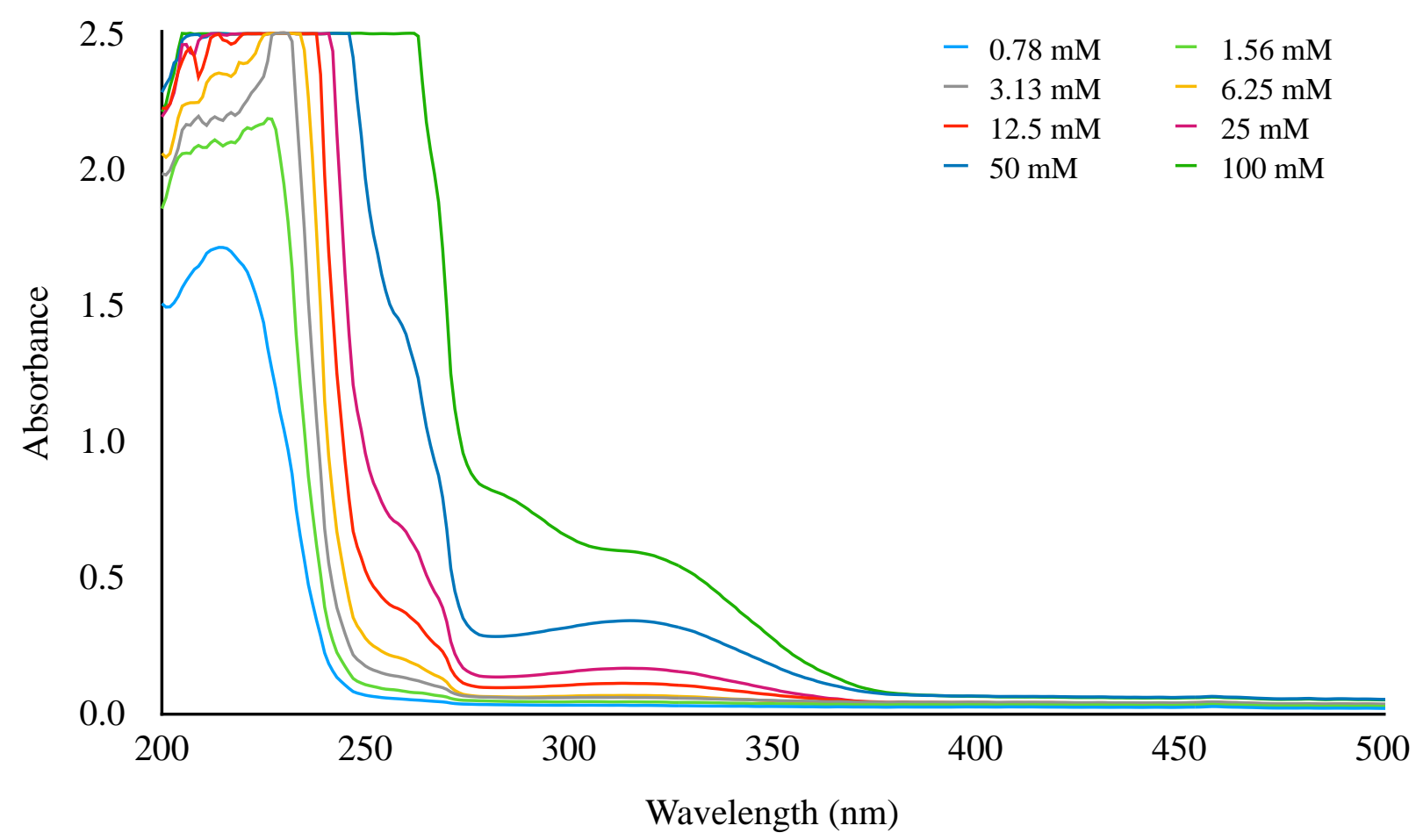

Figure S16. UV-vis absorption spectra of IV + B. 


\section{Benchmarking of density functionals and basis sets for TD-DFT calculations}

All calculations were run using the IEFPCM(acetonitrile) solvent model. For the basis sets listed in the legend, 6-31G represents 6-31G+(d,p), pVDZ represents aug-cc-pVDZ, and pVTZ represents aug-cc-pVTZ.

Based on the results from comparing the maxima in each spectra, the functional and basis set with the lowest RMSE is B3LYP/aug-cc-pVDZ, but since the line shape generated for this spectrum is very incorrect for $\mathbf{I}+\mathbf{A}$, the functional and basis set with the second lowest RMSE, PBE0/aug-cc-pVDZ, was chosen for the remainder of the study.

Based on these RMSE values, the accuracy of the TD-DFT results for these compounds do not improve by increasing the fraction of exact (HF) exchange past $25 \%$, as seen by worse RMSE values for M06-HF (100\% HF exchange) and M06-2X (54\% HF exchange) compared to PBE0 (25\% HF exchange). Even long-range corrected functionals, which employ a different amount of exact exchange in the short and long range regimes, did not show improved results compared to PBE0. This is likely because the excitations displayed some degree of chargetransfer character, and so a higher percentage of HF exchange was applied, over-correcting from the pure density functional. This is consistent with the results, where whPBE0 performed the best out of the range-separated functionals, having only $50 \% \mathrm{HF}$ exchange in the long range regime, while LC-whPBE and wB97XD performed the worst, both with $100 \%$ HF exchange in the long range regime. CAM-B3LYP performed intermediately, having $65 \% \mathrm{HF}$ exchange in the long range regime.
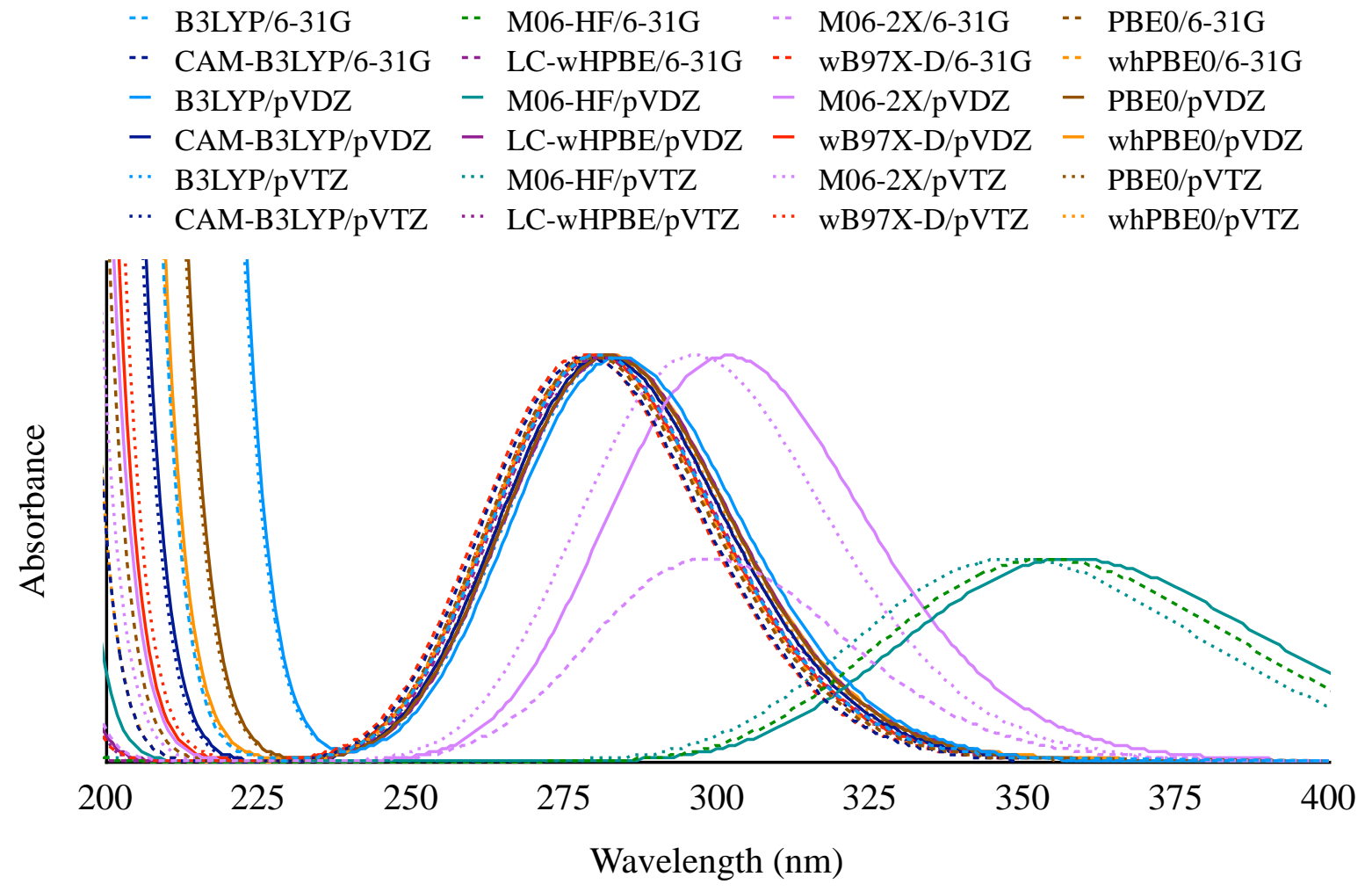

Figure S10. Theoretical UV-vis absorption spectra of A. 
Table S1. Comparison of theoretical and experimental UV-vis data for $\mathbf{A}$.

\begin{tabular}{|c|c|c|c|c|}
\hline & & Max wavelength (nm) & Max wavelength (eV) & Difference from experimental $(\mathrm{eV})$ \\
\hline \multicolumn{2}{|l|}{ Experimental } & 291.0 & 4.261 & - \\
\hline \multirow[t]{3}{*}{ B3LYP } & 6-31G & 280.4 & 4.422 & 0.1611 \\
\hline & pVDZ & 283.8 & 4.369 & 0.1081 \\
\hline & pVTZ & 283.1 & 4.380 & 0.1189 \\
\hline \multirow[t]{3}{*}{ M06-HF } & 6-31G & 353.7 & 3.505 & -0.7553 \\
\hline & pVDZ & 358.0 & 3.463 & -0.7974 \\
\hline & pVTZ & 348.3 & 3.560 & -0.7009 \\
\hline \multirow[t]{3}{*}{ M06-2X } & 6-31G & 298.4 & 4.155 & -0.1057 \\
\hline & pVDZ & 302.0 & 4.105 & -0.1552 \\
\hline & pVTZ & 296.4 & 4.183 & -0.0776 \\
\hline \multirow[t]{3}{*}{ PBEO } & 6-31G & 279.8 & 4.431 & 0.1705 \\
\hline & pVDZ & 282.4 & 4.390 & 0.1298 \\
\hline & pVTZ & 281.7 & 4.401 & 0.1407 \\
\hline \multirow[t]{3}{*}{ CAM-B3LYP } & 6-31G & 278.6 & 4.450 & 0.1896 \\
\hline & pVDZ & 281.6 & 4.403 & 0.1422 \\
\hline & pVTZ & 280.4 & 4.422 & 0.1611 \\
\hline \multirow[t]{3}{*}{ LC-wHPBE } & 6-31G & 280.7 & 4.417 & 0.1563 \\
\hline & pVDZ & 282.8 & 4.384 & 0.1235 \\
\hline & pVTZ & 281.6 & 4.403 & 0.1422 \\
\hline \multirow[t]{3}{*}{ wB97X-D } & $6-31 G$ & 278.6 & 4.450 & 0.1896 \\
\hline & pVDZ & 280.4 & 4.422 & 0.1611 \\
\hline & pVTZ & 279.8 & 4.431 & 0.1705 \\
\hline \multirow[t]{3}{*}{ whPBE0 } & 6-31G & 279.8 & 4.431 & 0.1705 \\
\hline & pVDZ & 282.4 & 4.390 & 0.1298 \\
\hline & pVTZ & 281.7 & 4.401 & 0.1407 \\
\hline
\end{tabular}




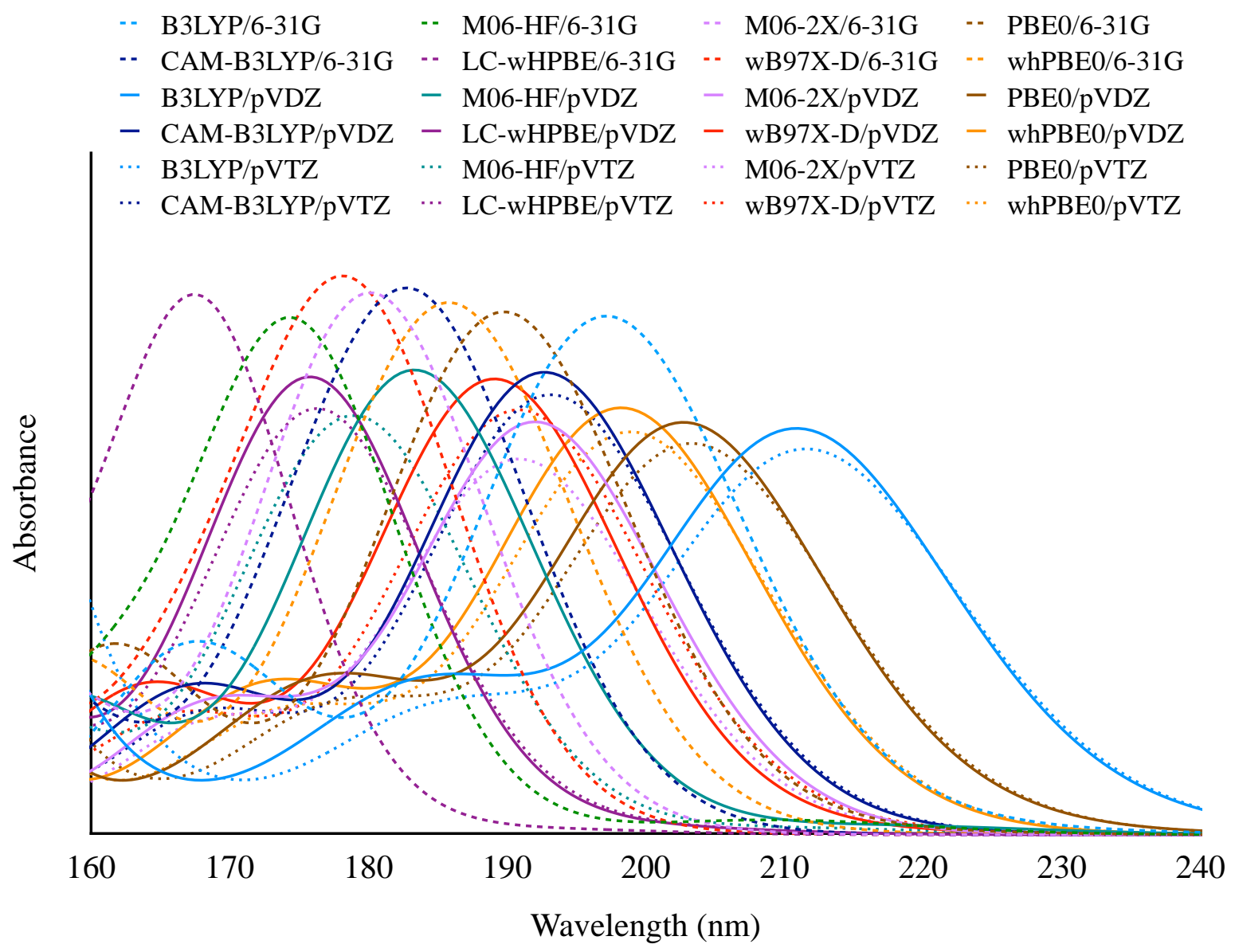

Figure S11. Theoretical UV-vis absorption spectra of $\mathbf{I}$. 
Table S2. Comparison of theoretical and experimental UV-vis data for I.

\begin{tabular}{|c|c|c|c|c|}
\hline & & Max wavelength (nm) & Max wavelength (eV) & Difference from experimental $(\mathrm{eV})$ \\
\hline \multicolumn{2}{|l|}{ Experimental } & 208.0 & 5.961 & - \\
\hline \multirow[t]{3}{*}{ B3LYP } & 6-31G & 197.3 & 6.285 & 0.3239 \\
\hline & pVDZ & 211.0 & 5.876 & -0.0848 \\
\hline & pVTZ & 211.5 & 5.862 & -0.0986 \\
\hline \multirow[t]{3}{*}{ M06-HF } & $6-31 G$ & 174.4 & 7.109 & 1.1484 \\
\hline & pVDZ & 183.2 & 6.768 & 0.8069 \\
\hline & pVTZ & 178.8 & 6.934 & 0.9735 \\
\hline \multirow[t]{3}{*}{ M06-2X } & $6-31 G$ & 180.0 & 6.888 & 0.9272 \\
\hline & pVDZ & 192.0 & 6.458 & 0.4967 \\
\hline & pVTZ & 190.7 & 6.502 & 0.5414 \\
\hline \multirow[t]{3}{*}{ PBEO } & 6-31G & 189.6 & 6.539 & 0.5785 \\
\hline & pVDZ & 202.6 & 6.121 & 0.1601 \\
\hline & pVTZ & 203.4 & 6.094 & 0.1336 \\
\hline \multirow[t]{3}{*}{ CAM-B3LYP } & $6-31 G$ & 182.8 & 6.783 & 0.8217 \\
\hline & pVDZ & 192.9 & 6.428 & 0.4673 \\
\hline & pVTZ & 193.3 & 6.413 & 0.4526 \\
\hline \multirow[t]{3}{*}{ LC-wHPBE } & 6-31G & 167.3 & 7.412 & 1.4510 \\
\hline & pVDZ & 175.9 & 7.048 & 1.0870 \\
\hline & pVTZ & 176.3 & 7.033 & 1.0726 \\
\hline \multirow[t]{3}{*}{ wB97X-D } & 6-31G & 178.0 & 6.965 & 1.0046 \\
\hline & pVDZ & 189.2 & 6.553 & 0.5923 \\
\hline & pVTZ & 190.8 & 6.498 & 0.5373 \\
\hline \multirow[t]{3}{*}{ whPBE0 } & 6-31G & 185.6 & 6.680 & 0.7194 \\
\hline & pVDZ & 198.2 & 6.257 & 0.2960 \\
\hline & pVTZ & 199.0 & 6.229 & 0.2683 \\
\hline
\end{tabular}




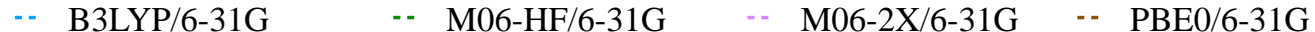

-- CAM-B3LYP/6-31G -- $\quad$ LC-wHPBE/6-31G $\quad$-- $\quad$ wB97X-D/6-31G -- whPBE0/6-31G

- B3LYP/pVDZ - M06-HF/pVDZ - M06-2X/pVDZ - PBE0/pVDZ

- CAM-B3LYP/pVDZ - LC-wHPBE/pVDZ - wB97X-D/pVDZ - whPBE0/pVDZ

$\begin{array}{llllllll}\cdots & \text { B3LYP/pVTZ } & \cdots & \text { M06-HF/pVTZ } & \cdots & \text { M06-2X/pVTZ } & \cdots & \text { PBE0/pVTZ }\end{array}$

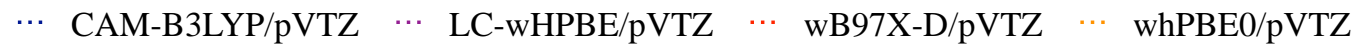

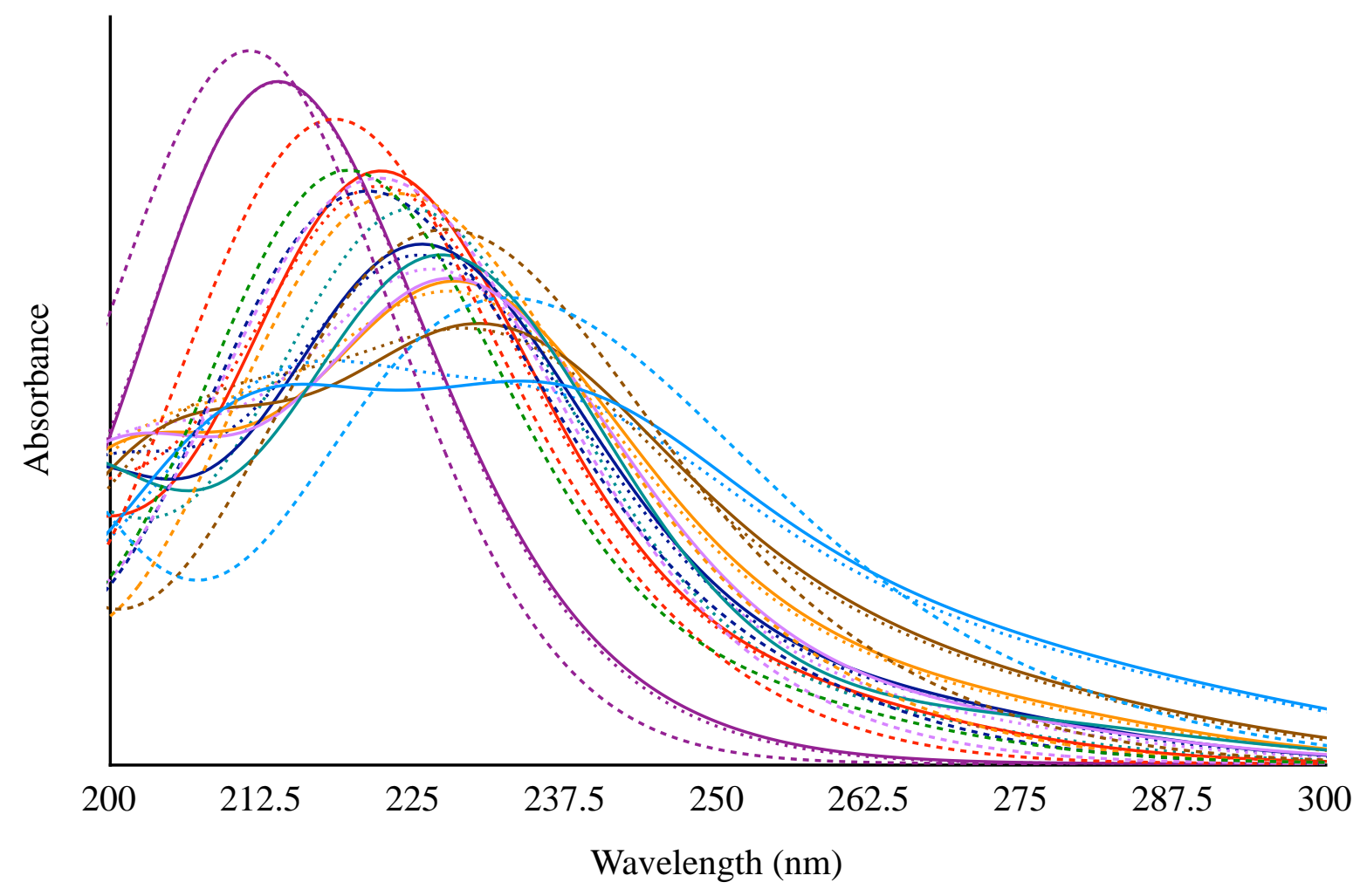

Figure S12. Theoretical UV-vis absorption spectra of $\mathbf{I}+\mathbf{A}$. 
Table S3. Comparison of theoretical and experimental UV-vis data for I + A.

\begin{tabular}{|c|c|c|c|c|}
\hline & & Max wavelength (nm) & Max wavelength (eV) & Difference from experimental $(\mathrm{eV})$ \\
\hline Experimental & & 235.0 & 5.276 & - \\
\hline B3LYP & 6-31G & 233.0 & 5.321 & 0.0453 \\
\hline & pVDZ & 234.1 & 5.296 & 0.0203 \\
\hline & pVTZ & 218.0 & 5.687 & 0.4114 \\
\hline M06-HF & 6-31G & 219.8 & 5.641 & 0.3649 \\
\hline & pVDZ & 227.6 & 5.448 & 0.1715 \\
\hline & pVTZ & 225.2 & 5.506 & 0.2296 \\
\hline M06-2X & 6-31G & 222.2 & 5.580 & 0.3039 \\
\hline & pVDZ & 228.2 & 5.433 & 0.1572 \\
\hline & pVTZ & 226.4 & 5.476 & 0.2004 \\
\hline PBEO & $6-31 G$ & 227.6 & 5.448 & 0.1715 \\
\hline & pVDZ & 230.6 & 5.377 & 0.1007 \\
\hline & pVTZ & 229.2 & 5.409 & 0.1335 \\
\hline CAM-B3LYP & 6-31G & 221.6 & 5.595 & 0.3190 \\
\hline & pVDZ & 225.8 & 5.491 & 0.2150 \\
\hline & pVTZ & 225.8 & 5.491 & 0.2150 \\
\hline LC-wHPBE & $6-31 G$ & 211.4 & 5.866 & 0.5901 \\
\hline & pVDZ & 214.0 & 5.794 & 0.5177 \\
\hline & pVTZ & 214.0 & 5.794 & 0.5177 \\
\hline wB97X-D & 6-31G & 218.5 & 5.674 & 0.3984 \\
\hline & pVDZ & 222.2 & 5.580 & 0.3039 \\
\hline & pVTZ & 222.2 & 5.580 & 0.3039 \\
\hline whPBE0 & $6-31 G$ & 224.0 & 5.535 & 0.2591 \\
\hline & pVDZ & 228.2 & 5.433 & 0.1572 \\
\hline & pVTZ & 227.6 & 5.448 & 0.1715 \\
\hline
\end{tabular}


Table S4. Comparison of the accuracy of various functionals and basis sets for calculating the UV-vis absorbance spectra for $\mathbf{A}, \mathbf{I}$, and $\mathbf{I}+\mathbf{A}$.

\begin{tabular}{|c|c|c|c|c|c|}
\hline \multirow{2}{*}{ Functional } & \multirow{2}{*}{ Basis set } & \multicolumn{3}{|c|}{$\mathbf{E}_{\text {TDDFT }}-\mathbf{E}_{\exp }(\mathbf{e V})$} & \multirow{2}{*}{ RMSE } \\
\hline & & I & $\mathbf{A}$ & $\mathbf{I}+\mathbf{A}$ & \\
\hline \multirow[t]{3}{*}{ B3LYP } & $6-31 G$ & 0.1611 & 0.3239 & 0.0453 & 0.2105 \\
\hline & pVDZ & 0.1081 & -0.0848 & 0.0203 & 0.0802 \\
\hline & pVTZ & 0.1189 & -0.0986 & 0.4114 & 0.2537 \\
\hline \multirow[t]{3}{*}{ M06HF } & $6-31 G$ & -0.7553 & 1.1484 & 0.3649 & 0.8211 \\
\hline & pVDZ & -0.7974 & 0.8069 & 0.1715 & 0.6624 \\
\hline & pVTZ & -0.7009 & 0.9735 & 0.2296 & 0.7051 \\
\hline \multirow[t]{3}{*}{ M062X } & 6-31G & -0.1057 & 0.9272 & 0.3039 & 0.5667 \\
\hline & pVDZ & -0.1552 & 0.4967 & 0.1572 & 0.3139 \\
\hline & pVTZ & -0.0776 & 0.5414 & 0.2004 & 0.3363 \\
\hline \multirow[t]{3}{*}{ PBEO } & $6-31 G$ & 0.1705 & 0.5785 & 0.1715 & 0.3620 \\
\hline & pVDZ & 0.1298 & 0.1601 & 0.1007 & 0.1324 \\
\hline & pVTZ & 0.1407 & 0.1336 & 0.1335 & 0.1360 \\
\hline \multirow[t]{3}{*}{ CAM-B3LYP } & 6-31G & 0.1896 & 0.8217 & 0.3190 & 0.5206 \\
\hline & pVDZ & 0.1422 & 0.4673 & 0.2150 & 0.3081 \\
\hline & pVTZ & 0.1611 & 0.4526 & 0.2150 & 0.3039 \\
\hline \multirow[t]{3}{*}{ LC-wHPBE } & $6-31 G$ & 0.1563 & 1.4510 & 0.5901 & 0.9089 \\
\hline & pVDZ & 0.1235 & 1.0870 & 0.5177 & 0.6988 \\
\hline & pVTZ & 0.1422 & 1.0726 & 0.5177 & 0.6925 \\
\hline \multirow[t]{3}{*}{ wB97X-D } & $6-31 G$ & 0.1896 & 1.0046 & 0.3984 & 0.6335 \\
\hline & pVDZ & 0.1611 & 0.5923 & 0.3039 & 0.3954 \\
\hline & pVTZ & 0.1705 & 0.5373 & 0.3039 & 0.3698 \\
\hline \multirow[t]{3}{*}{ whPBE0 } & 6-31G & 0.1705 & 0.7194 & 0.2591 & 0.4523 \\
\hline & pVDZ & 0.1298 & 0.2960 & 0.1572 & 0.2075 \\
\hline & pVTZ & 0.1407 & 0.2683 & 0.1715 & 0.2010 \\
\hline
\end{tabular}




\section{E. Summary of TD-DFT analysis for enamines and dienamines}

Table S5. TD-DFT vertical excitation and energies of key molecular orbitals for enamines formed with I-IV.

\begin{tabular}{|c|c|c|c|c|c|c|c|}
\hline & $\begin{array}{l}\text { Key orbital } \\
(\mathrm{eV})\end{array}$ & gies & $\begin{array}{l}\lambda_{\text {calc }} \\
(\mathbf{n m})\end{array}$ & $\begin{array}{l}\text { Oscillator } \\
\text { Strength }\end{array}$ & Assignment & Coefficient & $\%$ Contribution \\
\hline \multirow[t]{3}{*}{$\mathbf{I}+\mathbf{A}$} & \multirow{3}{*}{$\begin{array}{l}\text { HOMO } \\
\text { LUMO } \\
\text { LUMO + } 7\end{array}$} & \multirow{3}{*}{$\begin{array}{r}-5.37 \\
-0.01 \\
0.83\end{array}$} & 278.19 & 0.0323 & HOMO $\rightarrow$ LUMO & 0.67845 & $92 \%$ \\
\hline & & & 228.55 & 0.1316 & $\mathrm{HOMO} \rightarrow \mathrm{LUMO}+6$ & 0.29594 & $18 \%$ \\
\hline & & & & & $\mathrm{HOMO} \rightarrow \mathrm{LUMO}+7$ & 0.60838 & $74 \%$ \\
\hline \multirow[t]{4}{*}{$\mathbf{I I}+\mathbf{A}$} & \multirow{4}{*}{$\begin{array}{l}\text { HOMO } \\
\text { LUMO } \\
\text { LUMO + } 1\end{array}$} & \multirow{4}{*}{$\begin{array}{r}-5.45 \\
-0.09 \\
0.03\end{array}$} & 283.73 & 0.0124 & HOMO $\rightarrow$ LUMO & 0.54084 & $59 \%$ \\
\hline & & & & & $\mathrm{HOMO} \rightarrow \mathrm{LUMO}+1$ & 0.44436 & $39 \%$ \\
\hline & & & 271.32 & 0.0245 & HOMO $\rightarrow$ LUMO & -0.41407 & $34 \%$ \\
\hline & & & & & $\mathrm{HOMO} \rightarrow \mathrm{LUMO}+1$ & 0.52084 & $54 \%$ \\
\hline \multirow[t]{8}{*}{$\mathrm{III}+\mathbf{A}$} & \multirow{8}{*}{$\begin{array}{l}\text { HOMO } \\
\text { LUMO } \\
\text { LUMO + 1 } \\
\text { LUMO + } 2 \\
\text { LUMO + } 3\end{array}$} & \multirow{8}{*}{$\begin{array}{l}-5.39 \\
-1.68 \\
-1.43 \\
-1.29 \\
-1.16\end{array}$} & 408.19 & 0.0115 & HOMO $\rightarrow$ LUMO & 0.67621 & $91 \%$ \\
\hline & & & 382.23 & 0.0245 & $\mathrm{HOMO} \rightarrow \mathrm{LUMO}+1$ & 0.64740 & $84 \%$ \\
\hline & & & & & & & \\
\hline & & & 361.74 & 0.0021 & $\mathrm{HOMO} \rightarrow \mathrm{LUMO}+2$ & 0.47427 & $45 \%$ \\
\hline & & & & & $\mathrm{HOMO} \rightarrow \mathrm{LUMO}+3$ & 0.50879 & $52 \%$ \\
\hline & & & 360.02 & 0.0057 & $\mathrm{HOMO} \rightarrow \mathrm{LUMO}+1$ & 0.22686 & $10 \%$ \\
\hline & & & & & $\mathrm{HOMO} \rightarrow \mathrm{LUMO}+2$ & 0.47952 & $46 \%$ \\
\hline & & & & & $\mathrm{HOMO} \rightarrow \mathrm{LUMO}+3$ & -0.46504 & $43 \%$ \\
\hline \multirow[t]{4}{*}{$\mathbf{I V}+\mathbf{A}$} & \multirow{4}{*}{$\begin{array}{l}\text { HOMO } \\
\text { LUMO } \\
\text { LUMO + } 1\end{array}$} & \multirow{4}{*}{$\begin{array}{l}-5.53 \\
-0.39 \\
-0.38\end{array}$} & 289.54 & 0.0040 & HOMO $\rightarrow$ LUMO & 0.60873 & $74 \%$ \\
\hline & & & & & $\mathrm{HOMO} \rightarrow \mathrm{LUMO}+1$ & -0.35397 & $25 \%$ \\
\hline & & & 288.51 & 0.0080 & HOMO $\rightarrow$ LUMO & 0.35119 & $25 \%$ \\
\hline & & & & & $\mathrm{HOMO} \rightarrow \mathrm{LUMO}+1$ & 0.60693 & $74 \%$ \\
\hline
\end{tabular}

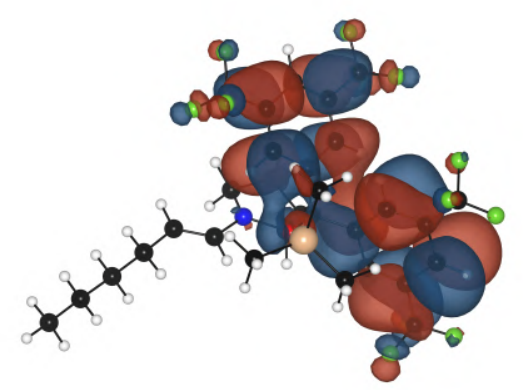

$\mathrm{LUMO}+2$

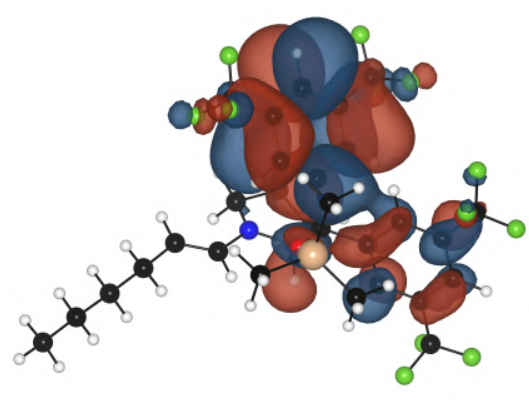

$\mathrm{LUMO}+3$

Figure S13. Additional orbitals involved in excited states of III + A. 
Table S6. TD-DFT vertical excitation and energies of key molecular orbitals for dienamines formed with I, III, and IV.

\begin{tabular}{|c|c|c|c|c|c|c|c|}
\hline & $\begin{array}{l}\text { Key orbital } \\
(\mathrm{eV})\end{array}$ & gies & $\begin{array}{l}\lambda_{\text {calc }} \\
(\mathbf{n m})\end{array}$ & $\begin{array}{l}\text { Oscillator } \\
\text { Strength }\end{array}$ & Assignment & Coefficient & $\%$ Contribution \\
\hline \multirow[t]{4}{*}{$\mathbf{I}+\mathbf{B}$} & \multirow{4}{*}{$\begin{array}{l}\text { HOMO } \\
\text { LUMO } \\
\text { LUMO + } 1\end{array}$} & \multirow{4}{*}{$\begin{array}{l}-4.99 \\
-0.10 \\
-0.01\end{array}$} & \multirow[t]{2}{*}{302.17} & \multirow[t]{2}{*}{0.0324} & HOMO $\rightarrow$ LUMO & 0.31273 & $20 \%$ \\
\hline & & & & & $\mathrm{HOMO} \rightarrow \mathrm{LUMO}+1$ & 0.60736 & $74 \%$ \\
\hline & & & \multirow[t]{2}{*}{287.89} & \multirow[t]{2}{*}{0.6850} & $\mathrm{HOMO} \rightarrow$ LUMO & 0.60594 & $73 \%$ \\
\hline & & & & & $\mathrm{HOMO} \rightarrow \mathrm{LUMO}+1$ & -0.31612 & $20 \%$ \\
\hline \multirow[t]{11}{*}{ III + B } & \multirow{11}{*}{$\begin{array}{l}\text { HOMO } \\
\text { LUMO } \\
\text { LUMO + } 1 \\
\text { LUMO + } 2 \\
\text { LUMO + } 3 \\
\text { LUMO + } 4 \\
\text { LUMO + 5 } \\
\text { LUMO + } 7\end{array}$} & \multirow{11}{*}{$\begin{array}{r}-5.14 \\
-1.70 \\
-1.46 \\
-1.31 \\
-1.20 \\
-0.23 \\
-0.10 \\
0.09\end{array}$} & 439.21 & 0.0110 & $\mathrm{HOMO} \rightarrow$ LUMO & 0.67381 & $91 \%$ \\
\hline & & & & & & & \\
\hline & & & 409.07 & 0.0156 & $\mathrm{HOMO} \rightarrow \mathrm{LUMO}+1$ & 0.64744 & $84 \%$ \\
\hline & & & 384.38 & 0.0006 & $\mathrm{HOMO} \rightarrow \mathrm{LUMO}+2$ & 0.37538 & $28 \%$ \\
\hline & & & & & $\mathrm{HOMO} \rightarrow \mathrm{LUMO}+3$ & 0.58813 & $69 \%$ \\
\hline & & & 383.50 & 0.0089 & $\mathrm{HOMO} \rightarrow \mathrm{LUMO}+1$ & 0.21958 & $10 \%$ \\
\hline & & & & & $\mathrm{HOMO} \rightarrow \mathrm{LUMO}+2$ & 0.56606 & $64 \%$ \\
\hline & & & & & $\mathrm{HOMO} \rightarrow \mathrm{LUMO}+3$ & -0.35890 & $26 \%$ \\
\hline & & & 294.12 & 0.1844 & $\mathrm{HOMO} \rightarrow \mathrm{LUMO}+4$ & 0.65661 & $86 \%$ \\
\hline & & & 277.78 & 0.4636 & $\mathrm{HOMO} \rightarrow \mathrm{LUMO}+5$ & 0.53852 & $58 \%$ \\
\hline & & & & & $\mathrm{HOMO} \rightarrow \mathrm{LUMO}+7$ & -0.33938 & $23 \%$ \\
\hline \multirow[t]{8}{*}{$I V+B$} & \multirow{8}{*}{$\begin{array}{l}\text { HOMO } \\
\text { LUMO } \\
\text { LUMO + } 1 \\
\text { LUMO + } 2 \\
\text { LUMO + } 3\end{array}$} & \multirow{8}{*}{$\begin{array}{l}-5.28 \\
-0.43 \\
-0.43 \\
-0.18 \\
-0.08\end{array}$} & 303.34 & 0.0155 & $\mathrm{HOMO} \rightarrow \mathrm{LUMO}+1$ & 0.69119 & $96 \%$ \\
\hline & & & 30229 & 00308 & $\mathrm{HOMO} \rightarrow \mathrm{IJMO}$ & 069185 & $96 \%$ \\
\hline & & & $y$ & 0 & HUIVIO $\rightarrow$ LOIVIO & oJ & $90 \%$ \\
\hline & & & 278.35 & 0.0996 & $\mathrm{HOMO} \rightarrow \mathrm{LUMO}+2$ & -0.29146 & $17 \%$ \\
\hline & & & & & $\mathrm{HOMO} \rightarrow \mathrm{LUMO}+3$ & 0.54102 & $59 \%$ \\
\hline & & & & & $\mathrm{HOMO} \rightarrow \mathrm{LUMO}+4$ & 0.28180 & $16 \%$ \\
\hline & & & 277.20 & 0.4662 & $\mathrm{HOMO} \rightarrow \mathrm{LUMO}+2$ & 0.56770 & $64 \%$ \\
\hline & & & & & $\mathrm{HOMO} \rightarrow \mathrm{LUMO}+3$ & 0.32849 & $22 \%$ \\
\hline
\end{tabular}
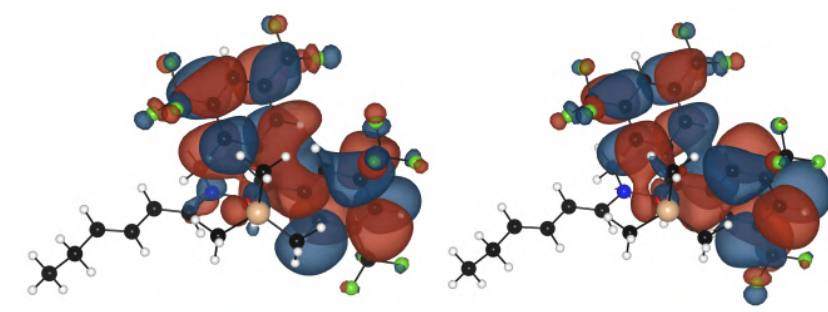

$\mathrm{LUMO}+2$

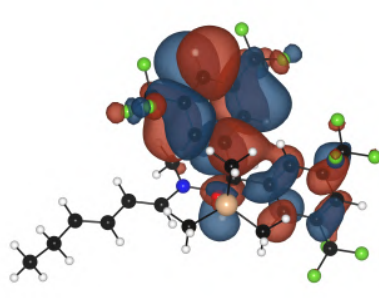

$\mathrm{LUMO}+3$

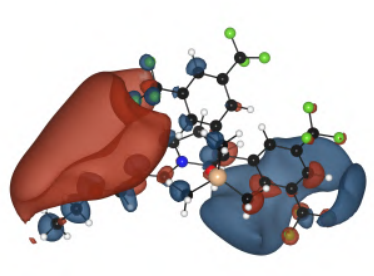

LUMO+7

Figure S14. Additional orbitals involved in excited states of III + B. 


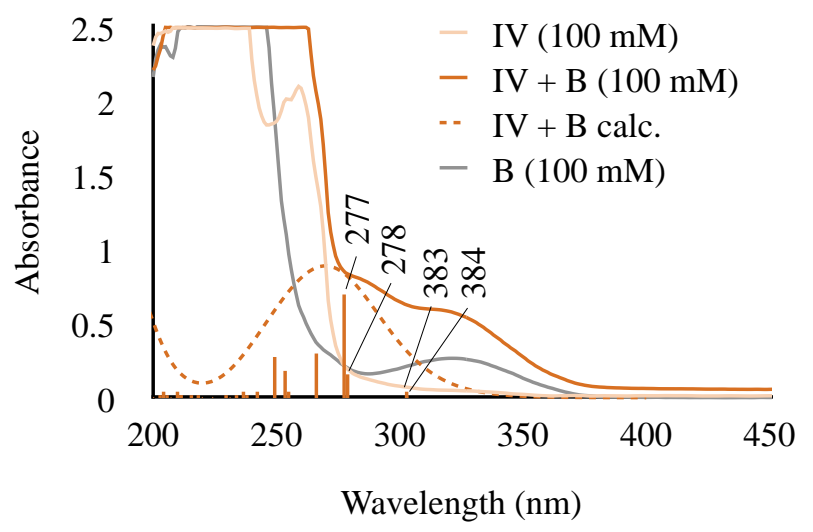

Figure S15. UV-vis absorption spectra, recorded in acetonitrile in $1 \mathrm{~mm}$ path quartz cuvettes, of $\mathbf{I V}, \mathbf{B}$, and IV $+\mathbf{B}$. Calculated absorbance spectrum of the dienamine is normalized for comparison with experimental data. The vertical excitations contributing to the calculated spectrum are shown as bars.

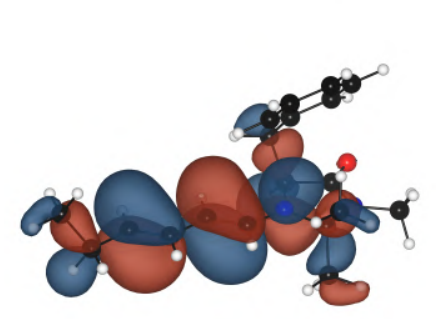

HOMO

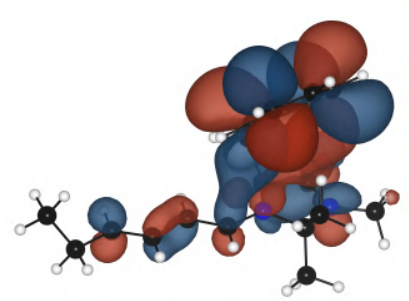

LUMO

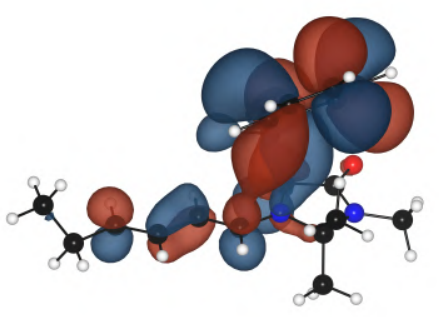

LUMO+1

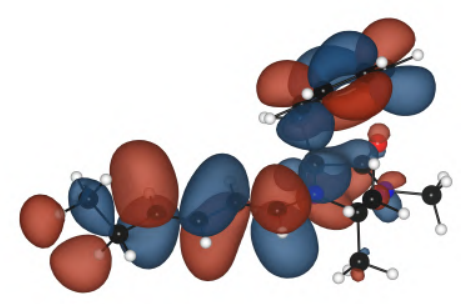

$\mathrm{LUMO}+2$

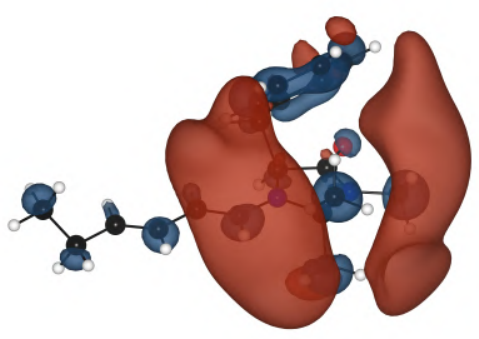

LUMO+3

Figure S16. Orbitals involved in excited states of IV + B. 


\section{F. Select examples of enamine $Z$ isomers}

Table S7. TD-DFT vertical excitation and energies of key molecular orbitals for $Z$ enamines formed with I and IV.

\begin{tabular}{|c|c|c|c|c|c|c|c|}
\hline & $\begin{array}{l}\text { Key orbital } \\
\text { energies (e) }\end{array}$ & & $\begin{array}{l}\lambda_{\text {calc }} \\
(\mathbf{n m})\end{array}$ & $\begin{array}{l}\text { Oscillator } \\
\text { Strength }\end{array}$ & Assignment & Coefficient & $\%$ Contribution \\
\hline \multirow[t]{2}{*}{ (Z) $\mathbf{I}+\mathbf{A}$} & \multirow{2}{*}{$\begin{array}{l}\text { HOMO } \\
\text { LUMO } \\
\text { LUMO + } 5\end{array}$} & \multirow{2}{*}{$\begin{array}{r}-5.40 \\
-0.07 \\
0.64\end{array}$} & 281.23 & 0.0340 & HOMO $\rightarrow$ LUMO & 0.68139 & $93 \%$ \\
\hline & & & 233.73 & 93 & $\begin{array}{l}\mathrm{HOMO} \rightarrow \mathrm{LUMO}+4 \\
\mathrm{HOMO} \rightarrow \mathrm{LUMO}+5\end{array}$ & $\begin{array}{r}-0.25335 \\
0.62268\end{array}$ & $\begin{array}{l}13 \% \\
78 \%\end{array}$ \\
\hline \multirow[t]{2}{*}{ (Z) $\mathbf{I V}+\mathbf{A}$} & \multirow[b]{2}{*}{4} & \multirow{2}{*}{$\begin{array}{l}-5.54 \\
-0.43 \\
-0.38\end{array}$} & 290.58 & 0.0057 & HOMO $\rightarrow$ LUMO & 0.69143 & $96 \%$ \\
\hline & & & 287.08 & 0.0068 & $\mathrm{HOMO} \rightarrow \mathrm{LUMO}+1$ & 0.69252 & $96 \%$ \\
\hline
\end{tabular}

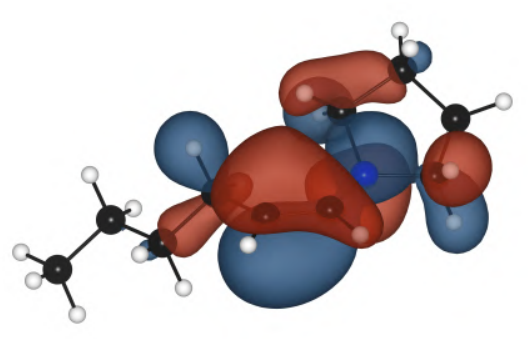

HOMO

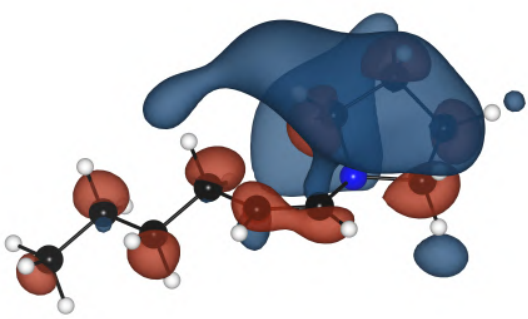

LUMO

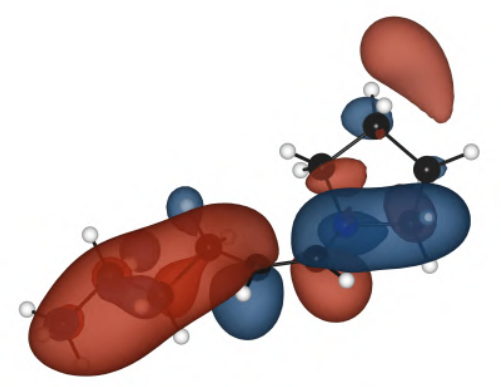

$\mathrm{LUMO}+5$

Figure S17. Orbitals involved in excited states of $(\boldsymbol{Z}) \mathbf{I}+\mathbf{A}$.

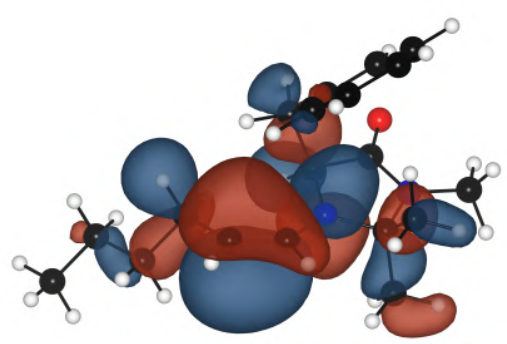

HOMO

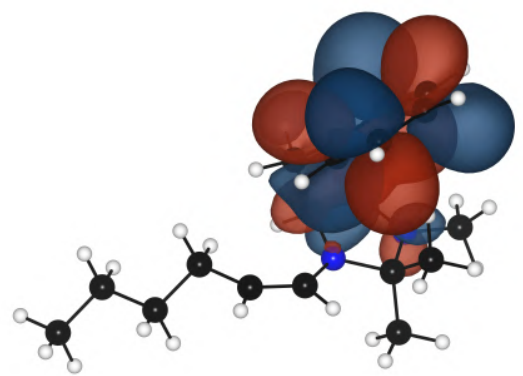

LUMO

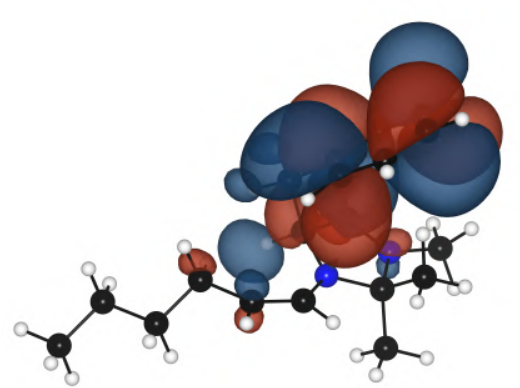

LUMO+1

Figure S18. Orbitals involved in excited states of $(Z) \mathbf{I V}+\mathbf{A}$. 


\section{G. Application of different functionals}

Of the four enamines studied, III + A displayed the largest error in the calculated UV-vis spectrum at the PBE0/aug-cc-pVDZ/IEFPCM(acetonitrile) level of theory compared to experimental data. Due to this, TD-DFT calculations using other functionals in combination with aug-cc-pVDZ were run on III $+\mathbf{A}$, and it was determined that M06-2X/aug-cc-pVDZ/ IEFPCM(acetonitrile) provided the best fit to experimental data. This level of theory was also applied to III + B and provided a more accurate computed spectra than PBE0/aug-cc-pVDZ/ IEFPCM(acetonitrile). Since M06-2X/aug-cc-pVDZ/IEFPCM(acetonitrile) did not provide a good fit for enamines formed with I (Figure S12), II, or IV (Figure S20), PBE0/aug-cc-pVDZ/ IEFPCM(acetonitrile) was determined to be the best general model for aminocatalytic systems, but M06-2X is recommended for systems specifically involving Jorgensen's catalyst.

(a)

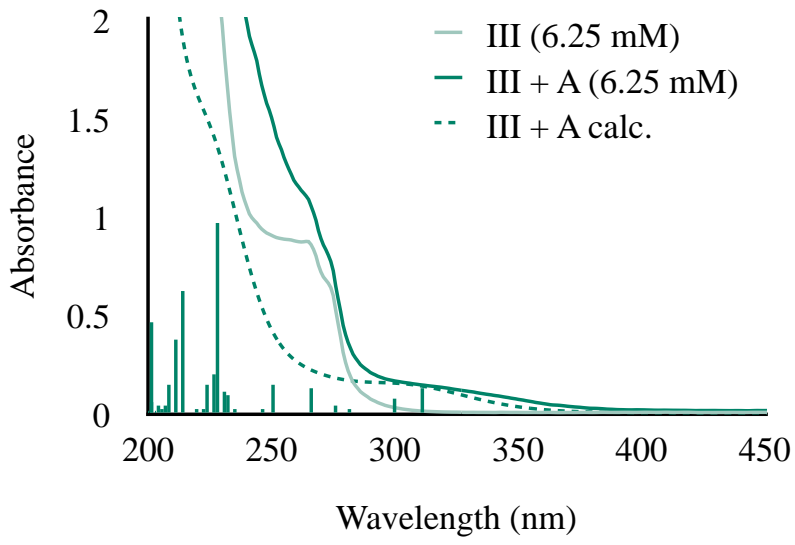

(b)

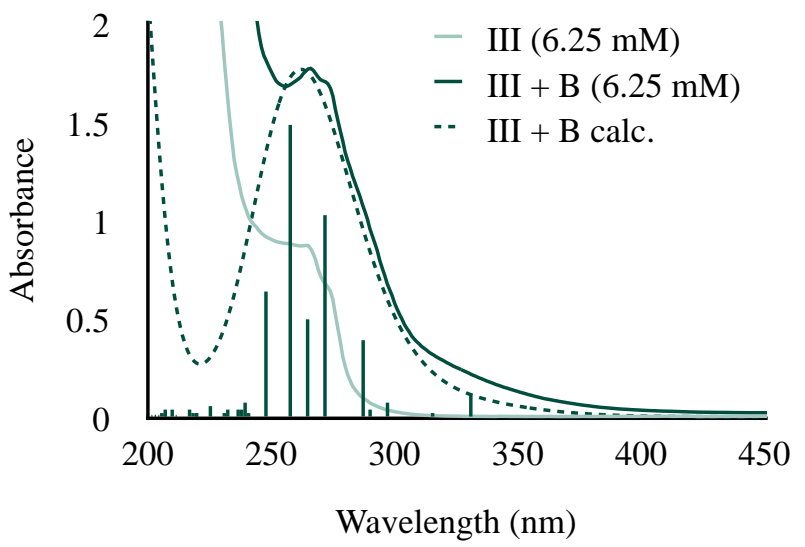

Figure S19. UV-vis absorption spectra, recorded in acetonitrile in $1 \mathrm{~mm}$ path quartz cuvettes, of (a) III and III + A, and (b) III + B. Calculated absorbance spectra at the M06-2X/aug-cc-pVDZ/ IEFPCM(acetonitrile) level of theory are normalized for comparison with experimental data. The vertical excitations contributing to the calculated spectra are shown as bars.

Table S8. TD-DFT vertical excitation and energies of key molecular orbitals for III $+\mathbf{A}$ and III + B calculated at the M06-2X/aug-cc-pVDZ/IEFPCM(acetonitrile) level of theory.

\begin{tabular}{|c|c|c|c|c|c|c|c|}
\hline \multirow{3}{*}{$\mathrm{III}+\mathbf{A}$} & \multicolumn{2}{|c|}{$\begin{array}{l}\text { Key orbital energies } \\
(\mathrm{eV})\end{array}$} & \multirow{2}{*}{\begin{tabular}{|l|}
$\begin{array}{l}\lambda_{\text {calc }} \\
(\mathbf{n m})\end{array}$ \\
311.59
\end{tabular}} & \multirow{2}{*}{$\begin{array}{r}\text { Oscillator } \\
\text { Strength }\end{array}$} & \multirow{2}{*}{$\begin{array}{l}\text { Assignment } \\
\mathrm{HOMO} \rightarrow \text { LUMO } \\
\mathrm{HOMO} \rightarrow \text { LUMO + } 1 \\
\mathrm{HOMO} \rightarrow \text { LUMO + } 2\end{array}$} & \multirow{2}{*}{\begin{tabular}{|r|} 
Coefficient \\
0.55011 \\
-0.35725 \\
0.24417 \\
\end{tabular}} & $\begin{array}{r}\% \text { Contribution } \\
61 \%\end{array}$ \\
\hline & $\begin{array}{l}\text { HOMO } \\
\text { LUMO } \\
\text { LUMO + } 1\end{array}$ & $\begin{array}{l}-6.52 \\
-0.98 \\
-0.72\end{array}$ & & & & & $\begin{array}{l}61 \% \\
26 \% \\
12 \%\end{array}$ \\
\hline & $\begin{array}{l}\text { LUMO + } 2 \\
\text { LUMO + } 3\end{array}$ & $\begin{array}{l}-0.56 \\
-0.46\end{array}$ & 299.64 & 0.0137 & $\begin{array}{l}\mathrm{HOMO} \rightarrow \mathrm{LUMO} \\
\mathrm{HOMO} \rightarrow \mathrm{LUMO}+1 \\
\mathrm{HOMO} \rightarrow \mathrm{LUMO}+3\end{array}$ & $\begin{array}{l}0.30001 \\
0.44088 \\
0.43073\end{array}$ & $\begin{array}{l}18 \% \\
39 \% \\
37 \%\end{array}$ \\
\hline
\end{tabular}




\begin{tabular}{|c|c|c|c|c|c|c|c|}
\hline & & & 282.01 & 0.0021 & $\begin{array}{l}\mathrm{HOMO} \rightarrow \mathrm{LUMO} \\
\mathrm{HOMO} \rightarrow \mathrm{LUMO}+1 \\
\mathrm{HOMO} \rightarrow \mathrm{LUMO}+3\end{array}$ & $\begin{array}{r}-0.29535 \\
-0.31369 \\
0.54260\end{array}$ & $\begin{array}{l}17 \% \\
20 \% \\
59 \%\end{array}$ \\
\hline & & & 276.41 & 0.0080 & $\begin{array}{l}\mathrm{HOMO} \rightarrow \mathrm{LUMO}+1 \\
\mathrm{HOMO} \rightarrow \mathrm{LUMO}+2\end{array}$ & $\begin{array}{l}0.26266 \\
0.63309\end{array}$ & $\begin{array}{l}14 \% \\
80 \%\end{array}$ \\
\hline \multirow[t]{4}{*}{ III + B } & \multirow{4}{*}{$\begin{array}{l}\text { HOMO } \\
\text { LUMO } \\
\text { LUMO + 1 } \\
\text { LUMO + } 2 \\
\text { LUMO + } 3\end{array}$} & \multirow{4}{*}{\begin{tabular}{l|}
-6.18 \\
-1.00 \\
-0.75 \\
-0.59 \\
-0.50
\end{tabular}} & 330.79 & 0.0296 & $\begin{array}{l}\mathrm{HOMO} \rightarrow \mathrm{LUMO} \\
\mathrm{HOMO} \rightarrow \mathrm{LUMO}+1 \\
\mathrm{HOMO} \rightarrow \mathrm{LUMO}+2\end{array}$ & $\begin{array}{l}0.56290 \\
0.34516 \\
0.22293\end{array}$ & $\begin{array}{l}63 \% \\
24 \% \\
10 \%\end{array}$ \\
\hline & & & 315.35 & 0.0047 & $\begin{array}{l}\mathrm{HOMO} \rightarrow \mathrm{LUMO} \\
\mathrm{HOMO} \rightarrow \mathrm{LUMO}+1 \\
\mathrm{HOMO} \rightarrow \mathrm{LUMO}+3\end{array}$ & $\begin{array}{r}-0.29659 \\
0.45408 \\
0.40967\end{array}$ & $\begin{array}{l}14 \% \\
41 \% \\
34 \%\end{array}$ \\
\hline & & & 296.50 & 0.0194 & $\begin{array}{l}\mathrm{HOMO} \rightarrow \mathrm{LUMO} \\
\mathrm{HOMO} \rightarrow \mathrm{LUMO}+1 \\
\mathrm{HOMO} \rightarrow \mathrm{LUMO}+3\end{array}$ & $\begin{array}{r}0.26887 \\
-0.32763 \\
0.55413\end{array}$ & $\begin{array}{l}14 \% \\
21 \% \\
61 \%\end{array}$ \\
\hline & & & 290.32 & 0.1118 & $\begin{array}{l}\mathrm{HOMO} \rightarrow \mathrm{LUMO}+1 \\
\mathrm{HOMO} \rightarrow \mathrm{LUMO}+2\end{array}$ & $\begin{array}{r}-0.23229 \\
0.63855\end{array}$ & $\begin{array}{l}11 \% \\
82 \%\end{array}$ \\
\hline
\end{tabular}

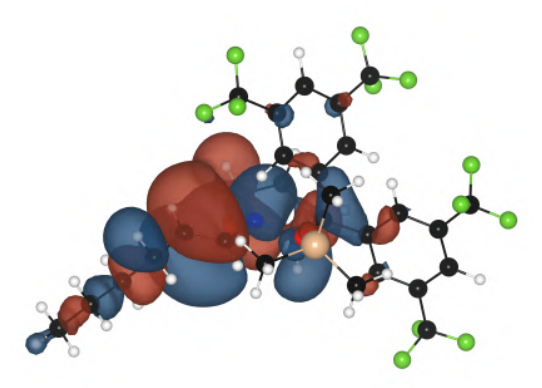

HOMO

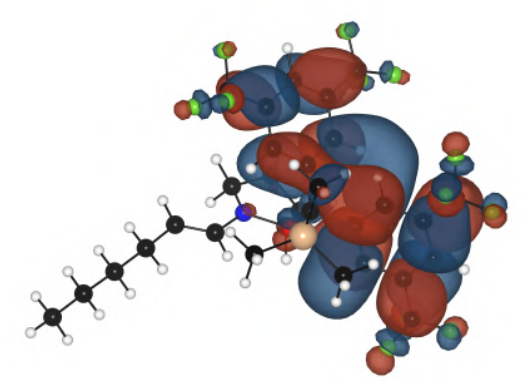

LUMO

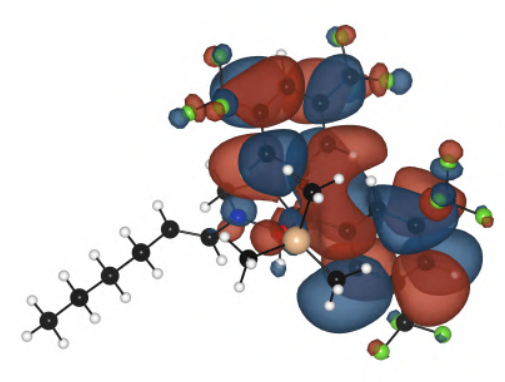

$\mathrm{LUMO}+1$

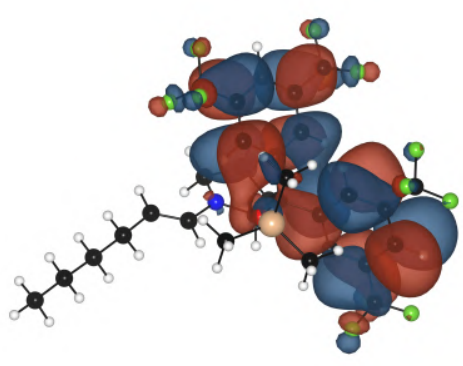

LUMO+2

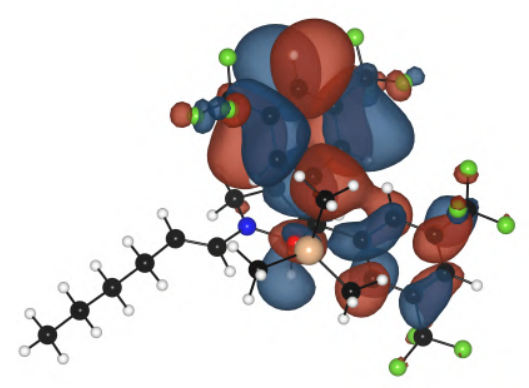

LUMO+3

Figure S20. Orbitals involved in excited states of III + A calculated at the the M06-2X/aug-ccpVDZ/IEFPCM(acetonitrile) level of theory. 


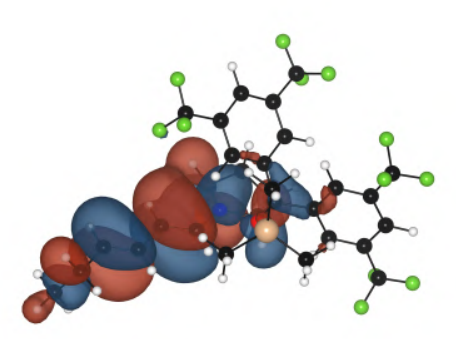

HOMO

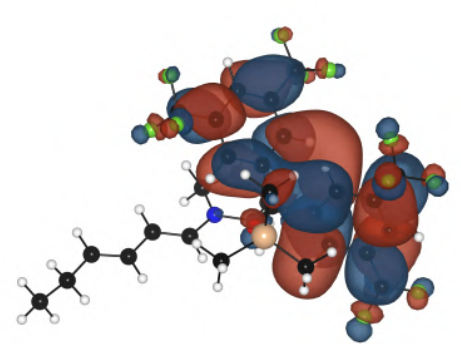

LUMO

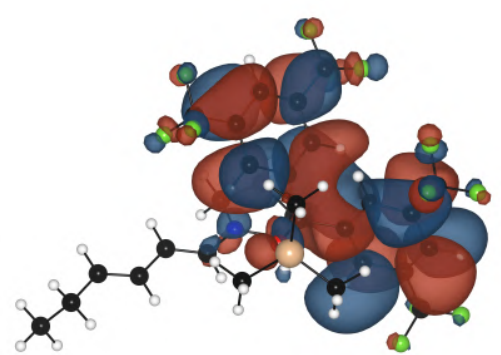

LUMO+1

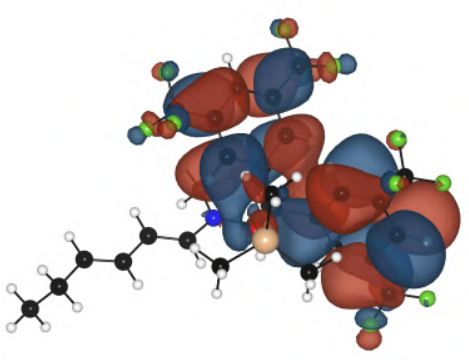

$\mathrm{LUMO}+2$

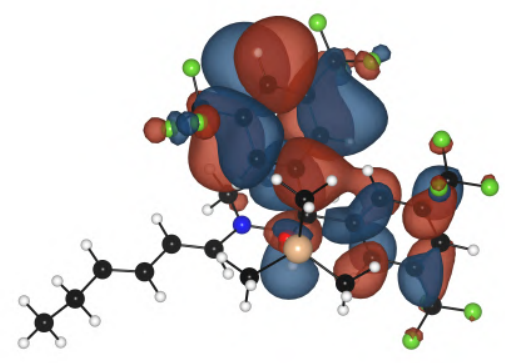

$\mathrm{LUMO}+3$

Figure S21. Orbitals involved in excited states of III + B calculated at the M06-2X/aug-ccpVDZ/IEFPCM(acetonitrile) level of theory.
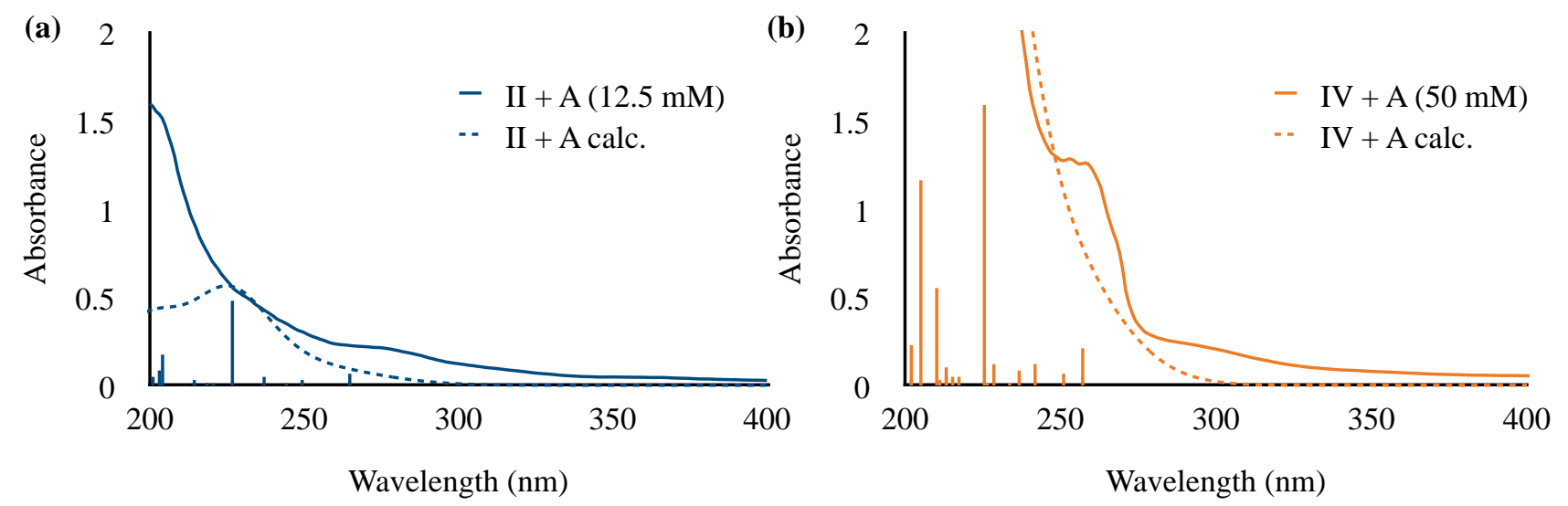

Figure S22. Comparison between experimental UV-vis absorption spectra and TD-DFT spectra at the M06-2X/aug-cc-pVDZ/IEFPCM(acetonitrile) level of theory for (a) II + A and (b) IV + A. The calculated spectra are normalized for comparison with experimental data. The vertical excitations contributing to the calculated spectra are shown as bars. 
In an attempt to improve the results for all four enamines, range-separated functionals were investigated. Since M06-2X uses 54\% exact (HF) exchange, while PBE0 uses 25\% exact exchange, the range-separated functional whPBE0 was employed, which uses $25 \%$ exact exchange in the short range regime, and 50\% exact exchange in the long range regime. whPBE0/aug-cc-pVDZ/IEFPCM(acetonitrile) was used to calculate the UV-vis spectra of enamines formed with all four catalysts, yielding poorer results for $\mathbf{I}+\mathbf{A}, \mathbf{I I}+\mathbf{A}$, and $\mathbf{I V}+\mathbf{A}$ than PBE0/aug-cc-pVDZ/IEFPCM(acetonitrile), but better results for III $+\mathbf{A}$. I $+\mathbf{A}$ data at this level of theory is shown in section Figure S12. The conclusions of the study do not change when using a range-separated functional.

(a)

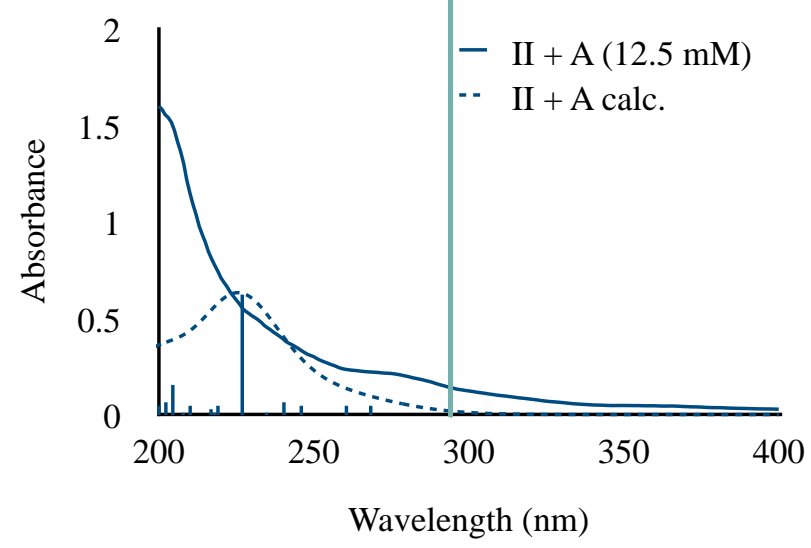

(b)

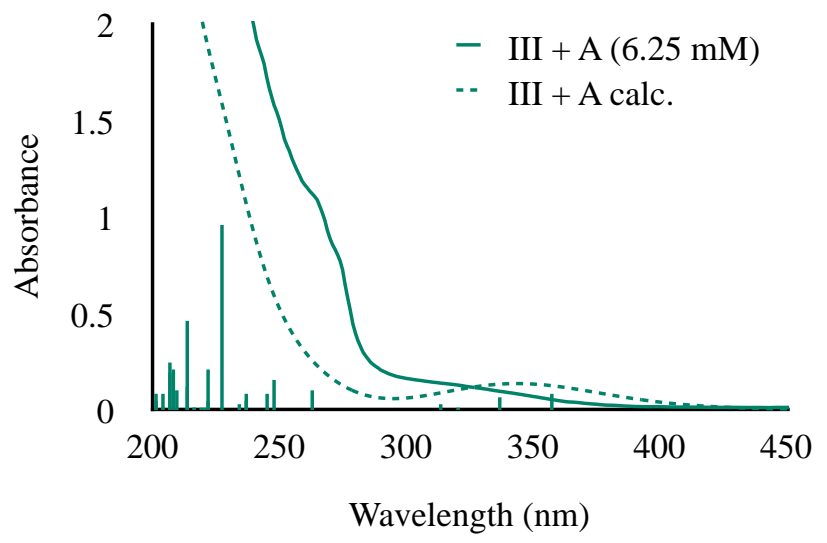

(c)

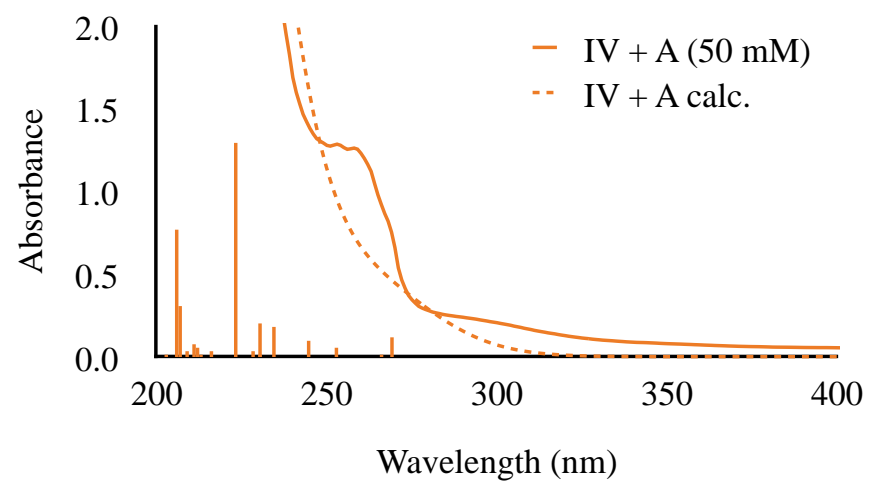

Figure S23. Comparison between experimental UV-vis absorption spectra and TD-DFT spectra at the whPBE0/aug-cc-pVDZ/IEFPCM(acetonitrile) level of theory for (a) II + A, (b) III + A, and (c) IV + A. The calculated spectra are normalized for comparison with experimental data. The vertical excitations contributing to the calculated spectra are shown as bars. 
Table S9. TD-DFT vertical excitation and energies of key molecular orbitals for enamines formed with I-IV at the whPBE0/aug-cc-pVDZ/IEFPCM(acetonitrile) level of theory.

\begin{tabular}{|c|c|c|c|c|c|c|c|}
\hline & $\begin{array}{l}\text { Key orbital } \\
(\mathrm{eV})\end{array}$ & & $\begin{array}{l}\lambda_{\text {calc }} \\
(\mathbf{n m})\end{array}$ & $\begin{array}{l}\text { Oscillator } \\
\text { Strength }\end{array}$ & Assignment & Coefficient & $\%$ Contribution \\
\hline \multirow[t]{2}{*}{$\mathbf{I}+\mathbf{A}$} & \multirow{2}{*}{$\begin{array}{l}\text { HOMO } \\
\text { LUMO } \\
\text { LUMO + } 7\end{array}$} & \multirow{2}{*}{$\begin{array}{r}-5.37 \\
0.32 \\
1.22\end{array}$} & 271.27 & 0.0346 & HOMO $\rightarrow$ LUMO & 0.64647 & $84 \%$ \\
\hline & & & 228.94 & 0.2722 & $\begin{array}{l}\mathrm{HOMO} \rightarrow \mathrm{LUMO}+4 \\
\mathrm{HOMO} \rightarrow \mathrm{LUMO}+5 \\
\mathrm{HOMO} \rightarrow \mathrm{LUMO}+7\end{array}$ & $\begin{array}{r}0.22299 \\
-0.24564 \\
0.51139\end{array}$ & $\begin{array}{l}10 \% \\
12 \% \\
52 \%\end{array}$ \\
\hline \multirow[t]{2}{*}{$\mathbf{I I}+\mathbf{A}$} & \multirow[t]{2}{*}{$\begin{array}{l}\text { HOMO } \\
\text { LUMO }\end{array}$} & \multirow[t]{2}{*}{$\begin{array}{r}-6.09 \\
0.27\end{array}$} & 267.93 & 0.0206 & $\begin{array}{l}\mathrm{HOMO} \rightarrow \mathrm{LUMO} \\
\mathrm{HOMO} \rightarrow \mathrm{LUMO}+2 \\
\mathrm{HOMO} \rightarrow \mathrm{LUMO}+3 \\
\mathrm{HOMO} \rightarrow \mathrm{LUMO}+4\end{array}$ & $\begin{array}{r}0.41046 \\
-0.27341 \\
0.33309 \\
-0.33825\end{array}$ & $\begin{array}{l}34 \% \\
15 \% \\
22 \% \\
23 \%\end{array}$ \\
\hline & & & 260.05 & 0.0235 & $\begin{array}{l}\mathrm{HOMO} \rightarrow \mathrm{LUMO} \\
\mathrm{HOMO} \rightarrow \mathrm{LUMO}+3 \\
\mathrm{HOMO} \rightarrow \mathrm{LUMO}+4 \\
\mathrm{HOMO} \rightarrow \mathrm{LUMO}+5\end{array}$ & \begin{tabular}{r|r}
0.46879 \\
-0.34448 \\
0.24934 \\
0.22725
\end{tabular} & $\begin{array}{l}44 \% \\
24 \% \\
12 \% \\
10 \%\end{array}$ \\
\hline \multirow[t]{4}{*}{ III + A } & \multirow{4}{*}{$\begin{array}{l}\text { HOMO } \\
\text { LUMO } \\
\text { LUMO + } 1 \\
\text { LUMO + } 2 \\
\text { LUMO + } 3\end{array}$} & \multirow{4}{*}{$\begin{array}{l}-6.03 \\
-1.16 \\
-0.91 \\
-0.76 \\
-0.64\end{array}$} & 357.39 & 0.0219 & $\begin{array}{l}\mathrm{HOMO} \rightarrow \text { LUMO } \\
\mathrm{HOMO} \rightarrow \mathrm{LUMO}+1\end{array}$ & $\begin{array}{r}0.58885 \\
-0.31476\end{array}$ & $\begin{array}{l}69 \% \\
20 \%\end{array}$ \\
\hline & & & 337.49 & 0.0161 & $\begin{array}{l}\mathrm{HOMO} \rightarrow \mathrm{LUMO} \\
\mathrm{HOMO} \rightarrow \mathrm{LUMO}+1 \\
\mathrm{HOMO} \rightarrow \mathrm{LUMO}+3\end{array}$ & $\begin{array}{l}0.28542 \\
0.51358 \\
0.36188\end{array}$ & $\begin{array}{l}16 \% \\
53 \% \\
26 \%\end{array}$ \\
\hline & & & 320.38 & 0.0008 & $\begin{array}{l}\mathrm{HOMO} \rightarrow \mathrm{LUMO} \\
\mathrm{HOMO} \rightarrow \mathrm{LUMO}+1 \\
\mathrm{HOMO} \rightarrow \mathrm{LUMO}+3\end{array}$ & $\begin{array}{r}-0.24979 \\
-0.23569 \\
0.59089\end{array}$ & $\begin{array}{l}12 \% \\
11 \% \\
70 \%\end{array}$ \\
\hline & & & 313.49 & 0.0090 & $\begin{array}{l}\mathrm{HOMO} \rightarrow \mathrm{LUMO}+1 \\
\mathrm{HOMO} \rightarrow \mathrm{LUMO}+2\end{array}$ & $\begin{array}{l}0.27537 \\
0.63366\end{array}$ & $\begin{array}{l}15 \% \\
80 \%\end{array}$ \\
\hline $\mathbf{I V}+\mathbf{A}$ & $\begin{array}{l}\text { HOMO } \\
\text { LUMO } \\
\text { LUMO + } 1\end{array}$ & $\begin{array}{r}-6.17 \\
0.12 \\
0.14\end{array}$ & $\begin{array}{l}268.76 \\
266.13\end{array}$ & $\begin{array}{l}0.0182 \\
0.0037\end{array}$ & $\begin{array}{l}\text { HOMO } \rightarrow \text { LUMO } \\
\text { HOMO } \rightarrow \text { LUMO } \\
\text { HOMO } \rightarrow \text { LUMO + } 1\end{array}$ & $\begin{array}{r}0.64740 \\
-0.22619 \\
0.64868\end{array}$ & $\begin{array}{l}84 \% \\
10 \% \\
84 \%\end{array}$ \\
\hline
\end{tabular}

Figure S24. Orbitals involved in excited states of $\mathbf{I}+\mathbf{A}$ calculated at the whPBE0/aug-ccpVDZ/IEFPCM(acetonitrile) level of theory. 


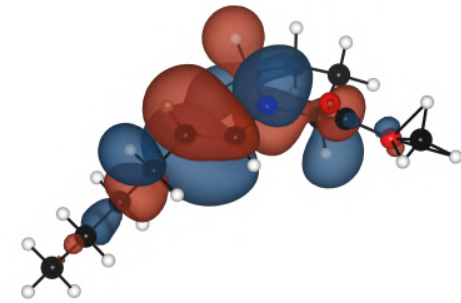

HOMO

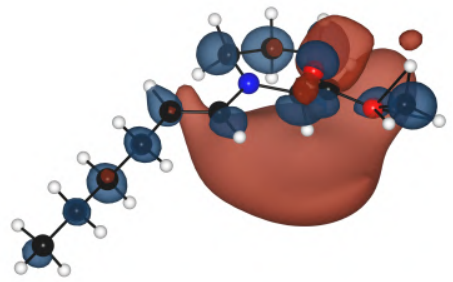

LUMO

Figure S25. Orbitals involved in excited states of II + A calculated at the whPBE0/aug-ccpVDZ/IEFPCM(acetonitrile) level of theory.

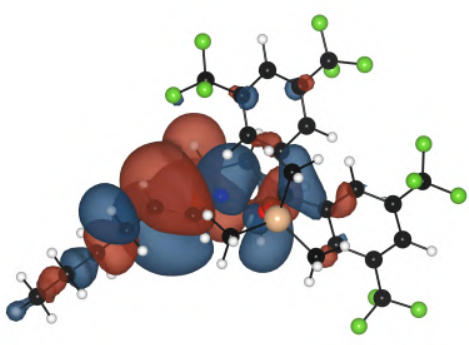

HOMO

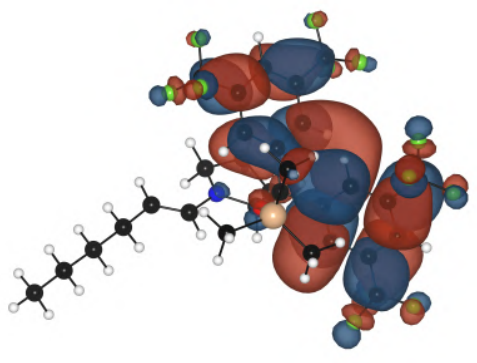

LUMO

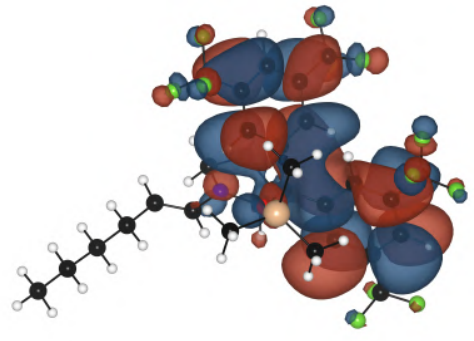

LUMO+1

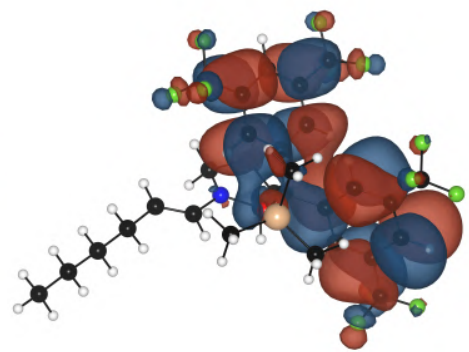

$\mathrm{LUMO}+2$

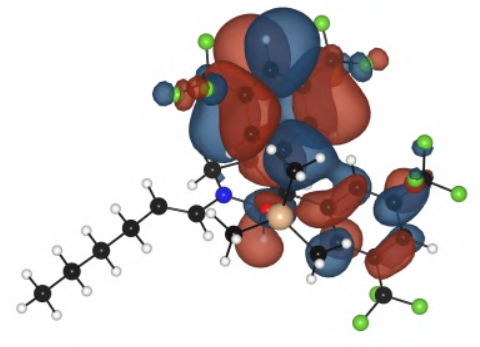

$\mathrm{LUMO}+3$

Figure S26. Orbitals involved in excited states of III + A calculated at the whPBE0/aug-ccpVDZ/IEFPCM(acetonitrile) level of theory.

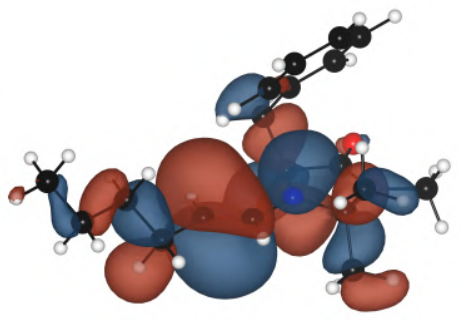

HOMO

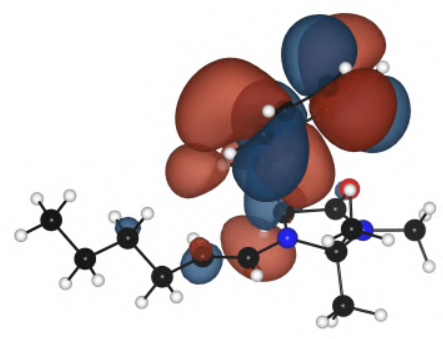

LUMO

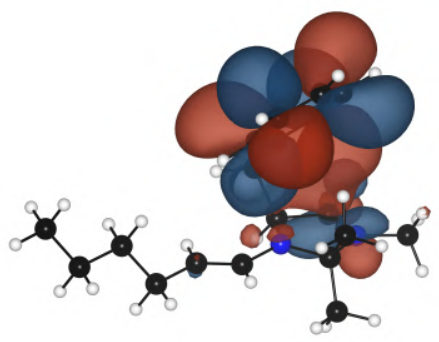

LUMO+1

Figure S27. Orbitals involved in excited states of IV $+\mathbf{A}$ calculated at the whPBE0/aug-ccpVDZ/IEFPCM(acetonitrile) level of theory. 


\section{H. Fluorescence and optical gap of enamines}

In order to further confirm the validity of our method, it was in our interest to calculate the optical gap of the enamines through comparison of the fluorescence and UV-vis absorption spectra. However, based on the results of the fluorescence experiments we have determined that the non-isolable nature of the enamines studied makes their emission spectra difficult to analyze and impossible to evaluate quantitatively. We have included details on III + $\mathbf{A}$ as an example.

Based on the experimental absorbance data collected for III and its corresponding enamine $(\mathbf{I I I}+\mathbf{A})$, the lowest energy transitions for the enamine occur at approximately $320 \mathrm{~nm}$, where there is no observed absorbance for III. Thus, fluorescence spectra for III $+\mathbf{A}$ and its individual components were measured on a Fluorolog-3 Horiba Jobin Yvon spectrofluorometer using an excitation wavelength of $320 \mathrm{~nm}$, with excitation and emission slits set to $3 \mathrm{~nm}$ band pass resolution (Figure S28a).

(a)

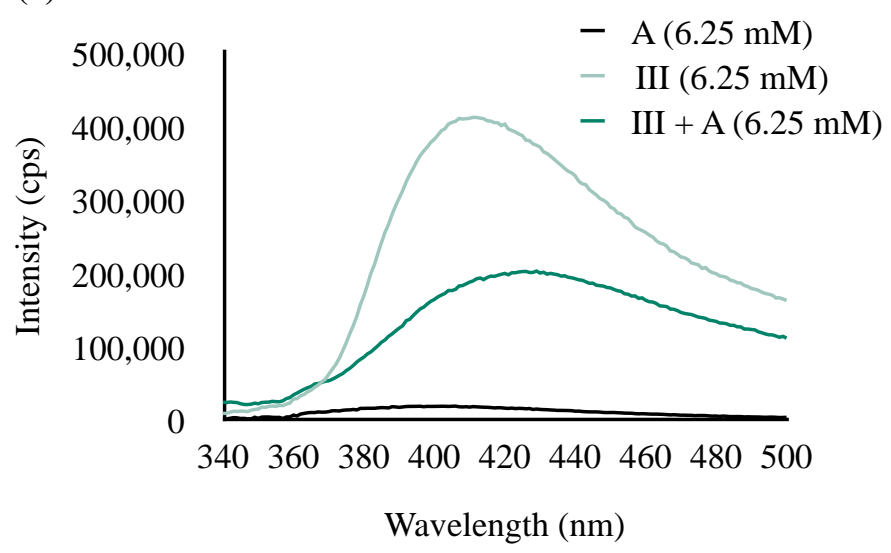

(b)

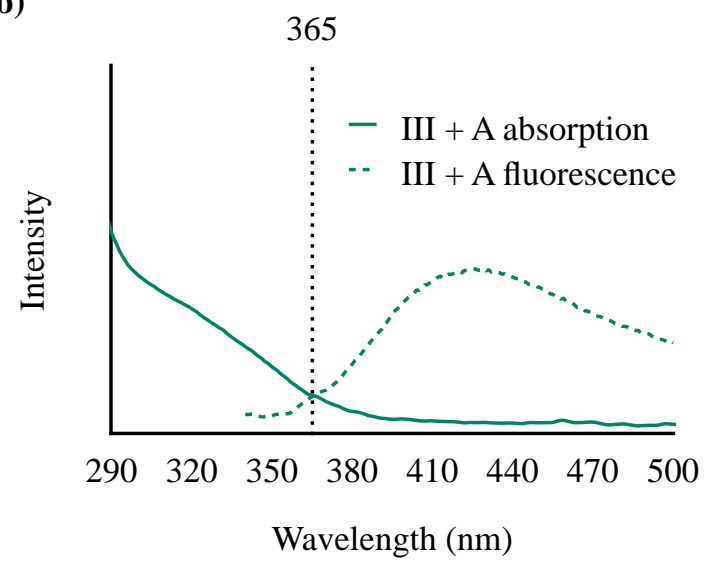

Figure S28. (a) Fluorescence spectra, recorded in acetonitrile in $10 \times 10 \mathrm{~mm}$ path quartz cuvettes, of $\mathbf{A}$, III, and III $+\mathbf{A}\left(\lambda_{\mathrm{ex}}=320 \mathrm{~nm}\right)$ and (b) direct comparison of the fluorescence and UV-vis absorption spectra of III $+\mathbf{A}$.

From these spectra, it is observed that fluorescence of the catalyst III interferes significantly with the spectrum of the enamine III $+\mathbf{A}$, and quenching of this fluorescence is observed in the enamine spectrum. Although a small shift in the fluorescence maximum is seen upon formation of the enamine, the subtraction of this data to yield the fluorescence spectrum of the enamine individually is not possible. Since the enamines are reactive intermediates that form in very low concentrations, quantitative use of the fluorescence spectra to calculate the optical gap is unachievable due to interfering fluorescence from the aldehyde (A) and catalysts (I-IV) which are excited at similar wavelengths to the enamines.

If we assume that the fluorescence of the enamine is approximately accurate despite contribution from the catalyst, the crossing point between the two spectra lies at $365 \mathrm{~nm}$, or 3.4 eV (Figure S28b). This estimate of the optical gap is consistent with theoretical data, which predicted a HOMO to LUMO gap of $3.7 \mathrm{eV}$ (Figure 3c). 


\section{TD-DFT analysis and optical gap of isolable enamine}

Optical absorption spectra of an isolable enamine formed with Jorgensen's catalyst (III) and phenylacetaldehyde (C) has been previously reported.18 Since our results showed that that the low lying unoccupied orbitals of dienamines formed with III remained localized on the substituent of the catalyst, it was of interest to apply our model to III $+\mathbf{C}$, which is even further conjugated. The theoretical spectrum of III $+\mathbf{C}$ is consistent with the previously reported experimental data, and the calculated molecular orbitals show that the low lying unoccupied orbitals are localized on the aryl substituents.

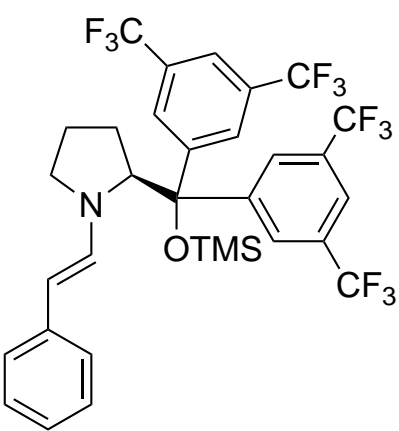

Figure S29. Structure of III + C.

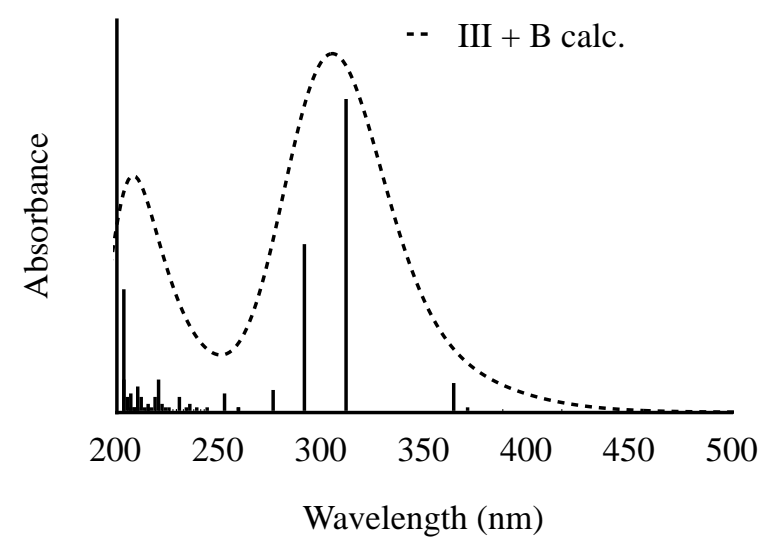

Figure S30. Calculated absorbance spectra of III + C. The vertical excitations contributing to the calculated spectra are shown as bars.

Table S10. TD-DFT vertical excitation and energies of key molecular orbitals for III + C.

\begin{tabular}{|c|c|c|c|c|c|c|}
\hline \multicolumn{2}{|c|}{$\begin{array}{l}\text { Key orbital energies } \\
(\mathrm{eV})\end{array}$} & \multirow{2}{*}{$\begin{array}{l}\lambda_{\text {calc }} \\
(\mathbf{n m})\end{array}$} & \multirow{2}{*}{$\begin{array}{r}\begin{array}{l}\text { Oscillator } \\
\text { Strength }\end{array} \\
0.0004\end{array}$} & \multirow{2}{*}{\begin{tabular}{|l} 
Assignment \\
HOMO $\rightarrow$ LUMO
\end{tabular}} & \multirow{2}{*}{$\begin{array}{r}\text { Coefficient } \\
0.65734\end{array}$} & \multirow{2}{*}{$\begin{array}{r}\% \text { Contribution } \\
86 \%\end{array}$} \\
\hline HOMO & -5.34 & & & & & \\
\hline LUMO & -1.71 & 388.38 & 0.0008 & & 0.60165 & $72 \%$ \\
\hline $\begin{array}{l}\mathrm{LUMO}+1 \\
\mathrm{LUMO}+2\end{array}$ & $\begin{array}{l}-1.44 \\
-1.32\end{array}$ & 388.38 & 0.0008 & $\mathrm{HOMO} \rightarrow \mathrm{LUMO}+3$ & $\begin{array}{l}0.60165 \\
0.24639\end{array}$ & $12 \%$ \\
\hline $\begin{array}{l}\mathrm{LUMO}+3 \\
\mathrm{LUMO}+4\end{array}$ & $\begin{array}{l}-1.25 \\
-0.65\end{array}$ & 372.25 & 0.0065 & $\mathrm{HOMO} \rightarrow \mathrm{LUMO}+3$ & 0.65571 & $86 \%$ \\
\hline \multirow[t]{3}{*}{$\mathrm{LUMO}+5$} & -0.22 & 364.02 & 0.0440 & $\begin{array}{l}\mathrm{HOMO} \rightarrow \mathrm{LUMO}+1 \\
\mathrm{HOMO} \rightarrow \mathrm{LUMO}+2\end{array}$ & $\begin{array}{l}0.22706 \\
0.66507\end{array}$ & $\begin{array}{l}10 \% \\
88 \%\end{array}$ \\
\hline & & 312.76 & 0.4766 & $\mathrm{HOMO} \rightarrow \mathrm{LUMO}+4$ & 0.66753 & $89 \%$ \\
\hline & & 292.34 & 0.2572 & $\mathrm{HOMO} \rightarrow \mathrm{LUMO}+5$ & 0.63023 & $79 \%$ \\
\hline
\end{tabular}




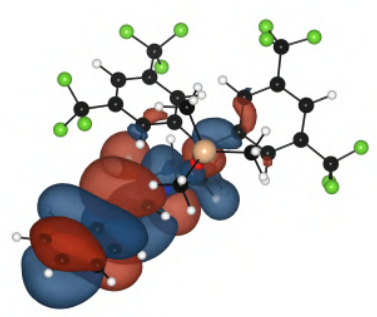

HOMO

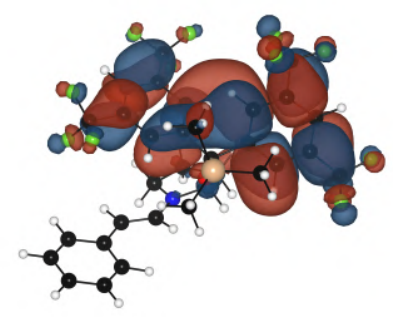

LUMO

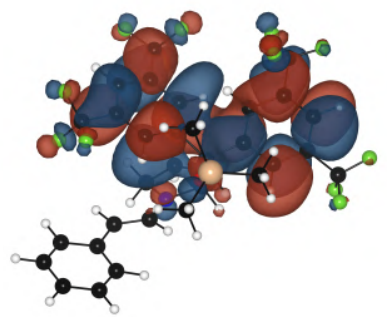

LUMO+1

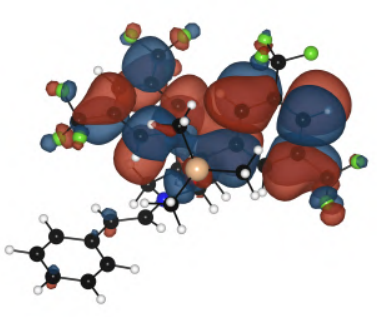

$\mathrm{LUMO}+2$

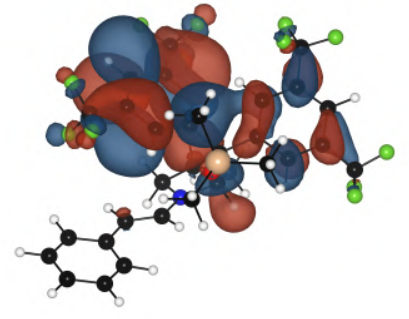

$\mathrm{LUMO}+3$

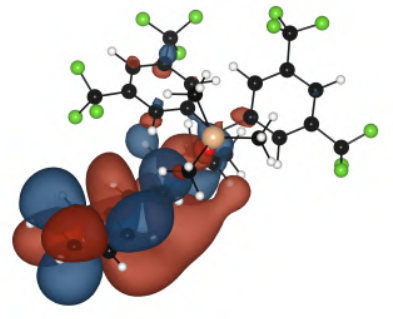

$\mathrm{LUMO}+4$

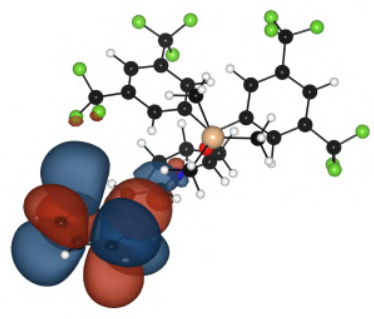

$\mathrm{LUMO}+5$

Figure S31. Orbitals involved in excited states of III + C.

Although it is impossible to accurately calculate the optical gap for nonisolable enamines, as discussed in Appendix $\mathrm{H}$, the emission spectrum of this previously studied isolable enamine has been reported. Through comparison of the reported absorption and emission spectra, ${ }^{18}$ the optical gap measured at the crossing point between the two spectra is at approximately $405 \mathrm{~nm}$, or $3.1 \mathrm{eV}$. From our calculations at the PBE0/aug-ccpVDZ/IEFPCM(acetonitrile) level of theory, the HOMO to LUMO gap of the isolable polyenamine $\mathbf{I I I}+\mathbf{C}$ is calculated to be $3.6 \mathrm{eV}$. Thus, our theoretical data is consistent with the previously reported experimental data for isolable enamines, providing further evidence of the accuracy of the method used in our work. 


\section{J. Ground state geometry optimized structures}

All geometry optimizations were performed at the M06-2X/6-31G+(d,p)/IEFPCM(acetonitrile) level of theory. Analysis of vibrational frequencies verified all of these structures as minima.

A

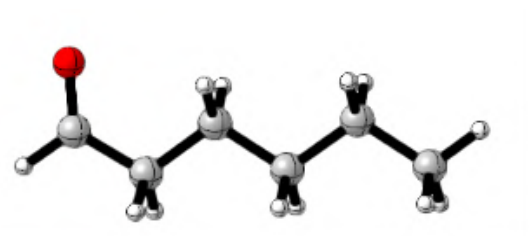

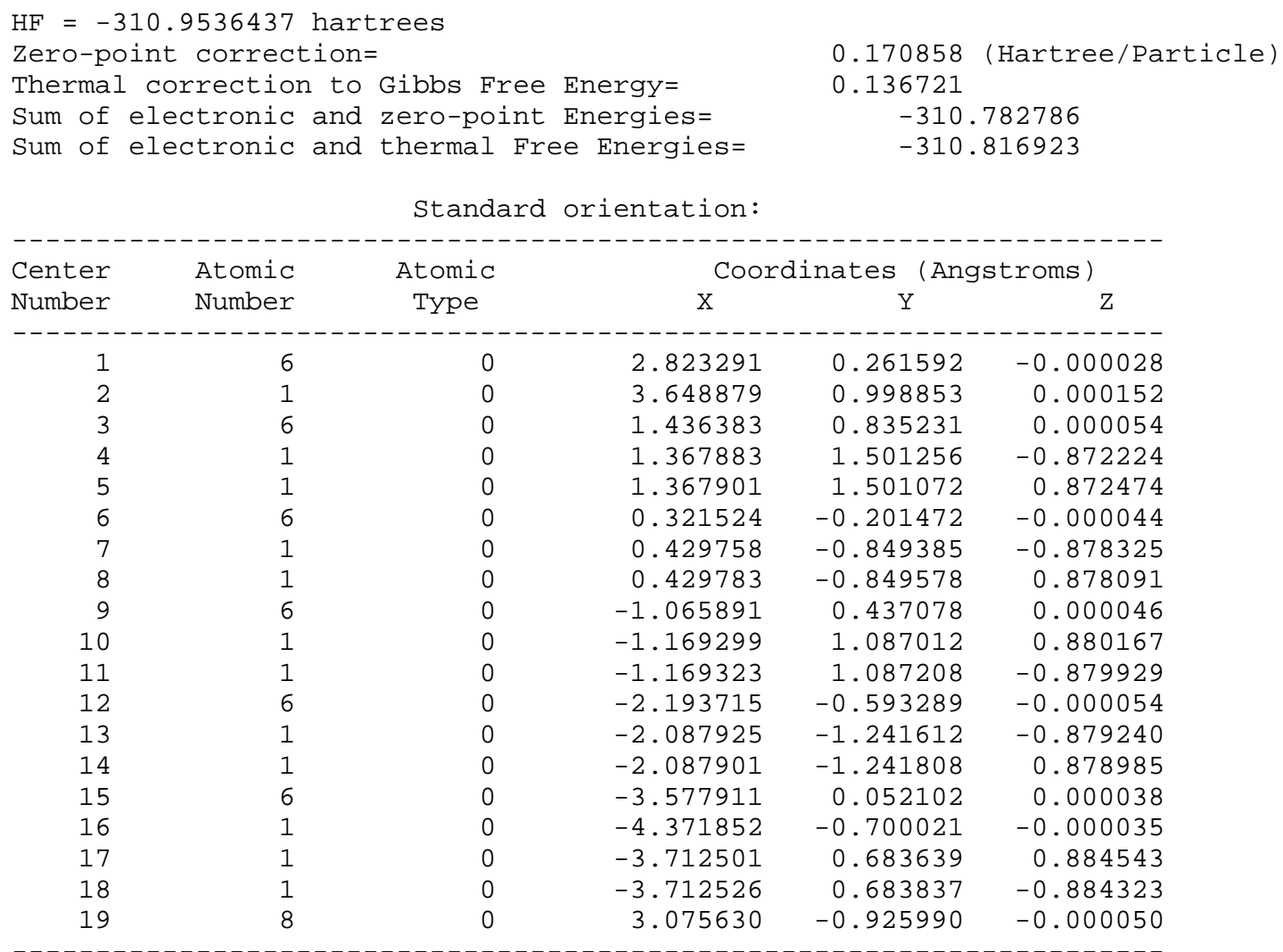

I

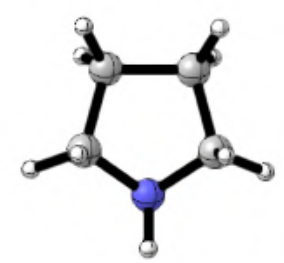


$\mathrm{HF}=-212.4944683$ hartrees

Zero-point correction=

Thermal correction to Gibbs Free Energy=

Sum of electronic and zero-point Energies=

Sum of electronic and thermal Free Energies=

\author{
0.130686 (Hartree/Particle) \\ 0.102673 \\ $-212.363783$ \\ $-212.391796$
}

Standard orientation:

\begin{tabular}{|c|c|c|c|c|c|}
\hline \multirow{2}{*}{$\begin{array}{l}\text { Center } \\
\text { Number }\end{array}$} & \multirow{2}{*}{$\begin{array}{l}\text { Atomic } \\
\text { Number }\end{array}$} & \multirow{2}{*}{$\begin{array}{c}\text { Atomic } \\
\text { Type }\end{array}$} & \multicolumn{3}{|c|}{ Coordinates (Angstroms) } \\
\hline & & & $\mathrm{X}$ & $\mathrm{Y}$ & Z \\
\hline 1 & 6 & 0 & -1.155200 & -0.445118 & 0.175105 \\
\hline 2 & 6 & 0 & 1.155206 & -0.445104 & 0.175103 \\
\hline 3 & 6 & 0 & 0.776054 & 1.026587 & -0.057960 \\
\hline 4 & 6 & 0 & -0.776066 & 1.026577 & -0.057962 \\
\hline 5 & 1 & 0 & -2.076134 & -0.739262 & -0.334919 \\
\hline 6 & 1 & 0 & -1.283716 & -0.630595 & 1.254710 \\
\hline 7 & 1 & 0 & 1.283727 & -0.630583 & 1.254707 \\
\hline 8 & 1 & 0 & 2.076141 & -0.739237 & -0.334924 \\
\hline 9 & 1 & 0 & 1.195476 & 1.675152 & 0.714463 \\
\hline 10 & 1 & 0 & 1.158804 & 1.368517 & -1.023006 \\
\hline 11 & 1 & 0 & -1.195499 & 1.675141 & 0.714457 \\
\hline 12 & 1 & 0 & -1.158817 & 1.368499 & -1.023011 \\
\hline 13 & 7 & 0 & 0.000006 & -1.168999 & -0.365106 \\
\hline 14 & 1 & 0 & 0.000012 & -2.142293 & -0.072452 \\
\hline
\end{tabular}

\title{
$\mathbf{I}+\mathbf{A}$
}

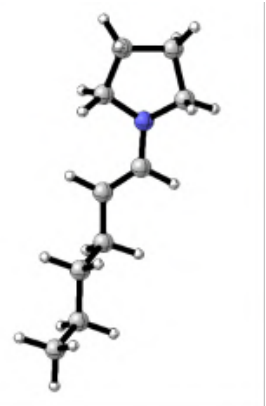

$\mathrm{HF}=-447.0479425$ hartrees

Zero-point correction=

Thermal correction to Gibbs Free Energy=

Sum of electronic and zero-point Energies=

0.277290 (Hartree/Particle)

Sum of electronic and thermal Free Energies=

0.236968

$-446.770653$

$-446.810974$

Standard orientation:

\begin{tabular}{|c|c|c|c|c|c|}
\hline \multirow{2}{*}{$\begin{array}{l}\text { Center } \\
\text { Number }\end{array}$} & \multirow{2}{*}{$\begin{array}{l}\text { Atomic } \\
\text { Number }\end{array}$} & \multirow{2}{*}{$\begin{array}{l}\text { Atomic } \\
\text { Type }\end{array}$} & \multicolumn{3}{|c|}{ Coordinates (Angstroms) } \\
\hline & & & $\mathrm{X}$ & $Y$ & $\mathrm{Z}$ \\
\hline 1 & 6 & 0 & 2.292933 & 1.045072 & -0.413899 \\
\hline 2 & 6 & 0 & 2.863139 & -1.005835 & 0.698310 \\
\hline 3 & 6 & 0 & 4.170382 & -0.288245 & 0.377464 \\
\hline 4 & 6 & 0 & 3.708931 & 1.165101 & 0.184834 \\
\hline 5 & 1 & 0 & 2.260561 & 1.289894 & -1.482926 \\
\hline 6 & 1 & 0 & 1.582184 & 1.713066 & 0.096745 \\
\hline
\end{tabular}




$\begin{array}{rrrrrr}7 & 1 & 0 & 2.584866 & -0.849299 & 1.754134 \\ 8 & 1 & 0 & 2.893336 & -2.082155 & 0.505405 \\ 9 & 1 & 0 & 4.917520 & -0.395454 & 1.166604 \\ 10 & 1 & 0 & 4.586646 & -0.686248 & -0.553546 \\ 11 & 1 & 0 & 3.656807 & 1.665301 & 1.156495 \\ 12 & 1 & 0 & 4.381506 & 1.743389 & -0.451735 \\ 13 & 7 & 0 & 1.925838 & -0.352678 & -0.210453 \\ 14 & 6 & 0 & 0.606333 & -0.743198 & -0.264412 \\ 15 & 1 & 0 & 0.439061 & -1.766767 & 0.072934 \\ 16 & 6 & 0 & -0.433440 & -0.016494 & -0.718709 \\ 17 & 1 & 0 & -0.273842 & 1.003536 & -1.065414 \\ 18 & 6 & 0 & -1.837925 & -0.549192 & -0.788764 \\ 19 & 1 & 0 & -2.198626 & -0.535382 & -1.827899 \\ 20 & 1 & 0 & -1.847510 & -1.600821 & -0.472204 \\ 21 & 6 & 0 & -2.829121 & 0.244618 & 0.070486 \\ 22 & 1 & 0 & -2.510190 & 0.197920 & 1.120671 \\ 23 & 1 & 0 & -2.790111 & 1.304309 & -0.218965 \\ 24 & 6 & 0 & -4.265988 & -0.259403 & -0.051470 \\ 25 & 1 & 0 & -4.300742 & -1.319627 & 0.231214 \\ 26 & 1 & 0 & -4.576713 & -0.208935 & -1.103102 \\ 27 & 6 & 0 & -5.243678 & 0.535341 & 0.812152 \\ 28 & 1 & 0 & -6.266684 & 0.161735 & 0.711026 \\ 29 & 1 & 0 & -4.966307 & 0.474674 & 1.869892 \\ 30 & 1 & 0 & -5.242024 & 1.593016 & 0.527884 \\ ------------------------------------------------------\end{array}$

\section{(Z) I + A}

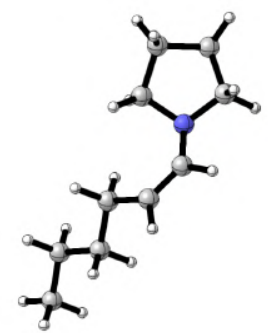

$\mathrm{HF}=-447.0434507$ hartrees

Zero-point correction=

Thermal correction to Gibbs Free Energy=

Sum of electronic and zero-point Energies=

0.277533 (Hartree/Particle)

Sum of electronic and thermal Free Energies=

0.237522

$-446.765917$

$-446.805929$

Standard orientation:

\begin{tabular}{|c|c|c|c|c|c|}
\hline \multirow{2}{*}{$\begin{array}{l}\text { Center } \\
\text { Number }\end{array}$} & \multirow{2}{*}{$\begin{array}{l}\text { Atomic } \\
\text { Number }\end{array}$} & \multirow{2}{*}{$\begin{array}{c}\text { Atomic } \\
\text { Type }\end{array}$} & \multicolumn{3}{|c|}{ Coordinates (Angstroms) } \\
\hline & & & $\mathrm{x}$ & $\mathrm{Y}$ & Z \\
\hline 1 & 6 & 0 & -1.663598 & -0.931022 & 0.381802 \\
\hline 2 & 6 & 0 & -3.037127 & 0.778568 & -0.637520 \\
\hline 3 & 6 & 0 & -3.792781 & -0.547843 & -0.642187 \\
\hline 4 & 6 & 0 & -3.145702 & -1.290602 & 0.530549 \\
\hline 5 & 1 & 0 & -1.149501 & -1.663523 & -0.252616 \\
\hline 6 & 1 & 0 & -1.137599 & -0.886958 & 1.341568 \\
\hline 7 & 1 & 0 & -3.476434 & 1.469562 & 0.099960 \\
\hline 8 & 1 & 0 & -3.041409 & 1.275581 & -1.612456 \\
\hline 9 & 1 & 0 & -4.870586 & -0.412732 & -0.530418 \\
\hline 10 & 1 & 0 & -3.606227 & -1.084234 & -1.578978 \\
\hline 11 & 1 & 0 & -3.533213 & -0.895090 & 1.475827 \\
\hline
\end{tabular}




$\begin{array}{rrrrrr}12 & 1 & 0 & -3.317992 & -2.369023 & 0.512503 \\ 13 & 7 & 0 & -1.673078 & 0.401980 & -0.247084 \\ 14 & 6 & 0 & -0.831885 & 1.409705 & 0.200103 \\ 15 & 1 & 0 & -1.301830 & 2.394040 & 0.225933 \\ 16 & 6 & 0 & 0.454647 & 1.299837 & 0.581579 \\ 17 & 1 & 0 & 0.926948 & 2.207896 & 0.951341 \\ 18 & 6 & 0 & 1.329433 & 0.077514 & 0.482337 \\ 19 & 1 & 0 & 1.398624 & -0.446151 & 1.447698 \\ 20 & 1 & 0 & 0.891541 & -0.636368 & -0.225467 \\ 21 & 6 & 0 & 2.748586 & 0.426601 & 0.022769 \\ 22 & 1 & 0 & 2.699289 & 0.925108 & -0.954955 \\ 23 & 1 & 0 & 3.185988 & 1.154505 & 0.720525 \\ 24 & 6 & 0 & 3.662833 & -0.793112 & -0.072393 \\ 25 & 1 & 0 & 3.223053 & -1.519269 & -0.768262 \\ 26 & 1 & 0 & 3.704971 & -1.288045 & 0.906504 \\ 27 & 6 & 0 & 5.075735 & -0.434304 & -0.528666 \\ 28 & 1 & 0 & 5.715721 & -1.319087 & -0.590521 \\ 29 & 1 & 0 & 5.057263 & 0.037459 & -1.516849 \\ 30 & 1 & 0 & 5.542093 & 0.270419 & 0.168008 \\ --------------------------------------------------------\end{array}$

\section{$\mathbf{I}+\mathbf{B}$}

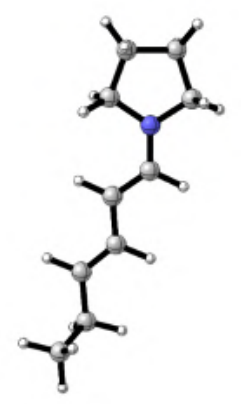

$\mathrm{HF}=-445.8334413$ hartrees

Zero-point correction=

Thermal correction to Gibbs Free Energy=

Sum of electronic and zero-point Energies=

0.253677 (Hartree/Particle)

0.213855

$-445.579764$

$-445.619587$

Standard orientation:

\begin{tabular}{|c|c|c|c|c|c|}
\hline \multirow{2}{*}{$\begin{array}{l}\text { Center } \\
\text { Number }\end{array}$} & \multirow{2}{*}{$\begin{array}{l}\text { Atomic } \\
\text { Number }\end{array}$} & \multirow{2}{*}{$\begin{array}{c}\text { Atomic } \\
\text { Type }\end{array}$} & \multicolumn{3}{|c|}{ Coordinates (Angstroms) } \\
\hline & & & $\mathrm{x}$ & $\mathrm{Y}$ & Z \\
\hline 1 & 6 & 0 & 2.244016 & 1.121588 & -0.078274 \\
\hline 2 & 6 & 0 & 2.957918 & -1.172374 & 0.288087 \\
\hline 3 & 6 & 0 & 4.149168 & -0.345682 & -0.197958 \\
\hline 4 & 6 & 0 & 3.751778 & 1.082266 & 0.198685 \\
\hline 5 & 1 & 0 & 2.018968 & 1.471795 & -1.097045 \\
\hline 6 & 1 & 0 & 1.703647 & 1.770234 & 0.623005 \\
\hline 7 & 1 & 0 & 3.066407 & -1.428614 & 1.352045 \\
\hline 8 & 1 & 0 & 2.817448 & -2.098780 & -0.276722 \\
\hline 9 & 1 & 0 & 5.092485 & -0.668365 & 0.246998 \\
\hline 10 & 1 & 0 & 4.233152 & -0.424334 & -1.287010 \\
\hline 11 & 1 & 0 & 3.935497 & 1.234997 & 1.267244 \\
\hline 12 & 1 & 0 & 4.295837 & 1.850500 & -0.353968 \\
\hline 13 & 7 & 0 & 1.832148 & -0.265565 & 0.077980 \\
\hline
\end{tabular}




$\begin{array}{rrrrrr}14 & 6 & 0 & 0.536007 & -0.658277 & 0.030581 \\ 15 & 1 & 0 & 0.389035 & -1.730725 & 0.158471 \\ 16 & 6 & 0 & -0.546070 & 0.143360 & -0.162003 \\ 17 & 1 & 0 & -0.419188 & 1.215858 & -0.293561 \\ 18 & 6 & 0 & -1.895203 & -0.393999 & -0.202736 \\ 19 & 6 & 0 & -3.022113 & 0.315197 & -0.392506 \\ 20 & 6 & 0 & -4.406719 & -0.267092 & -0.417070 \\ 21 & 1 & 0 & -4.343998 & -1.357016 & -0.314608 \\ 22 & 1 & 0 & -4.877362 & -0.068592 & -1.389591 \\ 23 & 6 & 0 & -5.304447 & 0.307882 & 0.685277 \\ 24 & 1 & 0 & -6.317681 & -0.100827 & 0.626265 \\ 25 & 1 & 0 & -4.897491 & 0.076648 & 1.674468 \\ 26 & 1 & 0 & -5.374387 & 1.397152 & 0.598270 \\ 27 & 1 & 0 & -1.985569 & -1.475285 & -0.067400 \\ 28 & 1 & 0 & -2.947851 & 1.397087 & -0.525222 \\ --------------------------------------------------\end{array}$

\section{$\mathbf{I I}+\mathbf{A}$}

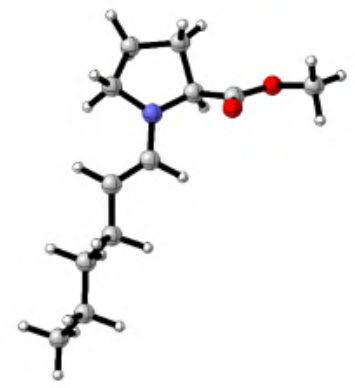

$\mathrm{HF}=-674.8521145$ hartrees

Zero-point correction=

Thermal correction to Gibbs Free Energy=

Sum of electronic and zero-point Energies=

0.320716 (Hartree/Particle)

Sum of electronic and thermal Free Energies=

0.273192

$-674.531398$

$-674.578923$

Standard orientation:

\begin{tabular}{|c|c|c|c|c|c|}
\hline \multirow{2}{*}{$\begin{array}{l}\text { Center } \\
\text { Number }\end{array}$} & \multirow{2}{*}{$\begin{array}{l}\text { Atomic } \\
\text { Number }\end{array}$} & \multirow{2}{*}{$\begin{array}{c}\text { Atomic } \\
\text { Type }\end{array}$} & \multicolumn{3}{|c|}{ Coordinates (Angstroms) } \\
\hline & & & $\mathrm{x}$ & $\mathrm{Y}$ & Z \\
\hline 1 & 6 & 0 & 0.740146 & 2.280658 & 0.383732 \\
\hline 2 & 6 & 0 & 1.963984 & 0.395025 & -0.502253 \\
\hline 3 & 6 & 0 & 2.930320 & 1.584216 & -0.349114 \\
\hline 4 & 6 & 0 & 1.978378 & 2.783214 & -0.369766 \\
\hline 5 & 1 & 0 & -0.188663 & 2.678556 & -0.045127 \\
\hline 6 & 1 & 0 & 0.760326 & 2.552836 & 1.447478 \\
\hline 7 & 1 & 0 & 1.759710 & 0.207695 & -1.568289 \\
\hline 8 & 1 & 0 & 3.437602 & 1.516608 & 0.619774 \\
\hline 9 & 1 & 0 & 3.682491 & 1.605024 & -1.138763 \\
\hline 10 & 1 & 0 & 2.413697 & 3.674935 & 0.084808 \\
\hline 11 & 1 & 0 & 1.710655 & 3.021709 & -1.403691 \\
\hline 12 & 7 & 0 & 0.791404 & 0.830935 & 0.222794 \\
\hline 13 & 8 & 0 & 3.483649 & -1.372873 & -0.766372 \\
\hline 14 & 6 & 0 & 4.186476 & -2.538056 & -0.311859 \\
\hline 15 & 1 & 0 & 4.736376 & -2.310675 & 0.602845 \\
\hline 16 & 1 & 0 & 3.482189 & -3.350271 & -0.125119 \\
\hline 17 & 1 & 0 & 4.870504 & -2.800629 & -1.115415 \\
\hline 18 & 6 & 0 & 2.578467 & -0.867711 & 0.077087 \\
\hline 19 & 8 & 0 & 2.327226 & -1.349727 & 1.158710 \\
\hline
\end{tabular}




\begin{tabular}{rrrrrr}
20 & 6 & 0 & -0.345999 & 0.055550 & 0.288243 \\
21 & 1 & 0 & -0.199062 & -0.972585 & -0.042390 \\
22 & 6 & 0 & -1.555520 & 0.439479 & 0.737446 \\
23 & 1 & 0 & -1.705901 & 1.456742 & 1.095748 \\
24 & 6 & 0 & -2.742714 & -0.482370 & 0.779639 \\
25 & 1 & 0 & -3.114718 & -0.573003 & 1.810647 \\
26 & 1 & 0 & -2.435398 & -1.490505 & 0.471091 \\
27 & 6 & 0 & -3.903024 & -0.015906 & -0.107627 \\
28 & 1 & 0 & -3.559868 & 0.032240 & -1.150059 \\
29 & 1 & 0 & -4.184465 & 1.008537 & 0.174398 \\
30 & 6 & 0 & -5.130203 & -0.920674 & -0.013570 \\
31 & 1 & 0 & -5.466112 & -0.963739 & 1.030594 \\
32 & 1 & 0 & -4.844782 & -1.944162 & -0.289609 \\
33 & 6 & 0 & -6.278279 & -0.449125 & -0.904019 \\
34 & 1 & 0 & -5.970735 & -0.424720 & -1.954842 \\
35 & 1 & 0 & -7.147646 & -1.107947 & -0.823468 \\
36 & 1 & 0 & -6.595221 & 0.561825 & -0.626499 \\
\hline------------------------------------------------------
\end{tabular}

\title{
III + A
}

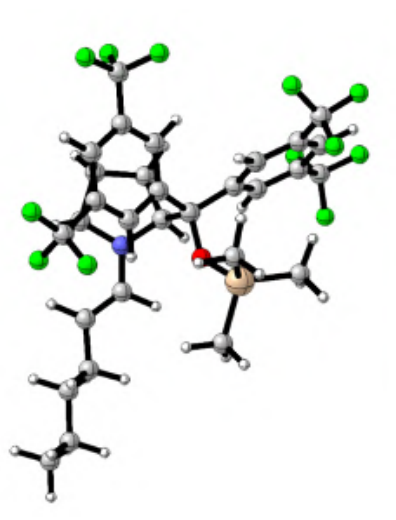

$\mathrm{HF}=-2779.9260104$ hartrees

Zero-point correction=

Thermal correction to Gibbs Free Energy=

Sum of electronic and zero-point Energies=

Sum of electronic and thermal Free Energies=

\author{
0.593854 (Hartree/Particle) \\ 0.504120 \\ $-2779.332156$ \\ $-2779.421891$
}

Standard orientation:

\begin{tabular}{|c|c|c|c|c|c|}
\hline \multirow{2}{*}{$\begin{array}{l}\text { Center } \\
\text { Number }\end{array}$} & \multirow{2}{*}{$\begin{array}{l}\text { Atomic } \\
\text { Number }\end{array}$} & \multirow{2}{*}{$\begin{array}{l}\text { Atomic } \\
\text { Type }\end{array}$} & \multicolumn{3}{|c|}{ Coordinates (Angstroms) } \\
\hline & & & $\mathrm{X}$ & $\mathrm{Y}$ & Z \\
\hline 1 & 6 & 0 & -4.415867 & -0.868834 & -0.597248 \\
\hline 2 & 6 & 0 & -3.093869 & -1.129978 & -0.609497 \\
\hline 3 & 7 & 0 & -2.144578 & -0.477468 & -1.365909 \\
\hline 4 & 6 & 0 & -0.764661 & -0.921657 & -1.442979 \\
\hline 5 & 6 & 0 & -0.286962 & -0.412807 & -2.812777 \\
\hline 6 & 6 & 0 & -1.230140 & 0.751787 & -3.163291 \\
\hline 7 & 6 & 0 & -2.541930 & 0.399457 & -2.456005 \\
\hline 8 & 1 & 0 & -4.824116 & -0.076876 & -1.223673 \\
\hline 9 & 1 & 0 & -2.686291 & -1.903272 & 0.038039 \\
\hline 10 & 1 & 0 & -0.740608 & -2.015166 & -1.383464 \\
\hline 11 & 1 & 0 & 0.766473 & -0.117227 & -2.810433 \\
\hline 12 & 1 & 0 & -0.397042 & -1.218873 & -3.543700 \\
\hline 13 & 1 & 0 & -0.840261 & 1.699895 & -2.784927 \\
\hline 14 & 1 & 0 & -1.365802 & 0.857247 & -4.241218 \\
\hline 15 & 1 & 0 & -3.058206 & 1.289771 & -2.072949 \\
\hline
\end{tabular}




\begin{tabular}{|c|c|c|c|c|c|}
\hline 16 & 1 & 0 & -3.242855 & -0.129009 & -3.121648 \\
\hline 17 & 6 & 0 & 0.065550 & -0.416197 & -0.208526 \\
\hline 18 & 8 & 0 & -0.590806 & -1.004262 & 0.895482 \\
\hline 19 & 14 & 0 & -0.181854 & -1.236775 & 2.517492 \\
\hline 20 & 6 & 0 & 0.329702 & 0.370850 & 3.337934 \\
\hline 21 & 1 & 0 & 0.544738 & 0.175031 & 4.394551 \\
\hline 22 & 1 & 0 & 1.227128 & 0.815222 & 2.897548 \\
\hline 23 & 1 & 0 & -0.475999 & 1.110700 & 3.289505 \\
\hline 24 & 6 & 0 & -1.795538 & -1.849665 & 3.233780 \\
\hline 25 & 1 & 0 & -2.096675 & -2.789390 & 2.759618 \\
\hline 26 & 1 & 0 & -1.705365 & -2.022815 & 4.310844 \\
\hline 27 & 1 & 0 & -2.590206 & -1.114147 & 3.068863 \\
\hline 28 & 6 & 0 & 1.154262 & -2.542028 & 2.685098 \\
\hline 29 & 1 & 0 & 1.204235 & -2.878673 & 3.726484 \\
\hline 30 & 1 & 0 & 0.919183 & -3.409866 & 2.059480 \\
\hline 31 & 1 & 0 & 2.146166 & -2.175039 & 2.403715 \\
\hline 32 & 6 & 0 & 1.519934 & -0.906829 & -0.236194 \\
\hline 33 & 6 & 0 & 2.523529 & -0.212243 & 0.445159 \\
\hline 34 & 6 & 0 & 1.853682 & -2.136474 & -0.810086 \\
\hline 35 & 6 & 0 & 3.813010 & -0.727340 & 0.541668 \\
\hline 36 & 1 & 0 & 2.306347 & 0.740465 & 0.917662 \\
\hline 37 & 6 & 0 & 3.147156 & -2.642572 & -0.704253 \\
\hline 38 & 1 & 0 & 1.111371 & -2.725630 & -1.337719 \\
\hline 39 & 6 & 0 & 4.145461 & -1.950251 & -0.028655 \\
\hline 40 & 1 & 0 & 5.149047 & -2.351082 & 0.050860 \\
\hline 41 & 6 & 0 & -0.059558 & 1.103811 & -0.143540 \\
\hline 42 & 6 & 0 & 0.830895 & 1.966140 & -0.783990 \\
\hline 43 & 6 & 0 & -1.192957 & 1.647954 & 0.465344 \\
\hline 44 & 6 & 0 & 0.599906 & 3.341023 & -0.791933 \\
\hline 45 & 1 & 0 & 1.707578 & 1.577592 & -1.295514 \\
\hline 46 & 6 & 0 & -1.414500 & 3.021537 & 0.441642 \\
\hline 47 & 1 & 0 & -1.905702 & 0.984544 & 0.947365 \\
\hline 48 & 6 & 0 & -0.522703 & 3.888651 & -0.182758 \\
\hline 49 & 1 & 0 & -0.698058 & 4.957871 & -0.194617 \\
\hline 50 & 6 & 0 & 4.831470 & 0.058130 & 1.320332 \\
\hline 51 & 6 & 0 & 3.437586 & -3.974361 & -1.340297 \\
\hline 52 & 6 & 0 & -2.655795 & 3.545313 & 1.107254 \\
\hline 53 & 6 & 0 & 1.595960 & 4.218151 & -1.495914 \\
\hline 54 & 9 & 0 & -3.771927 & 3.025713 & 0.558921 \\
\hline 55 & 9 & 0 & -2.760921 & 4.880512 & 1.026473 \\
\hline 56 & 9 & 0 & -2.693042 & 3.223332 & 2.415543 \\
\hline 57 & 9 & 0 & 1.279255 & 5.519426 & -1.424779 \\
\hline 58 & 9 & 0 & 2.833438 & 4.081387 & -0.979928 \\
\hline 59 & 9 & 0 & 1.696239 & 3.905523 & -2.803638 \\
\hline 60 & 9 & 0 & 4.873680 & 1.344975 & 0.927892 \\
\hline 61 & 9 & 0 & 4.542583 & 0.071764 & 2.637364 \\
\hline 62 & 9 & 0 & 6.070076 & -0.439290 & 1.194058 \\
\hline 63 & 9 & 0 & 2.637358 & -4.941388 & -0.851390 \\
\hline 64 & 9 & 0 & 3.228917 & -3.946214 & -2.670720 \\
\hline 65 & 9 & 0 & 4.703419 & -4.371624 & -1.146319 \\
\hline 66 & 6 & 0 & -5.388194 & -1.640543 & 0.251914 \\
\hline 67 & 1 & 0 & -4.836823 & -2.340862 & 0.894040 \\
\hline 68 & 1 & 0 & -5.926374 & -0.958553 & 0.926475 \\
\hline 69 & 6 & 0 & -6.424845 & -2.417686 & -0.568240 \\
\hline 70 & 1 & 0 & -5.903802 & -3.141213 & -1.210038 \\
\hline 71 & 1 & 0 & -6.945764 & -1.723242 & -1.242576 \\
\hline 72 & 6 & 0 & -7.451336 & -3.146355 & 0.296973 \\
\hline 73 & 1 & 0 & -6.928212 & -3.834684 & 0.973564 \\
\hline 74 & 1 & 0 & -7.966612 & -2.416688 & 0.934993 \\
\hline 75 & 6 & 0 & -8.476131 & -3.919075 & -0.531328 \\
\hline 76 & 1 & 0 & -7.983360 & -4.671560 & -1.156136 \\
\hline 77 & 1 & 0 & -9.202921 & -4.433307 & 0.104031 \\
\hline 78 & 1 & 0 & -9.027150 & -3.244430 & -1.195216 \\
\hline
\end{tabular}




\title{
III + B
}

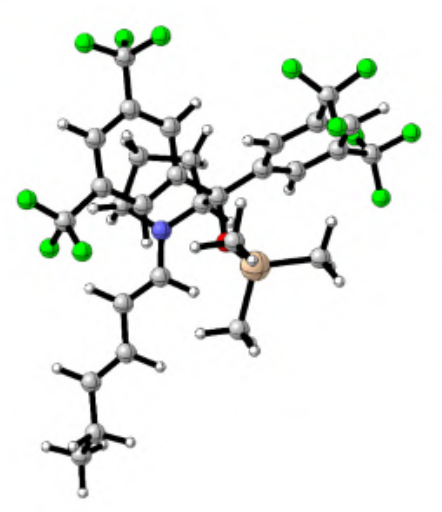

$\mathrm{HF}=-2778.710915$ hartrees

Zero-point correction=

Thermal correction to Gibbs Free Energy=

Sum of electronic and zero-point Energies=

\author{
0.570590 (Hartree/Particle) \\ 0.482589 \\ $-2778.140325$ \\ $-2778.228326$
}

Standard orientation:

\begin{tabular}{|c|c|c|c|c|c|}
\hline \multirow{2}{*}{$\begin{array}{l}\text { Center } \\
\text { Number }\end{array}$} & \multirow{2}{*}{$\begin{array}{l}\text { Atomic } \\
\text { Number }\end{array}$} & \multirow{2}{*}{$\begin{array}{c}\text { Atomic } \\
\text { Type }\end{array}$} & \multicolumn{3}{|c|}{ Coordinates (Angstroms) } \\
\hline & & & $\mathrm{X}$ & $\mathrm{Y}$ & Z \\
\hline 1 & 6 & 0 & -4.176241 & -1.427924 & -0.996892 \\
\hline 2 & 6 & 0 & -2.828124 & -1.583197 & -1.001341 \\
\hline 3 & 7 & 0 & -1.936197 & -0.814117 & -1.691799 \\
\hline 4 & 6 & 0 & -0.501615 & -1.034094 & -1.668633 \\
\hline 5 & 6 & 0 & -0.012422 & -0.365556 & -2.962292 \\
\hline 6 & 6 & 0 & -1.081233 & 0.687236 & -3.312755 \\
\hline 7 & 6 & 0 & -2.376082 & 0.159512 & -2.680755 \\
\hline 8 & 1 & 0 & -4.644316 & -0.624032 & -1.561215 \\
\hline 9 & 1 & 0 & -2.371920 & -2.370377 & -0.405654 \\
\hline 10 & 1 & 0 & -0.316612 & -2.113294 & -1.668850 \\
\hline 11 & 1 & 0 & 0.986422 & 0.068538 & -2.860167 \\
\hline 12 & 1 & 0 & 0.041657 & -1.124522 & -3.747381 \\
\hline 13 & 1 & 0 & -0.825147 & 1.661820 & -2.892202 \\
\hline 14 & 1 & 0 & -1.183673 & 0.813228 & -4.391933 \\
\hline 15 & 1 & 0 & -2.960226 & 0.960797 & -2.207838 \\
\hline 16 & 1 & 0 & -3.027795 & -0.336701 & -3.414304 \\
\hline 17 & 6 & 0 & 0.141759 & -0.497378 & -0.339930 \\
\hline 18 & 8 & 0 & -0.488058 & -1.262899 & 0.665055 \\
\hline 19 & 14 & 0 & -0.150304 & -1.580986 & 2.290454 \\
\hline 20 & 6 & 0 & 0.060196 & 0.001103 & 3.275291 \\
\hline 21 & 1 & 0 & 0.202166 & -0.258619 & 4.330497 \\
\hline 22 & 1 & 0 & 0.926315 & 0.592613 & 2.964664 \\
\hline 23 & 1 & 0 & -0.830730 & 0.633055 & 3.201216 \\
\hline 24 & 6 & 0 & -1.696866 & -2.482055 & 2.827006 \\
\hline 25 & 1 & 0 & -1.823682 & -3.407541 & 2.256065 \\
\hline 26 & 1 & 0 & -1.651778 & -2.738785 & 3.890114 \\
\hline 27 & 1 & 0 & -2.579736 & -1.855154 & 2.661724 \\
\hline 28 & 6 & 0 & 1.355176 & -2.687414 & 2.452418 \\
\hline 29 & 1 & 0 & 1.396535 & -3.095681 & 3.468285 \\
\hline 30 & 1 & 0 & 1.288921 & -3.527378 & 1.752564 \\
\hline 31 & 1 & 0 & 2.294910 & -2.158048 & 2.265654 \\
\hline 32 & 6 & 0 & 1.654819 & -0.748849 & -0.277314 \\
\hline 33 & 6 & 0 & 2.478983 & 0.044361 & 0.526515 \\
\hline 34 & 6 & 0 & 2.224428 & -1.864681 & -0.895421 \\
\hline
\end{tabular}




\begin{tabular}{|c|c|c|c|c|c|}
\hline 35 & 6 & 0 & 3.823959 & -0.267802 & 0.700014 \\
\hline 36 & 1 & 0 & 2.076005 & 0.915368 & 1.033360 \\
\hline 37 & 6 & 0 & 3.572130 & -2.166977 & -0.713007 \\
\hline 38 & 1 & 0 & 1.628614 & -2.522850 & -1.518620 \\
\hline 39 & 6 & 0 & 4.391516 & -1.378399 & 0.085919 \\
\hline 40 & 1 & 0 & 5.438640 & -1.620686 & 0.224780 \\
\hline 41 & 6 & 0 & -0.232795 & 0.975477 & -0.184786 \\
\hline 42 & 6 & 0 & 0.544131 & 2.012031 & -0.704119 \\
\hline 43 & 6 & 0 & -1.466527 & 1.290347 & 0.388632 \\
\hline 44 & 6 & 0 & 0.102341 & 3.331617 & -0.627006 \\
\hline 45 & 1 & 0 & 1.497130 & 1.803183 & -1.183483 \\
\hline 46 & 6 & 0 & -1.898605 & 2.611890 & 0.449894 \\
\hline 47 & 1 & 0 & -2.092358 & 0.490518 & 0.775815 \\
\hline 48 & 6 & 0 & -1.121840 & 3.651685 & -0.051665 \\
\hline 49 & 1 & 0 & -1.460444 & 4.679508 & 0.003872 \\
\hline 50 & 6 & 0 & 4.643193 & 0.597632 & 1.617068 \\
\hline 51 & 6 & 0 & 4.121381 & -3.385890 & -1.402473 \\
\hline 52 & 6 & 0 & -3.239524 & 2.885376 & 1.071341 \\
\hline 53 & 6 & 0 & 0.983849 & 4.403394 & -1.203381 \\
\hline 54 & 9 & 0 & -4.230411 & 2.250708 & 0.414535 \\
\hline 55 & 9 & 0 & -3.546377 & 4.191339 & 1.082787 \\
\hline 56 & 9 & 0 & -3.294226 & 2.453591 & 2.346668 \\
\hline 57 & 9 & 0 & 0.475548 & 5.633400 & -1.039705 \\
\hline 58 & 9 & 0 & 2.207243 & 4.399557 & -0.638754 \\
\hline 59 & 9 & 0 & 1.178176 & 4.227007 & -2.525911 \\
\hline 60 & 9 & 0 & 4.422554 & 1.906379 & 1.397641 \\
\hline 61 & 9 & 0 & 4.339167 & 0.371323 & 2.911269 \\
\hline 62 & 9 & 0 & 5.960249 & 0.384717 & 1.480841 \\
\hline 63 & 9 & 0 & 3.460963 & -4.501126 & -1.035496 \\
\hline 64 & 9 & 0 & 4.001030 & -3.297059 & -2.741041 \\
\hline 65 & 9 & 0 & 5.419324 & -3.586976 & -1.133884 \\
\hline 66 & 6 & 0 & -5.038309 & -2.314991 & -0.231112 \\
\hline 67 & 6 & 0 & -6.378292 & -2.237643 & -0.161010 \\
\hline 68 & 6 & 0 & -7.249982 & -3.171949 & 0.628338 \\
\hline 69 & 1 & 0 & -6.619014 & -3.880137 & 1.178294 \\
\hline 70 & 1 & 0 & -7.817174 & -2.605210 & 1.378967 \\
\hline 71 & 6 & 0 & -8.240722 & -3.936290 & -0.258101 \\
\hline 72 & 1 & 0 & -7.708804 & -4.559514 & -0.983453 \\
\hline 73 & 1 & 0 & -8.890355 & -4.582661 & 0.339478 \\
\hline 74 & 1 & 0 & -8.876860 & -3.241368 & -0.816018 \\
\hline 75 & 1 & 0 & -4.535086 & -3.104501 & 0.333515 \\
\hline 76 & 1 & 0 & -6.890753 & -1.454927 & -0.725161 \\
\hline
\end{tabular}

\section{III + C}

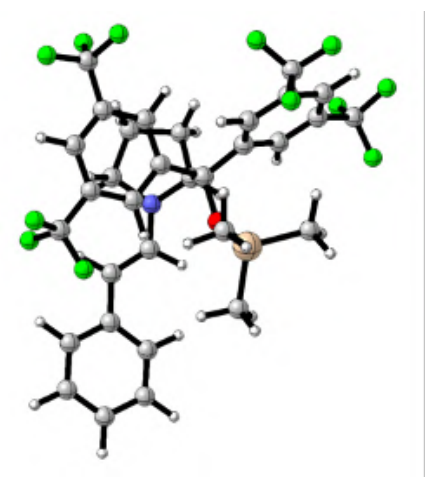


$\mathrm{HF}=-2853.72061$ hartrees

Zero-point correction=

Thermal correction to Gibbs Free Energy=

Sum of electronic and zero-point Energies=

Sum of electronic and thermal Free Energies=

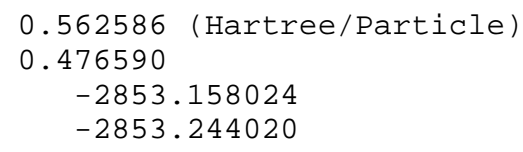

Standard orientation:

\begin{tabular}{|c|c|c|c|c|c|}
\hline \multirow{2}{*}{$\begin{array}{l}\text { Center } \\
\text { Number }\end{array}$} & \multirow{2}{*}{$\begin{array}{l}\text { Atomic } \\
\text { Number }\end{array}$} & \multirow{2}{*}{$\begin{array}{l}\text { Atomic } \\
\text { Type }\end{array}$} & \multicolumn{3}{|c|}{ Coordinates (Angstroms) } \\
\hline & & & $\mathrm{x}$ & $\mathrm{Y}$ & Z \\
\hline 1 & 6 & 0 & 3.745128 & -1.100961 & 1.413878 \\
\hline 2 & 6 & 0 & 2.435660 & -1.434527 & 1.518925 \\
\hline 3 & 7 & 0 & 1.482468 & -0.704460 & 2.169018 \\
\hline 4 & 6 & 0 & 0.058435 & -0.882986 & 1.945623 \\
\hline 5 & 6 & 0 & -0.584831 & -0.068467 & 3.079300 \\
\hline 6 & 6 & 0 & 0.482637 & 0.944176 & 3.556005 \\
\hline 7 & 6 & 0 & 1.805763 & 0.513284 & 2.896709 \\
\hline 8 & 1 & 0 & 4.088785 & -0.145713 & 1.803217 \\
\hline 9 & 1 & 0 & 2.049786 & -2.337751 & 1.053151 \\
\hline 10 & 1 & 0 & -0.169415 & -1.950896 & 2.026477 \\
\hline 11 & 1 & 0 & -1.509032 & 0.422066 & 2.763186 \\
\hline 12 & 1 & 0 & -0.850562 & -0.750902 & 3.889738 \\
\hline 13 & 1 & 0 & 0.223574 & 1.964143 & 3.265373 \\
\hline 14 & 1 & 0 & 0.566625 & 0.929764 & 4.643903 \\
\hline 15 & 1 & 0 & 2.195499 & 1.290745 & 2.220699 \\
\hline 16 & 1 & 0 & 2.592785 & 0.292946 & 3.627296 \\
\hline 17 & 6 & 0 & -0.368927 & -0.480428 & 0.486132 \\
\hline 18 & 8 & 0 & 0.229336 & -1.467591 & -0.325933 \\
\hline 19 & 14 & 0 & -0.027482 & -1.970753 & -1.921756 \\
\hline 20 & 6 & 0 & 0.003505 & -0.530322 & -3.123081 \\
\hline 21 & 1 & 0 & -0.205411 & -0.911650 & -4.129138 \\
\hline 22 & 1 & 0 & -0.752636 & 0.227595 & -2.896523 \\
\hline 23 & 1 & 0 & 0.982381 & -0.041356 & -3.145168 \\
\hline 24 & 6 & 0 & 1.440112 & -3.094635 & -2.191823 \\
\hline 25 & 1 & 0 & 1.411111 & -3.942002 & -1.499064 \\
\hline 26 & 1 & 0 & 1.456161 & -3.486376 & -3.213723 \\
\hline 27 & 1 & 0 & 2.373746 & -2.547443 & -2.018178 \\
\hline 28 & 6 & 0 & -1.645997 & -2.904424 & -2.071519 \\
\hline 29 & 1 & 0 & -1.665893 & -3.441198 & -3.026409 \\
\hline 30 & 1 & 0 & -1.749242 & -3.639178 & -1.266152 \\
\hline 31 & 1 & 0 & -2.515167 & -2.238480 & -2.043784 \\
\hline 32 & 6 & 0 & -1.888861 & -0.541543 & 0.292861 \\
\hline 33 & 6 & 0 & -2.548161 & 0.299725 & -0.604304 \\
\hline 34 & 6 & 0 & -2.629173 & -1.555063 & 0.910258 \\
\hline 35 & 6 & 0 & -3.905357 & 0.130223 & -0.873200 \\
\hline 36 & 1 & 0 & -2.009083 & 1.093265 & -1.112870 \\
\hline 37 & 6 & 0 & -3.984104 & -1.709806 & 0.636786 \\
\hline 38 & 1 & 0 & -2.154722 & -2.245859 & 1.599987 \\
\hline 39 & 6 & 0 & -4.642763 & -0.873964 & -0.260076 \\
\hline 40 & 1 & 0 & -5.697403 & -1.002798 & -0.472981 \\
\hline 41 & 6 & 0 & 0.234239 & 0.890071 & 0.175455 \\
\hline 42 & 6 & 0 & -0.352582 & 2.076191 & 0.612620 \\
\hline 43 & 6 & 0 & 1.482296 & 0.953203 & -0.451139 \\
\hline 44 & 6 & 0 & 0.295615 & 3.297201 & 0.418269 \\
\hline 45 & 1 & 0 & -1.320450 & 2.065486 & 1.108358 \\
\hline 46 & 6 & 0 & 2.118637 & 2.173950 & -0.632353 \\
\hline 47 & 1 & 0 & 1.966387 & 0.037337 & -0.770762 \\
\hline 48 & 6 & 0 & 1.536304 & 3.364611 & -0.200591 \\
\hline 49 & 1 & 0 & 2.034454 & 4.316632 & -0.347527 \\
\hline 50 & 6 & 0 & -4.547478 & 1.059986 & -1.865302 \\
\hline 51 & 6 & 0 & -4.719993 & -2.836673 & 1.308576 \\
\hline 52 & 6 & 0 & 3.493169 & 2.207602 & -1.240308 \\
\hline 53 & 6 & 0 & -0.386003 & 4.543673 & 0.909463 \\
\hline
\end{tabular}




\begin{tabular}{|c|c|c|c|c|c|}
\hline 54 & 9 & 0 & 4.453905 & 2.240197 & -0.293702 \\
\hline 55 & 9 & 0 & 3.677751 & 3.295603 & -2.009165 \\
\hline 56 & 9 & 0 & 3.739371 & 1.131190 & -2.004165 \\
\hline 57 & 9 & 0 & 0.300606 & 5.656817 & 0.614836 \\
\hline 58 & 9 & 0 & -1.615777 & 4.680634 & 0.377527 \\
\hline 59 & 9 & 0 & -0.553157 & 4.522702 & 2.247130 \\
\hline 60 & 9 & 0 & -4.408115 & 2.348667 & -1.500160 \\
\hline 61 & 9 & 0 & -3.982451 & 0.947807 & -3.083584 \\
\hline 62 & 9 & 0 & -5.859285 & 0.827951 & -2.013859 \\
\hline 63 & 9 & 0 & -4.292119 & -4.037443 & 0.870842 \\
\hline 64 & 9 & 0 & -4.532334 & -2.829303 & 2.641349 \\
\hline 65 & 9 & 0 & -6.042383 & -2.786921 & 1.091901 \\
\hline 66 & 6 & 0 & 4.746682 & -1.917230 & 0.720875 \\
\hline 67 & 6 & 0 & 5.979867 & -1.336601 & 0.372738 \\
\hline 68 & 6 & 0 & 4.542104 & -3.265596 & 0.370623 \\
\hline 69 & 6 & 0 & 6.956187 & -2.058678 & -0.309958 \\
\hline 70 & 1 & 0 & 6.164712 & -0.298053 & 0.636805 \\
\hline 71 & 6 & 0 & 5.513587 & -3.983943 & -0.320766 \\
\hline 72 & 1 & 0 & 3.618830 & -3.765076 & 0.650136 \\
\hline 73 & 6 & 0 & 6.728420 & -3.387934 & -0.667662 \\
\hline 74 & 1 & 0 & 7.896649 & -1.579337 & -0.565766 \\
\hline 75 & 1 & 0 & 5.325188 & -5.021944 & -0.579628 \\
\hline 76 & 1 & 0 & 7.486311 & -3.953285 & -1.200381 \\
\hline
\end{tabular}

\section{$\mathrm{IV}+\mathrm{A}$}

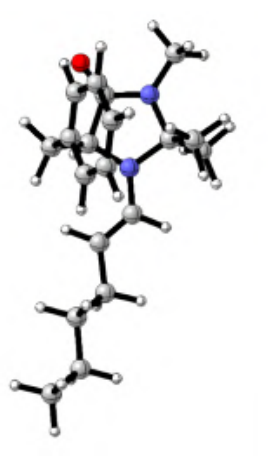

$\mathrm{HF}=-925.2773459$ hartrees

Zero-point correction=

Thermal correction to Gibbs Free Energy=

Sum of electronic and zero-point Energies=

Sum of electronic and thermal Free Energies=

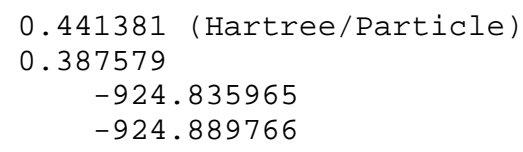

Standard orientation:

\begin{tabular}{|c|c|c|c|c|c|}
\hline \multirow{2}{*}{$\begin{array}{l}\text { Center } \\
\text { Number }\end{array}$} & \multirow{2}{*}{$\begin{array}{l}\text { Atomic } \\
\text { Number }\end{array}$} & \multirow{2}{*}{$\begin{array}{c}\text { Atomic } \\
\text { Type }\end{array}$} & \multicolumn{3}{|c|}{ Coordinates (Angstroms) } \\
\hline & & & $\mathrm{X}$ & $\mathrm{Y}$ & Z \\
\hline 1 & 6 & 0 & -0.783976 & -0.823416 & 1.325523 \\
\hline 2 & 1 & 0 & -0.377085 & -1.562302 & 2.034573 \\
\hline 3 & 6 & 0 & -1.429273 & -1.436856 & -0.941949 \\
\hline 4 & 6 & 0 & -2.287760 & -1.017255 & 1.222832 \\
\hline 5 & 7 & 0 & -0.341561 & -1.072855 & -0.023979 \\
\hline 6 & 7 & 0 & -2.589331 & -1.332352 & -0.050155 \\
\hline 7 & 8 & 0 & -3.082613 & -0.873448 & 2.149397 \\
\hline 8 & 6 & 0 & -3.949530 & -1.480151 & -0.524893 \\
\hline
\end{tabular}




$\begin{array}{rrr}-4.608088 & -1.432830 & 0.341994 \\ -4.207542 & -0.672638 & -1.216627 \\ -4.084488 & -2.441613 & -1.026225 \\ -1.287653 & -2.873087 & -1.455370 \\ -2.155951 & -3.156020 & -2.056272 \\ -0.403505 & -2.964696 & -2.091231 \\ -1.192329 & -3.562396 & -0.612073 \\ -1.542031 & -0.438953 & -2.096187 \\ -0.602512 & -0.419521 & -2.656160 \\ -2.338640 & -0.729036 & -2.787742 \\ -1.739398 & 0.563653 & -1.705095 \\ -0.466888 & 0.599218 & 1.848935 \\ -1.010806 & 0.722361 & 2.791089 \\ 0.601523 & 0.672010 & 2.066885 \\ -0.860992 & 1.656512 & 0.849614 \\ -2.179637 & 2.119589 & 0.770897 \\ 0.076000 & 2.136290 & -0.071717 \\ -2.554340 & 3.036842 & -0.211853 \\ -2.916618 & 1.752708 & 1.481599 \\ -0.292649 & 3.057587 & -1.051334 \\ 1.099515 & 1.770165 & -0.023751 \\ -1.611608 & 3.507685 & -1.126561 \\ -3.581329 & 3.386205 & -0.260493 \\ 0.447050 & 3.419562 & -1.759148 \\ -1.902013 & 4.222697 & -1.890109 \\ 0.981833 & -1.276800 & -0.346652 \\ 1.159452 & -1.436180 & -1.409738 \\ 2.031357 & -1.262028 & 0.494762 \\ 1.879444 & -1.095140 & 1.559755 \\ 3.452509 & -1.411013 & 0.028328 \\ 3.942713 & -2.232727 & 0.569442 \\ 3.464240 & -1.686301 & -1.034674 \\ 4.284676 & -0.138181 & 0.227867 \\ 4.232790 & 0.165822 & 1.282996 \\ 3.832613 & 0.677926 & -0.352615 \\ 5.747429 & -0.307493 & -0.178357 \\ 5.795343 & -0.618969 & -1.229937 \\ 6.190728 & -1.123307 & 0.407171 \\ 6.563260 & 0.968920 & 0.017766 \\ 7.607323 & 0.828993 & -0.276592 \\ 6.151993 & 1.789055 & -0.580259 \\ 6.548360 & 1.282091 & 1.067111\end{array}$

\section{(Z) $\mathrm{IV}+\mathrm{A}$}

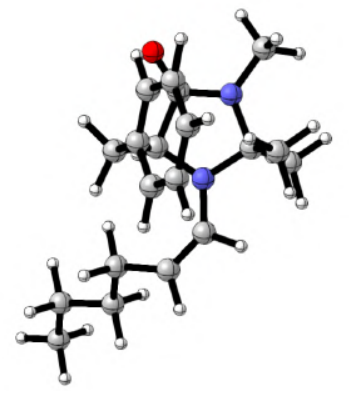


$\mathrm{HF}=-925.2718061$ hartrees

Zero-point correction=

Thermal correction to Gibbs Free Energy=

Sum of electronic and zero-point Energies=

Sum of electronic and thermal Free Energies=

\author{
0.441986 (Hartree/Particle) \\ 0.388564 \\ $-924.829820$ \\ $-924.883242$
}

Standard orientation:

\begin{tabular}{|c|c|c|c|c|c|}
\hline \multirow{2}{*}{$\begin{array}{l}\text { Center } \\
\text { Number }\end{array}$} & \multirow{2}{*}{$\begin{array}{l}\text { Atomic } \\
\text { Number }\end{array}$} & \multirow{2}{*}{$\begin{array}{l}\text { Atomic } \\
\text { Type }\end{array}$} & \multicolumn{3}{|c|}{ Coordinates (Angstroms) } \\
\hline & & & $\mathrm{x}$ & $\mathrm{Y}$ & Z \\
\hline 1 & 6 & 0 & -0.116159 & 0.512138 & 0.910313 \\
\hline 2 & 1 & 0 & -1.034594 & 0.892105 & 1.376178 \\
\hline 3 & 6 & 0 & 1.026100 & 1.585929 & -0.957877 \\
\hline 4 & 6 & 0 & 1.028012 & 1.384735 & 1.397947 \\
\hline 5 & 7 & 0 & -0.087337 & 0.726400 & -0.520594 \\
\hline 6 & 7 & 0 & 1.616014 & 1.955334 & 0.332464 \\
\hline 7 & 8 & 0 & 1.356933 & 1.518723 & 2.575051 \\
\hline 8 & 6 & 0 & 2.810084 & 2.768680 & 0.437971 \\
\hline 9 & 1 & 0 & 2.933828 & 3.041915 & 1.485546 \\
\hline 10 & 1 & 0 & 3.692632 & 2.212676 & 0.106103 \\
\hline 11 & 1 & 0 & 2.708903 & 3.676290 & -0.161045 \\
\hline 12 & 6 & 0 & 0.496942 & 2.826508 & -1.682584 \\
\hline 13 & 1 & 0 & 1.313692 & 3.491040 & -1.976909 \\
\hline 14 & 1 & 0 & -0.030749 & 2.525413 & -2.591763 \\
\hline 15 & 1 & 0 & -0.196599 & 3.367635 & -1.033868 \\
\hline 16 & 6 & 0 & 2.059945 & 0.847585 & -1.814649 \\
\hline 17 & 1 & 0 & 1.606507 & 0.492203 & -2.743404 \\
\hline 18 & 1 & 0 & 2.873337 & 1.526313 & -2.087864 \\
\hline 19 & 1 & 0 & 2.467800 & -0.006066 & -1.266992 \\
\hline 20 & 6 & 0 & 0.096006 & -0.954485 & 1.352618 \\
\hline 21 & 1 & 0 & 0.174836 & -0.946612 & 2.445064 \\
\hline 22 & 1 & 0 & -0.790607 & -1.536136 & 1.087350 \\
\hline 23 & 6 & 0 & 1.320911 & -1.573713 & 0.727089 \\
\hline 24 & 6 & 0 & 2.598740 & -1.320508 & 1.242009 \\
\hline 25 & 6 & 0 & 1.204365 & -2.369558 & -0.417142 \\
\hline 26 & 6 & 0 & 3.733308 & -1.838573 & 0.617399 \\
\hline 27 & 1 & 0 & 2.702389 & -0.708251 & 2.134752 \\
\hline 28 & 6 & 0 & 2.336074 & -2.894296 & -1.041394 \\
\hline 29 & 1 & 0 & 0.216002 & -2.566227 & -0.825893 \\
\hline 30 & 6 & 0 & 3.605364 & -2.624935 & -0.528713 \\
\hline 31 & 1 & 0 & 4.717022 & -1.631220 & 1.027817 \\
\hline 32 & 1 & 0 & 2.227068 & -3.508910 & -1.929915 \\
\hline 33 & 1 & 0 & 4.488020 & -3.029063 & -1.014599 \\
\hline 34 & 6 & 0 & -0.902863 & 0.117664 & -1.453331 \\
\hline 35 & 1 & 0 & -0.492556 & 0.168729 & -2.459701 \\
\hline 36 & 6 & 0 & -2.080282 & -0.524952 & -1.320638 \\
\hline 37 & 1 & 0 & -2.457288 & -0.955333 & -2.246846 \\
\hline 38 & 6 & 0 & -2.977556 & -0.721430 & -0.128641 \\
\hline 39 & 1 & 0 & -3.000801 & -1.785830 & 0.153159 \\
\hline 40 & 1 & 0 & -2.619482 & -0.175795 & 0.747846 \\
\hline 41 & 6 & 0 & -4.416202 & -0.276265 & -0.420367 \\
\hline 42 & 1 & 0 & -4.786430 & -0.808559 & -1.307508 \\
\hline 43 & 1 & 0 & -4.417046 & 0.791994 & -0.675462 \\
\hline 44 & 6 & 0 & -5.364479 & -0.524235 & 0.750977 \\
\hline 45 & 1 & 0 & -4.991165 & 0.007325 & 1.635837 \\
\hline 46 & 1 & 0 & -5.353246 & -1.592521 & 1.003001 \\
\hline 47 & 6 & 0 & -6.795174 & -0.081438 & 0.450574 \\
\hline 48 & 1 & 0 & -7.459719 & -0.265233 & 1.299561 \\
\hline 49 & 1 & 0 & -6.830981 & 0.988663 & 0.220474 \\
\hline 50 & 1 & 0 & -7.195804 & -0.621583 & -0.413785 \\
\hline
\end{tabular}


$\mathrm{IV}+\mathrm{B}$

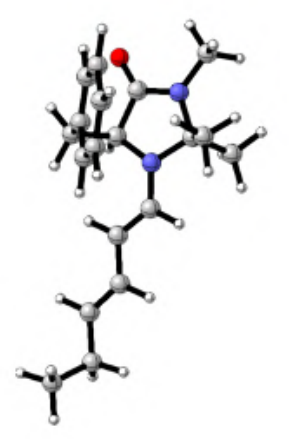

$\mathrm{HF}=-924.0615259$ hartrees

Zero-point correction=

Thermal correction to Gibbs Free Energy=

Sum of electronic and zero-point Energies= Sum of electronic and thermal Free Energies=

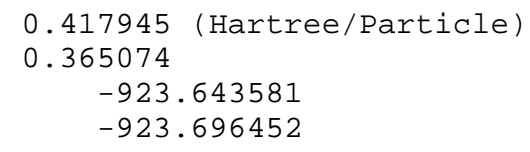

Standard orientation:

\begin{tabular}{|c|c|c|c|c|c|}
\hline \multirow{2}{*}{$\begin{array}{l}\text { Center } \\
\text { Number }\end{array}$} & \multirow{2}{*}{$\begin{array}{l}\text { Atomic } \\
\text { Number }\end{array}$} & \multirow{2}{*}{$\begin{array}{c}\text { Atomic } \\
\text { Type }\end{array}$} & \multicolumn{3}{|c|}{ Coordinates (Angstroms) } \\
\hline & & & $\mathrm{X}$ & $\mathrm{Y}$ & Z \\
\hline 1 & 6 & 0 & 0.560024 & -0.773837 & -1.299022 \\
\hline 2 & 1 & 0 & -0.010307 & -1.420277 & -1.983620 \\
\hline 3 & 6 & 0 & 1.216904 & -1.484555 & 0.941933 \\
\hline 4 & 6 & 0 & 2.008489 & -1.233697 & -1.275545 \\
\hline 5 & 7 & 0 & 0.150101 & -0.962090 & 0.073069 \\
\hline 6 & 7 & 0 & 2.322218 & -1.589128 & -0.015900 \\
\hline 7 & 8 & 0 & 2.761089 & -1.237023 & -2.246521 \\
\hline 8 & 6 & 0 & 3.659881 & -1.975328 & 0.383753 \\
\hline 9 & 1 & 0 & 4.272493 & -2.016381 & -0.516440 \\
\hline 10 & 1 & 0 & 4.083762 & -1.239671 & 1.073614 \\
\hline 11 & 1 & 0 & 3.656038 & -2.958489 & 0.860720 \\
\hline 12 & 6 & 0 & 0.865843 & -2.867721 & 1.497280 \\
\hline 13 & 1 & 0 & 1.709507 & -3.281958 & 2.055387 \\
\hline 14 & 1 & 0 & 0.019636 & -2.798880 & 2.185411 \\
\hline 15 & 1 & 0 & 0.606730 & -3.544408 & 0.678828 \\
\hline 16 & 6 & 0 & 1.558607 & -0.503731 & 2.064940 \\
\hline 17 & 1 & 0 & 0.667838 & -0.317508 & 2.671882 \\
\hline 18 & 1 & 0 & 2.329277 & -0.919018 & 2.720730 \\
\hline 19 & 1 & 0 & 1.904598 & 0.444944 & 1.645094 \\
\hline 20 & 6 & 0 & 0.477073 & 0.688377 & -1.801521 \\
\hline 21 & 1 & 0 & 0.981176 & 0.718152 & -2.772955 \\
\hline 22 & 1 & 0 & -0.570006 & 0.956604 & -1.961264 \\
\hline 23 & 6 & 0 & 1.112179 & 1.649820 & -0.829506 \\
\hline 24 & 6 & 0 & 2.496953 & 1.856013 & -0.820150 \\
\hline 25 & 6 & 0 & 0.329150 & 2.299307 & 0.130550 \\
\hline 26 & 6 & 0 & 3.085949 & 2.686617 & 0.133801 \\
\hline 27 & 1 & 0 & 3.115582 & 1.356544 & -1.562263 \\
\hline 28 & 6 & 0 & 0.913213 & 3.134884 & 1.082089 \\
\hline 29 & 1 & 0 & -0.746392 & 2.136306 & 0.134972 \\
\hline 30 & 6 & 0 & 2.295326 & 3.327449 & 1.088702 \\
\hline 31 & 1 & 0 & 4.161468 & 2.835852 & 0.128861 \\
\hline 32 & 1 & 0 & 0.290958 & 3.631099 & 1.820726 \\
\hline 33 & 1 & 0 & 2.752861 & 3.975124 & 1.830082 \\
\hline 34 & 6 & 0 & -1.154199 & -0.905237 & 0.477276 \\
\hline 35 & 1 & 0 & -1.299260 & -1.052644 & 1.546419 \\
\hline
\end{tabular}




$\begin{array}{rrrrrr}36 & 6 & 0 & -2.236470 & -0.668984 & -0.301568 \\ 37 & 1 & 0 & -2.129361 & -0.520587 & -1.373624 \\ 38 & 6 & 0 & -3.578707 & -0.602783 & 0.256102 \\ 39 & 6 & 0 & -4.701376 & -0.375588 & -0.445997 \\ 40 & 6 & 0 & -6.080086 & -0.301255 & 0.144418 \\ 41 & 1 & 0 & -6.028492 & -0.518758 & 1.217649 \\ 42 & 1 & 0 & -6.717023 & -1.074709 & -0.305116 \\ 43 & 6 & 0 & -6.737553 & 1.065836 & -0.079955 \\ 44 & 1 & 0 & -7.754160 & 1.086980 & 0.323485 \\ 45 & 1 & 0 & -6.158379 & 1.857184 & 0.405536 \\ 46 & 1 & 0 & -6.793262 & 1.298237 & -1.148417 \\ 47 & 1 & 0 & -4.625048 & -0.216032 & -1.523977 \\ 48 & 1 & 0 & -3.662388 & -0.756518 & 1.334780 \\ -------------------------------------------------------------------\end{array}$




\section{K. TD-DFT analysis}

TD-DFT calculations were run at the PBE0/aug-cc-pVDZ/IEFPCM level of theory unless otherwise stated. 50 vertical excitations were calculated for each one, but in many cases, the highest energy transitions were omitted. Transitions originating from the HOMO are in black text, and transitions originating from other orbitals are in grey text. Excitation wavelengths and energies are listed with oscillator strengths $f$ and orbital contributions. Orbital contributions < $10 \%$ were omitted.

Table S11. Excited states > $190 \mathrm{~nm}$ of $\mathbf{A}$.

$\begin{array}{cllll}\text { Excited State } & \mathbf{1 :} & \mathbf{4 . 3 8 8 5} \mathbf{~ e V} & \mathbf{2 8 2 . 5 2} \mathbf{~ n m} & \mathbf{f}=\mathbf{0 . 0 0 0 2} \\ 28 \rightarrow 29 & & 0.70094 & 98 \% & \end{array}$

Table S12. Excited states $>190 \mathrm{~nm}$ of $\mathbf{I}$.

\begin{tabular}{|c|c|c|c|c|}
\hline Excited State & 1: & $5.4970 \mathrm{eV}$ & $225.55 \mathrm{~nm}$ & $f=0.0010$ \\
\hline $20->21$ & & 0.67713 & $92 \%$ & \\
\hline Excited State & 2: & $6.0569 \mathrm{eV}$ & $204.70 \mathrm{~nm}$ & $f=0.0620$ \\
\hline $20->22$ & & 0.68840 & $95 \%$ & \\
\hline Excited State & 3: & $6.2016 \mathrm{eV}$ & $199.92 \mathrm{~nm}$ & $\mathbf{f}=\mathbf{0 . 0 3 3 7}$ \\
\hline $20->24$ & & 0.65611 & $86 \%$ & \\
\hline Excited State & 4: & $6.2377 \mathrm{eV}$ & $198.77 \mathrm{~nm}$ & $\mathbf{f}=\mathbf{0 . 0 0 3 7}$ \\
\hline $20->23$ & & 0.69755 & $97 \%$ & \\
\hline
\end{tabular}

Table S13. Excited states $>190 \mathrm{~nm}$ of $\mathbf{I}+\mathbf{A}$.

\begin{tabular}{|c|c|c|c|c|}
\hline Excited State & 1: & $4.4568 \mathrm{eV}$ & $278.19 \mathrm{~nm}$ & $f=0.0323$ \\
\hline $43->44$ & & 0.67845 & $92 \%$ & \\
\hline Excited State & 2: & $4.8281 \mathrm{eV}$ & $256.80 \mathrm{~nm}$ & $f=0.0023$ \\
\hline $43->46$ & & 0.53649 & $58 \%$ & \\
\hline $43->47$ & & -0.43297 & $37 \%$ & \\
\hline Excited State & 3: & $4.8652 \mathrm{eV}$ & 254.84 & $\mathrm{f}=\mathbf{0 . 0 3 8 3}$ \\
\hline $43->45$ & & 0.60956 & $74 \%$ & \\
\hline Excited State & 4: & $4.9075 \mathrm{eV}$ & $252.64 \mathrm{~nm}$ & $f=0.0306$ \\
\hline $43->45$ & & 0.25158 & $13 \%$ & \\
\hline $43->46$ & & 0.38051 & $29 \%$ & \\
\hline $43->47$ & & 0.50461 & $51 \%$ & \\
\hline Excited State & 5 & $5.1960 \mathrm{eV}$ & $238.61 \mathrm{~nm}$ & $f=0.0473$ \\
\hline
\end{tabular}




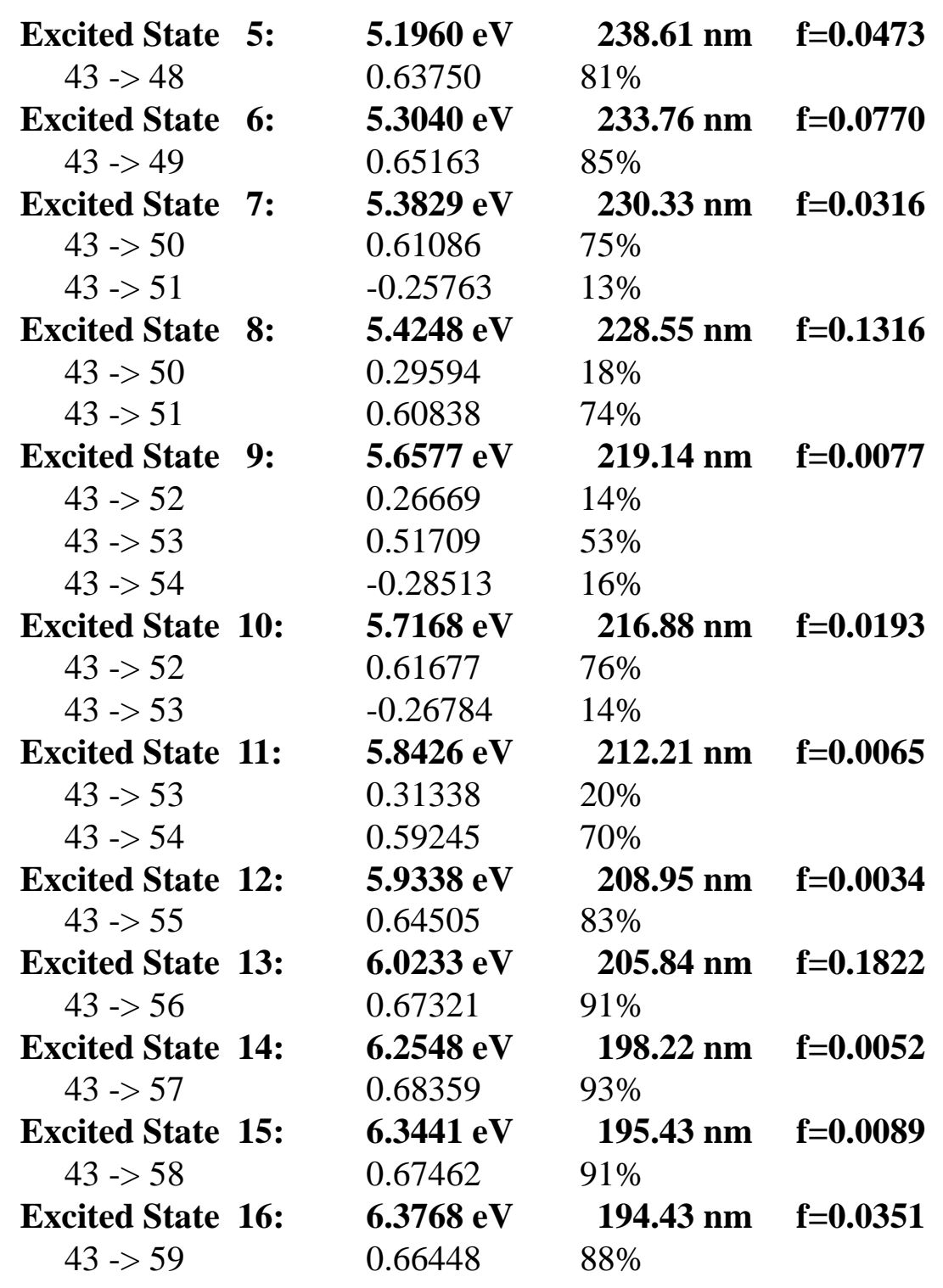

Table S14. Excited states > $190 \mathrm{~nm}$ of $\mathbf{I}+\mathbf{A}$ calculated at the whPBE0/aug-cc-pVDZ/ IEFPCM(acetonitrile) level of theory.

\begin{tabular}{|c|c|c|c|c|}
\hline Excited State & 1: & $4.5705 \mathrm{eV}$ & $271.27 \mathrm{~nm}$ & $f=0.0346$ \\
\hline $43->44$ & & 0.64647 & $84 \%$ & \\
\hline Excited State & 2: & $4.9542 \mathrm{eV}$ & $250.26 \mathrm{~nm}$ & $f=0.0016$ \\
\hline $43->46$ & & 0.61463 & $76 \%$ & \\
\hline $43->47$ & & -0.26638 & $14 \%$ & \\
\hline Excited State & 3: & $5.0290 \mathrm{eV}$ & $246.54 \mathrm{~nm}$ & $f=0.0650$ \\
\hline $43->46$ & & 0.26029 & $14 \%$ & \\
\hline $43->47$ & & 0.61130 & $75 \%$ & \\
\hline Excited State & 4: & $5.1154 \mathrm{eV}$ & $242.38 \mathrm{~nm}$ & $\mathrm{f}=\mathbf{0 . 0 0 4 4}$ \\
\hline
\end{tabular}




\begin{tabular}{|c|c|c|c|c|}
\hline $43->45$ & & 0.57637 & $66 \%$ & \\
\hline $43->48$ & & 0.32748 & $21 \%$ & \\
\hline Excited State & 5: & $5.4157 \mathrm{eV}$ & $228.94 \mathrm{~nm}$ & $f=0.2722$ \\
\hline $43->48$ & & 0.22299 & $10 \%$ & \\
\hline $43->49$ & & -0.24564 & $12 \%$ & \\
\hline $43->51$ & & 0.51139 & $52 \%$ & \\
\hline Excited State & 6: & $5.5218 \mathrm{eV}$ & $224.53 \mathrm{~nm}$ & $f=0.0130$ \\
\hline $43->44$ & & 0.21818 & $10 \%$ & \\
\hline $43->48$ & & 0.45430 & $41 \%$ & \\
\hline $43->49$ & & 0.33237 & $22 \%$ & \\
\hline Excited State & 7: & $5.5974 \mathrm{eV}$ & $221.50 \mathrm{~nm}$ & $f=0.0209$ \\
\hline $43->49$ & & 0.50472 & $51 \%$ & \\
\hline $43->51$ & & 0.36076 & $26 \%$ & \\
\hline Excited State & 8: & $5.6140 \mathrm{eV}$ & $220.85 \mathrm{~nm}$ & $f=0.0080$ \\
\hline $43->50$ & & 0.64190 & $82 \%$ & \\
\hline Excited State & 9: & $5.7778 \mathrm{eV}$ & $214.59 \mathrm{~nm}$ & $f=0.0098$ \\
\hline $43->53$ & & 0.59649 & $71 \%$ & \\
\hline Excited State & 10: & $5.9840 \mathrm{eV}$ & $207.19 \mathrm{~nm}$ & $f=0.0295$ \\
\hline $43->52$ & & 0.58332 & $68 \%$ & \\
\hline Excited State & 11: & $6.0992 \mathrm{eV}$ & $203.28 \mathrm{~nm}$ & $f=0.0092$ \\
\hline $43->54$ & & 0.55861 & $62 \%$ & \\
\hline Excited State & 12: & $6.1583 \mathrm{eV}$ & $201.33 \mathrm{~nm}$ & $f=0.1554$ \\
\hline $43->56$ & & 0.48535 & $47 \%$ & \\
\hline $43->57$ & & 0.31887 & $20 \%$ & \\
\hline Excited State & 13: & $6.1937 \mathrm{eV}$ & $200.18 \mathrm{~nm}$ & $f=0.0136$ \\
\hline $43->55$ & & 0.60761 & $74 \%$ & \\
\hline Excited State & 14: & $6.4534 \mathrm{eV}$ & $192.12 \mathrm{~nm}$ & $\mathbf{f}=\mathbf{0 . 0 0 1 7}$ \\
\hline $43->56$ & & -0.37148 & $28 \%$ & \\
\hline $43->57$ & & 0.51508 & $53 \%$ & \\
\hline
\end{tabular}

Table S15. Excited states $>190 \mathrm{~nm}$ of $(\boldsymbol{Z}) \mathbf{I}+\mathbf{A}$.

\begin{tabular}{|c|c|c|c|c|}
\hline $\begin{array}{c}\text { Excited State } \\
43->44\end{array}$ & 1: & $\begin{array}{l}4.4086 \mathrm{eV} \\
0.68139\end{array}$ & $\begin{array}{l}\mathbf{2 8 1 . 2 3} \mathbf{~ n m} \\
93 \%\end{array}$ & $f=0.0340$ \\
\hline Excited State & 2: & $4.8090 \mathrm{eV}$ & $257.82 \mathrm{~nm}$ & $f=0.0276$ \\
\hline $43->46$ & & 0.68313 & $93 \%$ & \\
\hline Excited State & 3: & $4.9117 \mathrm{eV}$ & $252.43 \mathrm{~nm}$ & $f=0.0175$ \\
\hline $43->45$ & & 0.47622 & $45 \%$ & \\
\hline $43->47$ & & 0.47851 & $46 \%$ & \\
\hline Excited State & 4: & $4.9481 \mathrm{eV}$ & $250.57 \mathrm{~nm}$ & $f=0.0051$ \\
\hline $43->45$ & & -0.44789 & $40 \%$ & \\
\hline $43->47$ & & 0.50027 & $50 \%$ & \\
\hline Excited Stat & 5: & $5.2413 \mathrm{eV}$ & $236.55 \mathrm{~nm}$ & $f=0.0889$ \\
\hline
\end{tabular}




\begin{tabular}{|c|c|c|c|}
\hline $43->48$ & 0.59391 & $71 \%$ & \\
\hline $43->49$ & 0.24455 & $12 \%$ & \\
\hline Excited State 6: & $5.3047 \mathrm{eV}$ & $233.73 \mathrm{~nm}$ & $f=0.1293$ \\
\hline $43->48$ & -0.25335 & $13 \%$ & \\
\hline $43->49$ & 0.62268 & $78 \%$ & \\
\hline Excited State 7: & $5.4185 \mathrm{eV}$ & $228.82 \mathrm{~nm}$ & $f=0.0161$ \\
\hline $43->50$ & 0.66265 & $88 \%$ & \\
\hline Excited State 8: & $5.5369 \mathrm{eV}$ & $223.92 \mathrm{~nm}$ & $f=0.0434$ \\
\hline $43->51$ & 0.57595 & $66 \%$ & \\
\hline $43->52$ & 0.31191 & $19 \%$ & \\
\hline Excited State 9: & $5.6271 \mathrm{eV}$ & $220.34 \mathrm{~nm}$ & $f=0.1168$ \\
\hline $43->51$ & -0.33687 & $23 \%$ & \\
\hline $43->52$ & 0.58112 & $68 \%$ & \\
\hline Excited State 10: & $5.7824 \mathrm{eV}$ & $214.42 \mathrm{~nm}$ & $\mathbf{f}=\mathbf{0 . 0 1 1 3}$ \\
\hline $43->53$ & 0.59496 & $71 \%$ & \\
\hline $43->54$ & -0.27522 & $15 \%$ & \\
\hline Excited State 11: & $5.8611 \mathrm{eV}$ & $211.54 \mathrm{~nm}$ & $f=0.0125$ \\
\hline $43->53$ & 0.29233 & $17 \%$ & \\
\hline $43->54$ & 0.57635 & $66 \%$ & \\
\hline Excited State 12: & $5.9900 \mathrm{eV}$ & $206.98 \mathrm{~nm}$ & $f=0.0073$ \\
\hline $43->55$ & 0.64024 & $82 \%$ & \\
\hline Excited State 13: & $6.0447 \mathrm{eV}$ & $205.11 \mathrm{~nm}$ & $f=0.0041$ \\
\hline $43->56$ & 0.65411 & $86 \%$ & \\
\hline Excited State 14: & $6.2631 \mathrm{eV}$ & $197.96 \mathrm{~nm}$ & $f=0.0095$ \\
\hline $43->57$ & 0.64926 & $84 \%$ & \\
\hline Excited State 15: & $6.4121 \mathrm{eV}$ & $193.36 \mathrm{~nm}$ & $\mathbf{f}=\mathbf{0 . 0 0 1 3}$ \\
\hline $43->58$ & 0.67221 & $90 \%$ & \\
\hline Excited State 16: & $6.4778 \mathrm{eV}$ & $191.40 \mathrm{~nm}$ & $f=0.0124$ \\
\hline $43->59$ & 0.63865 & $82 \%$ & \\
\hline
\end{tabular}

Table S16. Excited states $>190 \mathrm{~nm}$ of $\mathbf{I}+\mathbf{B}$.

\begin{tabular}{|c|c|c|c|c|}
\hline Excited State & 1: & $4.1031 \mathrm{eV}$ & $302.17 \mathrm{~nm}$ & $f=0.0324$ \\
\hline $42->43$ & & 0.31273 & $20 \%$ & \\
\hline $42->44$ & & 0.60736 & $74 \%$ & \\
\hline Excited State & 2: & $4.3067 \mathrm{eV}$ & $287.89 \mathrm{~nm}$ & $f=0.6850$ \\
\hline $42->43$ & & 0.60594 & $73 \%$ & \\
\hline $42->44$ & & -0.31612 & $20 \%$ & \\
\hline Excited State & 3: & $4.4293 \mathrm{eV}$ & $279.92 \mathrm{~nm}$ & $f=0.0002$ \\
\hline $42->46$ & & 0.69334 & $96 \%$ & \\
\hline Excited State & 4: & $4.5231 \mathrm{eV}$ & $274.11 \mathrm{~nm}$ & $\mathrm{f}=\mathbf{0 . 0 5 4 2}$ \\
\hline $42->45$ & & 0.67572 & $91 \%$ & \\
\hline Excited State & 5: & $4.8139 \mathrm{eV}$ & $257.55 \mathrm{~nm}$ & $f=0.1190$ \\
\hline
\end{tabular}




\begin{tabular}{|c|c|c|c|c|}
\hline $42->47$ & & 0.66945 & $90 \%$ & \\
\hline Excited State & 6: & $4.9645 \mathrm{eV}$ & $249.74 \mathrm{~nm}$ & $f=0.1809$ \\
\hline $42->48$ & & 0.63038 & $79 \%$ & \\
\hline Excited State & 7: & $4.9886 \mathrm{eV}$ & $248.54 \mathrm{~nm}$ & $f=0.0062$ \\
\hline $42->49$ & & 0.68804 & $95 \%$ & \\
\hline Excited State & 8: & $5.0092 \mathrm{eV}$ & $247.51 \mathrm{~nm}$ & $\mathbf{f}=\mathbf{0 . 0 5 0 7}$ \\
\hline $42->50$ & & 0.61470 & $76 \%$ & \\
\hline $42->51$ & & 0.23771 & $11 \%$ & \\
\hline Excited State & 9: & $5.1277 \mathrm{eV}$ & $241.79 \mathrm{~nm}$ & $f=0.0512$ \\
\hline $42->50$ & & -0.26309 & $14 \%$ & \\
\hline $42->51$ & & 0.60728 & $74 \%$ & \\
\hline Excited State & 10: & $5.3502 \mathrm{eV}$ & $231.74 \mathrm{~nm}$ & $f=0.0031$ \\
\hline $42->53$ & & 0.55327 & $61 \%$ & \\
\hline $42->54$ & & -0.39953 & $32 \%$ & \\
\hline Excited State & 11: & $5.3786 \mathrm{eV}$ & $230.51 \mathrm{~nm}$ & $f=0.0082$ \\
\hline $42->52$ & & 0.63017 & $79 \%$ & \\
\hline Excited State & 12: & $5.4572 \mathrm{eV}$ & $227.19 \mathrm{~nm}$ & $f=0.0041$ \\
\hline $42->53$ & & 0.39978 & $32 \%$ & \\
\hline $42->54$ & & 0.53315 & $57 \%$ & \\
\hline Excited State & 13: & $5.6994 \mathrm{eV}$ & $217.54 \mathrm{~nm}$ & $f=0.0056$ \\
\hline $42->55$ & & 0.68810 & $95 \%$ & \\
\hline Excited State & 14: & $5.8229 \mathrm{eV}$ & $212.93 \mathrm{~nm}$ & $\mathbf{f}=\mathbf{0 . 0 3 7 3}$ \\
\hline $42->56$ & & 0.51100 & $52 \%$ & \\
\hline $42->57$ & & -0.44721 & $40 \%$ & \\
\hline Excited State & 15: & $5.8692 \mathrm{eV}$ & $211.24 \mathrm{~nm}$ & $\mathbf{f}=\mathbf{0 . 0 0 1 7}$ \\
\hline $42->56$ & & 0.45127 & $41 \%$ & \\
\hline $42->57$ & & 0.51073 & $52 \%$ & \\
\hline Excited State & 16: & $5.9786 \mathrm{eV}$ & $207.38 \mathrm{~nm}$ & $\mathbf{f}=\mathbf{0 . 0 0 7 9}$ \\
\hline $42->58$ & & 0.67790 & $92 \%$ & \\
\hline Excited State & 17: & $6.1196 \mathrm{eV}$ & $202.60 \mathrm{~nm}$ & $\mathbf{f}=\mathbf{0 . 0 0 2 7}$ \\
\hline $42->59$ & & 0.68703 & $94 \%$ & \\
\hline Excited State & 18: & $6.3868 \mathrm{eV}$ & $194.12 \mathrm{~nm}$ & $f=0.0032$ \\
\hline $42->60$ & & 0.65959 & $87 \%$ & \\
\hline Excited State & 19: & $6.4248 \mathrm{eV}$ & $192.98 \mathrm{~nm}$ & $f=0.0086$ \\
\hline $42->61$ & & 0.64315 & $83 \%$ & \\
\hline
\end{tabular}

Table S17. Excited states $>190 \mathrm{~nm}$ of II $+\mathbf{A}$.

$\begin{array}{cclll}\text { Excited State } & \mathbf{1 :} & \mathbf{4 . 3 6 9 8} \mathbf{~ e V} & \mathbf{2 8 3 . 7 3} \mathbf{~ n m} & \mathbf{f = 0 . 0 1 2 4} \\ 58->59 & & 0.54084 & 59 \% & \\ 58->60 & & 0.44436 & 39 \% & \\ \text { Excited State } & \mathbf{2 :} & \mathbf{4 . 5 6 9 7} \mathbf{~ e V} & \mathbf{2 7 1 . 3 2} \mathbf{~ n m} & \mathbf{f = 0 . 0 2 4 5} \\ 58->59 & & -0.41407 & 34 \% & \end{array}$




\begin{tabular}{|c|c|c|c|c|}
\hline $58->60$ & & 0.52084 & $54 \%$ & \\
\hline Excited State & 3: & $4.8368 \mathrm{eV}$ & $256.33 \mathrm{~nm}$ & $f=0.0173$ \\
\hline $58->61$ & & 0.35807 & $26 \%$ & \\
\hline $58->62$ & & 0.51621 & $53 \%$ & \\
\hline $58->63$ & & 0.23004 & $11 \%$ & \\
\hline Excited State & 4: & $4.9443 \mathrm{eV}$ & $250.76 \mathrm{~nm}$ & $\mathrm{f}=\mathbf{0 . 0 2 4 7}$ \\
\hline $58->61$ & & -0.41759 & $35 \%$ & \\
\hline $58->62$ & & 0.42440 & $36 \%$ & \\
\hline $58->63$ & & -0.30175 & $18 \%$ & \\
\hline Excited State & 5: & $4.9958 \mathrm{eV}$ & $248.18 \mathrm{~nm}$ & $f=0.0172$ \\
\hline $58->61$ & & -0.37587 & $28 \%$ & \\
\hline $58->63$ & & 0.57592 & $66 \%$ & \\
\hline Excited State & 6: & $5.2408 \mathrm{eV}$ & $236.58 \mathrm{~nm}$ & $f=0.0821$ \\
\hline $58->64$ & & 0.60453 & $73 \%$ & \\
\hline Excited State & 7: & $5.3492 \mathrm{eV}$ & $231.78 \mathrm{~nm}$ & $f=0.0153$ \\
\hline $58->65$ & & 0.62866 & $79 \%$ & \\
\hline Excited State & 8: & $5.3868 \mathrm{eV}$ & $230.16 \mathrm{~nm}$ & $f=0.0944$ \\
\hline $58->66$ & & 0.61966 & $77 \%$ & \\
\hline Excited State & 9: & $5.4677 \mathrm{eV}$ & $226.76 \mathrm{~nm}$ & $f=0.0805$ \\
\hline $58->66$ & & 0.24697 & $12 \%$ & \\
\hline $58->67$ & & 0.62405 & $78 \%$ & \\
\hline Excited State & 10: & $5.7072 \mathrm{eV}$ & $217.24 \mathrm{~nm}$ & $f=0.0406$ \\
\hline $58->68$ & & 0.51662 & $53 \%$ & \\
\hline $58->70$ & & -0.28788 & $17 \%$ & \\
\hline $58->71$ & & -0.23453 & $11 \%$ & \\
\hline Excited State & 11: & $5.7627 \mathrm{eV}$ & $215.15 \mathrm{~nm}$ & $f=0.0322$ \\
\hline $58->68$ & & 0.42089 & $35 \%$ & \\
\hline $58->69$ & & 0.40116 & $32 \%$ & \\
\hline $58->70$ & & 0.22077 & $10 \%$ & \\
\hline $58->71$ & & 0.24124 & $12 \%$ & \\
\hline Excited State & 12: & $5.8266 \mathrm{eV}$ & $212.79 \mathrm{~nm}$ & $f=0.0153$ \\
\hline $58->69$ & & -0.46756 & $44 \%$ & \\
\hline $58->70$ & & 0.46830 & $44 \%$ & \\
\hline Excited State & 13: & $5.9017 \mathrm{eV}$ & $210.08 \mathrm{~nm}$ & $f=0.0578$ \\
\hline $58->70$ & & -0.28127 & $16 \%$ & \\
\hline $58->71$ & & 0.58455 & $68 \%$ & \\
\hline Excited State & 14: & $5.9371 \mathrm{eV}$ & $208.83 \mathrm{~nm}$ & $f=0.0028$ \\
\hline $57->59$ & & 0.39262 & $31 \%$ & \\
\hline $57 \rightarrow 60$ & & 0.55222 & $61 \%$ & \\
\hline Excited State & 15: & $5.9792 \mathrm{eV}$ & $207.36 \mathrm{~nm}$ & $f=0.0036$ \\
\hline $58->72$ & & 0.64945 & $84 \%$ & \\
\hline Excited State & 16: & $6.0635 \mathrm{eV}$ & $204.48 \mathrm{~nm}$ & $f=0.0713$ \\
\hline $58->73$ & & 0.65229 & $85 \%$ & \\
\hline Excited State & 17: & $6.2922 \mathrm{eV}$ & $197.04 \mathrm{~nm}$ & $f=0.0111$ \\
\hline $58->74$ & & 0.65737 & $86 \%$ & \\
\hline
\end{tabular}




\begin{tabular}{|c|c|c|c|}
\hline Excited State 18: & $6.3594 \mathrm{eV}$ & $194.96 \mathrm{~nm}$ & $f=0.0506$ \\
\hline 58 -> 75 & 0.62317 & $78 \%$ & \\
\hline 58 -> 76 & 0.22949 & $11 \%$ & \\
\hline Excited State 19: & $6.4567 \mathrm{eV}$ & $192.02 \mathrm{~nm}$ & $f=0.0117$ \\
\hline 58 -> 76 & 0.39029 & $30 \%$ & \\
\hline 58 -> 77 & 0.50981 & $52 \%$ & \\
\hline Excited State 20: & $6.4688 \mathrm{eV}$ & $191.66 \mathrm{~nm}$ & $f=0.0509$ \\
\hline 58 -> 76 & 0.48863 & $48 \%$ & \\
\hline 58 -> 77 & -0.43391 & $38 \%$ & \\
\hline
\end{tabular}

Table S18. Excited states > $190 \mathrm{~nm}$ of II + A calculated at the whPBE0/aug-cc-pVDZ/ $\operatorname{IEFPCM}($ acetonitrile) level of theory.

\begin{tabular}{|c|c|c|c|c|}
\hline Excited State & 1: & $4.6275 \mathrm{eV}$ & $267.93 \mathrm{~nm}$ & $f=0.0206$ \\
\hline 58 -> 59 & & 0.41046 & $34 \%$ & \\
\hline $58->61$ & & -0.27341 & $15 \%$ & \\
\hline 58 -> 62 & & 0.33309 & $22 \%$ & \\
\hline 58 -> 63 & & -0.33825 & $23 \%$ & \\
\hline Excited State & 2: & $4.7677 \mathrm{eV}$ & $260.05 \mathrm{~nm}$ & $f=0.0235$ \\
\hline 58 -> 59 & & 0.46879 & $44 \%$ & \\
\hline $58->62$ & & -0.34448 & $24 \%$ & \\
\hline $58->63$ & & 0.24934 & $12 \%$ & \\
\hline 58 -> 64 & & 0.22725 & $10 \%$ & \\
\hline Excited State & 3: & $5.0361 \mathrm{eV}$ & $246.19 \mathrm{~nm}$ & $f=0.0271$ \\
\hline $58->60$ & & 0.26603 & $14 \%$ & \\
\hline 58 -> 61 & & 0.38459 & $30 \%$ & \\
\hline $58->62$ & & 0.38552 & $30 \%$ & \\
\hline Excited State & 4: & $5.1710 \mathrm{eV}$ & $239.77 \mathrm{~nm}$ & $f=0.0326$ \\
\hline $58->61$ & & -0.40818 & $33 \%$ & \\
\hline $58->63$ & & 0.48700 & $47 \%$ & \\
\hline Excited State & 5: & $5.2749 \mathrm{eV}$ & $235.05 \mathrm{~nm}$ & $f=0.0016$ \\
\hline $58->60$ & & 0.52690 & $56 \%$ & \\
\hline 58 -> 62 & & -0.25736 & $13 \%$ & \\
\hline Excited State & 6: & $5.4750 \mathrm{eV}$ & $226.45 \mathrm{~nm}$ & $f=0.3129$ \\
\hline 58 -> 64 & & 0.24211 & $12 \%$ & \\
\hline 58 -> 66 & & -0.22640 & $10 \%$ & \\
\hline 58 -> 67 & & 0.39625 & $31 \%$ & \\
\hline $58->72$ & & -0.23066 & $11 \%$ & \\
\hline Excited State & 7: & $5.6576 \mathrm{eV}$ & $219.15 \mathrm{~nm}$ & $f=0.0205$ \\
\hline 58 -> 64 & & 0.47653 & $45 \%$ & \\
\hline 58 -> 66 & & 0.31370 & $20 \%$ & \\
\hline Excited State & 8: & $5.6919 \mathrm{eV}$ & $217.83 \mathrm{~nm}$ & $f=0.0052$ \\
\hline $58->65$ & & 0.59428 & $71 \%$ & \\
\hline
\end{tabular}




\begin{tabular}{|c|c|c|c|}
\hline Excited State 9: & $5.7214 \mathrm{eV}$ & $216.70 \mathrm{~nm}$ & $f=0.0124$ \\
\hline $58->66$ & 0.47644 & $45 \%$ & \\
\hline $58->67$ & 0.33055 & $22 \%$ & \\
\hline Excited State 10: & $5.9113 \mathrm{eV}$ & $209.74 \mathrm{~nm}$ & $f=0.0201$ \\
\hline $58->68$ & 0.39582 & $31 \%$ & \\
\hline $58->70$ & 0.28022 & $16 \%$ & \\
\hline $58->71$ & -0.28997 & $17 \%$ & \\
\hline Excited State 11: & $5.9614 \mathrm{eV}$ & $207.98 \mathrm{~nm}$ & $f=0.0014$ \\
\hline $57->62$ & -0.42452 & $36 \%$ & \\
\hline $57->63$ & 0.44135 & $39 \%$ & \\
\hline Excited State 12: & $6.0787 \mathrm{eV}$ & $203.96 \mathrm{~nm}$ & $\mathbf{f}=\mathbf{0 . 0 7 9 7}$ \\
\hline $58->67$ & -0.29604 & $18 \%$ & \\
\hline $58->69$ & 0.29423 & $17 \%$ & \\
\hline $58->70$ & 0.34935 & $24 \%$ & \\
\hline Excited State 13: & $6.1476 \mathrm{eV}$ & $201.68 \mathrm{~nm}$ & $f=0.0301$ \\
\hline $58->69$ & 0.44810 & $40 \%$ & \\
\hline $58->70$ & -0.26096 & $14 \%$ & \\
\hline $58->72$ & 0.28656 & $16 \%$ & \\
\hline Excited State 14: & $6.1966 \mathrm{eV}$ & $200.08 \mathrm{~nm}$ & $\mathrm{f}=0.0248$ \\
\hline $58->68$ & 0.38452 & $30 \%$ & \\
\hline $58->69$ & 0.30164 & $18 \%$ & \\
\hline $58->71$ & 0.27733 & $15 \%$ & \\
\hline $58->72$ & -0.21835 & $10 \%$ & \\
\hline Excited State 15: & $6.2820 \mathrm{eV}$ & $197.37 \mathrm{~nm}$ & $f=0.0047$ \\
\hline $58->70$ & 0.26381 & $14 \%$ & \\
\hline $58->71$ & 0.46690 & $44 \%$ & \\
\hline $58->72$ & 0.29639 & $18 \%$ & \\
\hline $58->73$ & 0.23709 & $11 \%$ & \\
\hline Excited State 16: & $6.3444 \mathrm{eV}$ & $195.42 \mathrm{~nm}$ & $f=0.0418$ \\
\hline $58->72$ & -0.35748 & $26 \%$ & \\
\hline $58->73$ & 0.49388 & $49 \%$ & \\
\hline
\end{tabular}

Table S19. First 50 excited states of III $+\mathbf{A}$.

\begin{tabular}{|c|c|c|c|c|}
\hline Excited State & 1: & $3.0374 \mathrm{eV}$ & $408.19 \mathrm{~nm}$ & $f=0.0115$ \\
\hline $175->176$ & & 0.67621 & $91 \%$ & \\
\hline Excited State & 2: & $3.2437 \mathrm{eV}$ & $382.23 \mathrm{~nm}$ & $f=0.0245$ \\
\hline 175 -> 177 & & 0.64740 & $84 \%$ & \\
\hline Excited State & 3: & $3.4274 \mathrm{eV}$ & $361.74 \mathrm{~nm}$ & $f=0.0021$ \\
\hline $175->178$ & & 0.47427 & $45 \%$ & \\
\hline $175->179$ & & 0.50879 & $52 \%$ & \\
\hline Excited State & 4: & $3.4438 \mathrm{eV}$ & $360.02 \mathrm{~nm}$ & $f=0.0057$ \\
\hline 175 -> 177 & & 0.22686 & $10 \%$ & \\
\hline
\end{tabular}




\begin{tabular}{|c|c|c|c|c|}
\hline 175 -> 178 & & 0.47952 & $46 \%$ & \\
\hline 175 -> 179 & & -0.46504 & $43 \%$ & \\
\hline Excited State & 5: & $4.4763 \mathrm{eV}$ & $276.98 \mathrm{~nm}$ & $f=0.0198$ \\
\hline $175->180$ & & 0.61637 & $76 \%$ & \\
\hline Excited State & 6: & $4.7497 \mathrm{eV}$ & $261.04 \mathrm{~nm}$ & $f=0.0069$ \\
\hline 175 -> 181 & & 0.58248 & $68 \%$ & \\
\hline 175 -> 185 & & 0.22946 & $11 \%$ & \\
\hline Excited State & 7: & $4.7861 \mathrm{eV}$ & $259.05 \mathrm{~nm}$ & $f=0.0369$ \\
\hline $175->181$ & & -0.24815 & $12 \%$ & \\
\hline 175 -> 182 & & 0.26904 & $14 \%$ & \\
\hline 175 -> 183 & & 0.53225 & $57 \%$ & \\
\hline Excited State & 8: & $4.9004 \mathrm{eV}$ & $253.01 \mathrm{~nm}$ & $f=0.0014$ \\
\hline 175 -> 182 & & 0.58758 & $69 \%$ & \\
\hline 175 -> 183 & & -0.28634 & $16 \%$ & \\
\hline Excited State & 9: & $5.1122 \mathrm{eV}$ & $242.53 \mathrm{~nm}$ & $f=\mathbf{0 . 0 5 3 2}$ \\
\hline $175->184$ & & 0.63622 & $81 \%$ & \\
\hline Excited State & 10: & $5.1372 \mathrm{eV}$ & $241.34 \mathrm{~nm}$ & $f=0.0127$ \\
\hline $174->176$ & & 0.52766 & $56 \%$ & \\
\hline Excited State & 11: & $5.1735 \mathrm{eV}$ & $239.65 \mathrm{~nm}$ & $f=0.0161$ \\
\hline $171->179$ & & 0.30169 & $18 \%$ & \\
\hline 173 -> 176 & & 0.44952 & $40 \%$ & \\
\hline 173 -> 177 & & -0.26934 & $15 \%$ & \\
\hline Excited State & 12: & $5.1940 \mathrm{eV}$ & $238.70 \mathrm{~nm}$ & $f=0.0059$ \\
\hline $175->185$ & & 0.61660 & $76 \%$ & \\
\hline Excited State & 13: & $5.2038 \mathrm{eV}$ & $238.26 \mathrm{~nm}$ & $\mathbf{f}=\mathbf{0 . 0 0 2 7}$ \\
\hline $175->186$ & & 0.62325 & $78 \%$ & \\
\hline Excited State & 14: & $5.2910 \mathrm{eV}$ & $234.33 \mathrm{~nm}$ & $f=0.0859$ \\
\hline $175->187$ & & 0.62166 & $77 \%$ & \\
\hline Excited State & 15: & $5.3517 \mathrm{eV}$ & $231.67 \mathrm{~nm}$ & $f=0.0040$ \\
\hline $175->188$ & & 0.61909 & $77 \%$ & \\
\hline Excited State & 16: & $5.3761 \mathrm{eV}$ & $230.62 \mathrm{~nm}$ & $f=0.0009$ \\
\hline 172 -> 176 & & 0.40413 & $33 \%$ & \\
\hline 174 -> 176 & & -0.39708 & $32 \%$ & \\
\hline Excited State & 17: & $5.4470 \mathrm{eV}$ & $227.62 \mathrm{~nm}$ & $f=0.0002$ \\
\hline 172 -> 176 & & -0.22626 & $10 \%$ & \\
\hline 173 -> 176 & & 0.45670 & $42 \%$ & \\
\hline 173 -> 177 & & 0.22162 & $10 \%$ & \\
\hline 174 -> 177 & & -0.33455 & $22 \%$ & \\
\hline Excited State & 18: & $5.4679 \mathrm{eV}$ & $226.75 \mathrm{~nm}$ & $f=0.0627$ \\
\hline 175 -> 189 & & 0.36517 & $27 \%$ & \\
\hline 175 -> 190 & & 0.48363 & $47 \%$ & \\
\hline Excited State & 19: & $5.5006 \mathrm{eV}$ & $225.40 \mathrm{~nm}$ & $f=0.0225$ \\
\hline 174 -> 177 & & 0.53829 & $58 \%$ & \\
\hline Excited State & 20: & $5.5239 \mathrm{eV}$ & $224.45 \mathrm{~nm}$ & $f=0.0186$ \\
\hline 175 -> 189 & & 0.51203 & $52 \%$ & \\
\hline 175 -> 190 & & -0.34025 & $23 \%$ & \\
\hline
\end{tabular}




\begin{tabular}{|c|c|c|c|}
\hline Excited State 21: & $5.5970 \mathrm{eV}$ & $221.52 \mathrm{~nm}$ & $f=0.0297$ \\
\hline $175->187$ & 0.25016 & $13 \%$ & \\
\hline 175 -> 190 & 0.30902 & $19 \%$ & \\
\hline 175 -> 191 & 0.48545 & $47 \%$ & \\
\hline Excited State 22: & $5.6387 \mathrm{eV}$ & $219.88 \mathrm{~nm}$ & $f=0.0172$ \\
\hline $173->177$ & -0.28782 & $17 \%$ & \\
\hline $174->178$ & 0.54627 & $60 \%$ & \\
\hline Excited State 23: & $5.6718 \mathrm{eV}$ & $218.60 \mathrm{~nm}$ & $f=0.0761$ \\
\hline $172->176$ & 0.22859 & $10 \%$ & \\
\hline $174->178$ & 0.21921 & $10 \%$ & \\
\hline 175 -> 192 & 0.41211 & $34 \%$ & \\
\hline Excited State 24: & $5.6763 \mathrm{eV}$ & $218.42 \mathrm{~nm}$ & $\mathbf{f}=\mathbf{0 . 0 3 7 1}$ \\
\hline $172->176$ & -0.28367 & $16 \%$ & \\
\hline 172 -> 177 & 0.34586 & $24 \%$ & \\
\hline 175 -> 192 & 0.33347 & $22 \%$ & \\
\hline Excited State 25: & $5.6966 \mathrm{eV}$ & $217.65 \mathrm{~nm}$ & $\mathbf{f}=\mathbf{0 . 0 2 3 7}$ \\
\hline 173 -> 177 & 0.28123 & $16 \%$ & \\
\hline 173 -> 178 & 0.47825 & $46 \%$ & \\
\hline Excited State 26: & $5.7625 \mathrm{eV}$ & $215.16 \mathrm{~nm}$ & $f=0.0089$ \\
\hline $175->193$ & 0.55833 & $62 \%$ & \\
\hline 175 -> 195 & -0.25736 & $13 \%$ & \\
\hline Excited State 27: & $5.7811 \mathrm{eV}$ & $214.46 \mathrm{~nm}$ & $f=0.0018$ \\
\hline 171 -> 176 & 0.39757 & $32 \%$ & \\
\hline $174->179$ & 0.50913 & $52 \%$ & \\
\hline Excited State 28: & $5.8010 \mathrm{eV}$ & $213.73 \mathrm{~nm}$ & $f=0.0158$ \\
\hline $170->176$ & -0.26051 & $14 \%$ & \\
\hline 171 -> 176 & -0.30118 & $18 \%$ & \\
\hline 173 -> 179 & 0.28749 & $17 \%$ & \\
\hline 174 -> 179 & 0.35109 & $25 \%$ & \\
\hline Excited State 29: & $5.8260 \mathrm{eV}$ & $212.81 \mathrm{~nm}$ & $f=0.0072$ \\
\hline 175 -> 194 & 0.51258 & $53 \%$ & \\
\hline 175 -> 195 & 0.31241 & $20 \%$ & \\
\hline Excited State 30: & $5.8340 \mathrm{eV}$ & $212.52 \mathrm{~nm}$ & $f=0.0239$ \\
\hline 169 -> 176 & -0.22437 & $10 \%$ & \\
\hline 170 -> 176 & 0.27143 & $15 \%$ & \\
\hline 172 -> 177 & 0.46271 & $43 \%$ & \\
\hline Excited State 31: & $5.8664 \mathrm{eV}$ & $211.35 \mathrm{~nm}$ & $f=0.0887$ \\
\hline 175 -> 194 & -0.25889 & $13 \%$ & \\
\hline 175 -> 195 & 0.43093 & $37 \%$ & \\
\hline 175 -> 196 & -0.30713 & $19 \%$ & \\
\hline Excited State 32: & 5.8858 eV & $210.65 \mathrm{~nm}$ & $f=0.0189$ \\
\hline 175 -> 196 & 0.42475 & $36 \%$ & \\
\hline 175 -> 197 & 0.32279 & $21 \%$ & \\
\hline Excited State 33: & $5.8933 \mathrm{eV}$ & $210.38 \mathrm{~nm}$ & $f=0.0323$ \\
\hline 169 -> 176 & -0.28013 & $16 \%$ & \\
\hline 172 -> 178 & 0.38465 & $30 \%$ & \\
\hline
\end{tabular}




\begin{tabular}{|c|c|c|c|}
\hline 173 -> 179 & 0.26178 & $14 \%$ & \\
\hline Excited State 34: & $5.9360 \mathrm{eV}$ & $208.87 \mathrm{~nm}$ & $f=0.0520$ \\
\hline 171 -> 176 & 0.22965 & $11 \%$ & \\
\hline 171 -> 177 & 0.28115 & $16 \%$ & \\
\hline 172 -> 178 & -0.28801 & $17 \%$ & \\
\hline 173 -> 179 & 0.32327 & $21 \%$ & \\
\hline Excited State 35: & $5.9481 \mathrm{eV}$ & $208.44 \mathrm{~nm}$ & $f=0.0140$ \\
\hline 175 -> 195 & -0.27171 & $15 \%$ & \\
\hline 175 -> 196 & -0.28887 & $17 \%$ & \\
\hline 175 -> 197 & 0.40668 & $33 \%$ & \\
\hline Excited State 36: & $5.9705 \mathrm{eV}$ & $207.66 \mathrm{~nm}$ & $f=0.0065$ \\
\hline 168 -> 176 & 0.35409 & $25 \%$ & \\
\hline 169 -> 176 & 0.24861 & $12 \%$ & \\
\hline 170 -> 176 & -0.29671 & $18 \%$ & \\
\hline 170 -> 177 & 0.24843 & $12 \%$ & \\
\hline Excited State 37: & $6.0168 \mathrm{eV}$ & $206.06 \mathrm{~nm}$ & $f=0.0668$ \\
\hline 175 -> 197 & 0.31155 & $19 \%$ & \\
\hline 175 -> 198 & -0.26543 & $14 \%$ & \\
\hline 175 -> 199 & 0.44928 & $40 \%$ & \\
\hline Excited State 38: & $6.0262 \mathrm{eV}$ & $205.74 \mathrm{~nm}$ & $f=0.0528$ \\
\hline 168 -> 176 & -0.36586 & $27 \%$ & \\
\hline 172 -> 179 & 0.36665 & $27 \%$ & \\
\hline Excited State 39: & $6.0372 \mathrm{eV}$ & $205.37 \mathrm{~nm}$ & $f=0.0179$ \\
\hline $175->198$ & 0.53297 & $57 \%$ & \\
\hline 175 -> 199 & 0.32025 & $21 \%$ & \\
\hline Excited State 40: & $6.0533 \mathrm{eV}$ & $204.82 \mathrm{~nm}$ & $f=0.0116$ \\
\hline $170->177$ & -0.26485 & $14 \%$ & \\
\hline 172 -> 178 & -0.22135 & $10 \%$ & \\
\hline 172 -> 179 & 0.45543 & $41 \%$ & \\
\hline Excited State 41: & $6.1114 \mathrm{eV}$ & $202.87 \mathrm{~nm}$ & $f=0.0254$ \\
\hline $170->177$ & 0.24437 & $12 \%$ & \\
\hline 171 -> 177 & 0.32717 & $21 \%$ & \\
\hline 171 -> 178 & 0.36550 & $27 \%$ & \\
\hline Excited State 42: & $6.1285 \mathrm{eV}$ & $202.31 \mathrm{~nm}$ & $f=0.0319$ \\
\hline 171 -> 178 & 0.26366 & $14 \%$ & \\
\hline 175 -> 200 & 0.42037 & $35 \%$ & \\
\hline Excited State 43: & $6.1343 \mathrm{eV}$ & $202.12 \mathrm{~nm}$ & $f=0.0297$ \\
\hline 170 -> 177 & 0.34485 & $24 \%$ & \\
\hline $170->178$ & -0.25401 & $13 \%$ & \\
\hline 175 -> 200 & 0.29781 & $18 \%$ & \\
\hline Excited State 44: & $6.1867 \mathrm{eV}$ & $200.40 \mathrm{~nm}$ & $f=0.0939$ \\
\hline 169 -> 177 & 0.38379 & $29 \%$ & \\
\hline 169 -> 178 & -0.30242 & $18 \%$ & \\
\hline 170 -> 177 & 0.23131 & $11 \%$ & \\
\hline Excited State 45: & $6.1986 \mathrm{eV}$ & $200.02 \mathrm{~nm}$ & $f=0.0084$ \\
\hline 175 -> 200 & 0.25555 & $13 \%$ & \\
\hline
\end{tabular}




\begin{tabular}{|c|c|c|c|}
\hline 175 -> 201 & 0.54310 & $59 \%$ & \\
\hline 175 -> 203 & 0.22918 & $11 \%$ & \\
\hline Excited State 46: & $6.2264 \mathrm{eV}$ & $199.13 \mathrm{~nm}$ & $f=0.0088$ \\
\hline 168 -> 177 & 0.49816 & $50 \%$ & \\
\hline Excited State 47: & $6.2920 \mathrm{eV}$ & $197.05 \mathrm{~nm}$ & $f=0.1084$ \\
\hline 169 -> 177 & 0.22218 & $10 \%$ & \\
\hline 170 -> 179 & 0.37045 & $27 \%$ & \\
\hline 171 -> 178 & -0.26490 & $14 \%$ & \\
\hline Excited State 48: & $6.3095 \mathrm{eV}$ & $196.50 \mathrm{~nm}$ & $f=0.0180$ \\
\hline 175 -> 201 & -0.21865 & $10 \%$ & \\
\hline $175->203$ & 0.58013 & $67 \%$ & \\
\hline Excited State 49: & $6.3263 \mathrm{eV}$ & $195.98 \mathrm{~nm}$ & $f=0.1248$ \\
\hline 175 -> 202 & 0.57556 & $66 \%$ & \\
\hline Excited State 50: & $6.3486 \mathrm{eV}$ & $195.29 \mathrm{~nm}$ & $f=0.0581$ \\
\hline 168 -> 178 & -0.33228 & $22 \%$ & \\
\hline 169 -> 177 & -0.23662 & $11 \%$ & \\
\hline $170->178$ & 0.37363 & $28 \%$ & \\
\hline 175 -> 202 & 0.23343 & $11 \%$ & \\
\hline
\end{tabular}

Table S20. Excited states > $200 \mathrm{~nm}$ of III + A calculated at the M06-2X/aug-cc-pVDZ/ IEFPCM(acetonitrile) level of theory.

\begin{tabular}{|c|c|c|c|c|}
\hline Excited State & 1: & $3.9791 \mathrm{eV}$ & $311.59 \mathrm{~nm}$ & $f=0.0244$ \\
\hline $175->176$ & & 0.55011 & $61 \%$ & \\
\hline 175 -> 177 & & -0.35725 & $26 \%$ & \\
\hline 175 -> 178 & & 0.24417 & $12 \%$ & \\
\hline Excited State & 2: & $4.1377 \mathrm{eV}$ & $299.64 \mathrm{~nm}$ & $\mathbf{f}=\mathbf{0 . 0 1 3 7}$ \\
\hline $175->176$ & & 0.30001 & $18 \%$ & \\
\hline 175 -> 177 & & 0.44088 & $39 \%$ & \\
\hline 175 -> 179 & & 0.43073 & $37 \%$ & \\
\hline Excited State & 3: & $4.3964 \mathrm{eV}$ & $282.01 \mathrm{~nm}$ & $f=0.0021$ \\
\hline 175 -> 176 & & -0.29535 & $17 \%$ & \\
\hline 175 -> 177 & & -0.31369 & $20 \%$ & \\
\hline 175 -> 179 & & 0.54260 & $59 \%$ & \\
\hline Excited State & 4: & $4.4854 \mathrm{eV}$ & $276.41 \mathrm{~nm}$ & $f=0.0080$ \\
\hline 175 -> 177 & & 0.26266 & $14 \%$ & \\
\hline 175 -> 178 & & 0.63309 & $80 \%$ & \\
\hline Excited State & 5: & $4.6676 \mathrm{eV}$ & $265.63 \mathrm{~nm}$ & $f=0.0254$ \\
\hline $175->180$ & & 0.49089 & $48 \%$ & \\
\hline 175 -> 183 & & -0.38834 & $30 \%$ & \\
\hline Excited State & 6: & $4.9410 \mathrm{eV}$ & $250.93 \mathrm{~nm}$ & $f=0.0295$ \\
\hline $175->182$ & & 0.48508 & $47 \%$ & \\
\hline 175 -> 184 & & 0.23380 & $11 \%$ & \\
\hline 175 -> 185 & & 0.30671 & $19 \%$ & \\
\hline
\end{tabular}




\begin{tabular}{|c|c|c|c|c|}
\hline Excited State & 7: & $5.0331 \mathrm{eV}$ & $246.34 \mathrm{~nm}$ & $f=0.0046$ \\
\hline $175->181$ & & 0.53026 & $56 \%$ & \\
\hline 175 -> 186 & & -0.28016 & $16 \%$ & \\
\hline Excited State & 8: & $5.2844 \mathrm{eV}$ & $234.62 \mathrm{~nm}$ & $f=0.0022$ \\
\hline 175 -> 180 & & 0.32384 & $21 \%$ & \\
\hline $175->181$ & & -0.25072 & $13 \%$ & \\
\hline $175->182$ & & -0.29058 & $17 \%$ & \\
\hline $175->183$ & & 0.31933 & $20 \%$ & \\
\hline 175 -> 186 & & -0.22350 & $10 \%$ & \\
\hline Excited State & 9: & $5.3430 \mathrm{eV}$ & $232.05 \mathrm{~nm}$ & $f=0.0165$ \\
\hline 174 -> 176 & & 0.31230 & $20 \%$ & \\
\hline 174 -> 177 & & -0.18523 & $7 \%$ & \\
\hline Excited State & 10: & $5.3583 \mathrm{eV}$ & $231.39 \mathrm{~nm}$ & $f=0.0230$ \\
\hline 171 -> 179 & & 0.24959 & $12 \%$ & \\
\hline $173->176$ & & 0.30990 & $19 \%$ & \\
\hline $174->177$ & & 0.29691 & $18 \%$ & \\
\hline Excited State & 11: & $5.4419 \mathrm{eV}$ & $227.83 \mathrm{~nm}$ & $f=0.1928$ \\
\hline $175->180$ & & -0.21881 & $10 \%$ & \\
\hline $175->184$ & & 0.23275 & $11 \%$ & \\
\hline $175->185$ & & -0.28373 & $16 \%$ & \\
\hline $175->188$ & & 0.31307 & $20 \%$ & \\
\hline Excited State & 12: & $5.4850 \mathrm{eV}$ & $226.04 \mathrm{~nm}$ & $f=0.0394$ \\
\hline $175->187$ & & 0.39989 & $32 \%$ & \\
\hline $175->193$ & & -0.26478 & $14 \%$ & \\
\hline Excited State & 13: & $5.5462 \mathrm{eV}$ & $223.55 \mathrm{~nm}$ & $f=0.0283$ \\
\hline $175->181$ & & 0.24812 & $12 \%$ & \\
\hline $175->184$ & & 0.38658 & $30 \%$ & \\
\hline $175->190$ & & -0.22979 & $11 \%$ & \\
\hline Excited State & 14: & $5.5834 \mathrm{eV}$ & $222.06 \mathrm{~nm}$ & $f=0.0024$ \\
\hline $175->183$ & & 0.33382 & $22 \%$ & \\
\hline 175 -> 186 & & 0.45125 & $41 \%$ & \\
\hline $175->190$ & & 0.24057 & $12 \%$ & \\
\hline Excited State & 15: & $5.6551 \mathrm{eV}$ & $219.24 \mathrm{~nm}$ & $f=0.0028$ \\
\hline $175->182$ & & -0.28566 & $16 \%$ & \\
\hline $175->185$ & & 0.40961 & $34 \%$ & \\
\hline $175->188$ & & 0.36854 & $27 \%$ & \\
\hline Excited State & 16: & $5.8078 \mathrm{eV}$ & $213.48 \mathrm{~nm}$ & $\mathbf{f}=\mathbf{0 . 1 2 3 7}$ \\
\hline $175->187$ & & -0.24231 & $12 \%$ & \\
\hline $175->189$ & & 0.23309 & $11 \%$ & \\
\hline 175 -> 191 & & 0.35271 & $25 \%$ & \\
\hline Excited State & 17: & $5.8781 \mathrm{eV}$ & $210.93 \mathrm{~nm}$ & $f=0.0746$ \\
\hline $175->187$ & & 0.29349 & $17 \%$ & \\
\hline $175->189$ & & 0.40797 & $33 \%$ & \\
\hline Excited State & 18: & $5.9698 \mathrm{eV}$ & $207.69 \mathrm{~nm}$ & $f=0.0285$ \\
\hline $175->188$ & & -0.22213 & $10 \%$ & \\
\hline $175->189$ & & -0.33115 & $22 \%$ & \\
\hline
\end{tabular}




\begin{tabular}{|c|c|c|c|}
\hline $175->191$ & 0.36804 & $27 \%$ & \\
\hline Excited State 19: & $5.9954 \mathrm{eV}$ & $206.80 \mathrm{~nm}$ & $f=0.0069$ \\
\hline 175 -> 184 & 0.25969 & $13 \%$ & \\
\hline 175 -> 187 & 0.21981 & $10 \%$ & \\
\hline 175 -> 190 & 0.44754 & $40 \%$ & \\
\hline 175 -> 197 & -0.22715 & $10 \%$ & \\
\hline Excited State 20: & $6.0284 \mathrm{eV}$ & $205.67 \mathrm{~nm}$ & $f=0.0033$ \\
\hline $171->176$ & -0.28628 & $16 \%$ & \\
\hline 173 -> 177 & 0.31544 & $20 \%$ & \\
\hline $174->176$ & -0.27974 & $16 \%$ & \\
\hline 174 -> 179 & -0.29847 & $18 \%$ & \\
\hline Excited State 21: & $6.0697 \mathrm{eV}$ & $204.27 \mathrm{~nm}$ & $f=0.0055$ \\
\hline 175 -> 191 & -0.23862 & $11 \%$ & \\
\hline 175 -> 193 & -0.27467 & $15 \%$ & \\
\hline 175 -> 194 & 0.41322 & $34 \%$ & \\
\hline Excited State 22: & $6.1114 \mathrm{eV}$ & $202.87 \mathrm{~nm}$ & $f=0.0015$ \\
\hline 169 -> 176 & 0.25195 & $13 \%$ & \\
\hline 171 -> 177 & -0.28911 & $17 \%$ & \\
\hline $173->178$ & 0.26216 & $14 \%$ & \\
\hline 174 -> 179 & 0.29690 & $18 \%$ & \\
\hline Excited State 23: & $6.1572 \mathrm{eV}$ & $201.36 \mathrm{~nm}$ & $f=0.0101$ \\
\hline $175->192$ & 0.27748 & $15 \%$ & \\
\hline $175->193$ & 0.30784 & $19 \%$ & \\
\hline 175 -> 194 & 0.30450 & $19 \%$ & \\
\hline Excited State 24: & $6.1658 \mathrm{eV}$ & $201.09 \mathrm{~nm}$ & $f=0.0905$ \\
\hline $175->192$ & -0.24096 & $12 \%$ & \\
\hline $175->193$ & 0.33632 & $23 \%$ & \\
\hline $175->195$ & 0.26146 & $14 \%$ & \\
\hline Excited State 25: & $6.1918 \mathrm{eV}$ & $200.24 \mathrm{~nm}$ & $\mathbf{f}=\mathbf{0 . 0 0 0 7}$ \\
\hline 175 -> 196 & 0.39553 & $31 \%$ & \\
\hline $175->199$ & -0.27657 & $15 \%$ & \\
\hline
\end{tabular}

Table S21. Excited states > $200 \mathrm{~nm}$ of III + A calculated at the whPBE0/aug-cc-pVDZ/ IEFPCM(acetonitrile) level of theory.

\begin{tabular}{|c|c|c|c|c|}
\hline Excited State & 1: & $3.4692 \mathrm{eV}$ & $357.39 \mathrm{~nm}$ & $f=0.0219$ \\
\hline $175->176$ & & 0.58885 & $69 \%$ & \\
\hline 175 -> 177 & & -0.31476 & $20 \%$ & \\
\hline Excited State & 2: & $3.6737 \mathrm{eV}$ & $337.49 \mathrm{~nm}$ & $f=0.0161$ \\
\hline $175->176$ & & 0.28542 & $16 \%$ & \\
\hline 175 -> 177 & & 0.51358 & $53 \%$ & \\
\hline 175 -> 179 & & 0.36188 & $26 \%$ & \\
\hline Excited State & 3. & $3.8699 \mathrm{eV}$ & $320.38 \mathrm{~nm}$ & $f=0.0008$ \\
\hline
\end{tabular}




\begin{tabular}{|c|c|c|c|c|}
\hline 175 -> 176 & & -0.24979 & $12 \%$ & \\
\hline 175 -> 177 & & -0.23569 & $11 \%$ & \\
\hline $175->179$ & & 0.59089 & $70 \%$ & \\
\hline Excited State & 4: & $3.9550 \mathrm{eV}$ & $313.49 \mathrm{~nm}$ & $f=0.0090$ \\
\hline $175->177$ & & 0.27537 & $15 \%$ & \\
\hline $175->178$ & & 0.63366 & $80 \%$ & \\
\hline Excited State & 5: & $4.7021 \mathrm{eV}$ & $263.68 \mathrm{~nm}$ & $f=0.0270$ \\
\hline $175->180$ & & 0.52246 & $55 \%$ & \\
\hline 175 -> 181 & & -0.29470 & $17 \%$ & \\
\hline Excited State & 6: & $5.0058 \mathrm{eV}$ & $247.68 \mathrm{~nm}$ & $f=0.0403$ \\
\hline 175 -> 181 & & 0.25803 & $13 \%$ & \\
\hline 175 -> 183 & & 0.45118 & $41 \%$ & \\
\hline $175->185$ & & 0.32097 & $21 \%$ & \\
\hline Excited State & 7: & $5.0616 \mathrm{eV}$ & $244.95 \mathrm{~nm}$ & $f=0.0223$ \\
\hline $175->181$ & & 0.47242 & $45 \%$ & \\
\hline 175 -> 182 & & -0.25142 & $13 \%$ & \\
\hline $175->183$ & & -0.24575 & $12 \%$ & \\
\hline $175->186$ & & 0.23504 & $11 \%$ & \\
\hline Excited State & 8: & $5.2212 \mathrm{eV}$ & $237.46 \mathrm{~nm}$ & $f=0.0121$ \\
\hline 169 -> 177 & & 0.22906 & $10 \%$ & \\
\hline 169 -> 178 & & 0.22052 & $10 \%$ & \\
\hline $172->176$ & & 0.26472 & $14 \%$ & \\
\hline $173->176$ & & 0.25309 & $13 \%$ & \\
\hline $174->176$ & & 0.31081 & $19 \%$ & \\
\hline Excited State & 9: & $5.2387 \mathrm{eV}$ & $236.67 \mathrm{~nm}$ & $\mathbf{f}=\mathbf{0 . 0 1 8 7}$ \\
\hline 171 -> 179 & & 0.33648 & $23 \%$ & \\
\hline 173 -> 176 & & 0.27322 & $15 \%$ & \\
\hline 173 -> 177 & & -0.33172 & $22 \%$ & \\
\hline 174 -> 176 & & -0.25025 & $13 \%$ & \\
\hline Excited State & 10: & $5.3074 \mathrm{eV}$ & $233.61 \mathrm{~nm}$ & $f=0.0055$ \\
\hline 175 -> 180 & & 0.23211 & $11 \%$ & \\
\hline $175->182$ & & 0.51717 & $53 \%$ & \\
\hline 175 -> 183 & & -0.26411 & $14 \%$ & \\
\hline Excited State & 11: & $5.4683 \mathrm{eV}$ & $226.73 \mathrm{~nm}$ & $\mathbf{f}=\mathbf{0 . 2 3 8 7}$ \\
\hline $175->180$ & & 0.22911 & $10 \%$ & \\
\hline 175 -> 184 & & -0.28802 & $17 \%$ & \\
\hline 175 -> 187 & & 0.32978 & $22 \%$ & \\
\hline 175 -> 195 & & 0.24549 & $12 \%$ & \\
\hline Excited State & 12: & $5.5821 \mathrm{eV}$ & $222.11 \mathrm{~nm}$ & $f=0.0096$ \\
\hline 175 -> 186 & & 0.46137 & $43 \%$ & \\
\hline $175->188$ & & 0.30198 & $18 \%$ & \\
\hline Excited State & 13: & $5.5853 \mathrm{eV}$ & $221.98 \mathrm{~nm}$ & $f=0.0526$ \\
\hline 175 -> 184 & & 0.32957 & $22 \%$ & \\
\hline 175 -> 185 & & -0.31201 & $19 \%$ & \\
\hline Excited State & 14: & $5.6183 \mathrm{eV}$ & $220.68 \mathrm{~nm}$ & $f=0.0041$ \\
\hline
\end{tabular}




\begin{tabular}{|c|c|c|c|}
\hline $175->184$ & 0.28359 & $16 \%$ & \\
\hline $175->185$ & 0.39146 & $31 \%$ & \\
\hline $175->190$ & -0.23080 & $11 \%$ & \\
\hline Excited State 15: & $5.6640 \mathrm{eV}$ & $218.90 \mathrm{~nm}$ & $f=0.0045$ \\
\hline $172->176$ & -0.31255 & $20 \%$ & \\
\hline $174->176$ & 0.50851 & $52 \%$ & \\
\hline Excited State 16: & $5.7127 \mathrm{eV}$ & $217.03 \mathrm{~nm}$ & $f=0.0022$ \\
\hline $175->183$ & -0.25226 & $13 \%$ & \\
\hline $175->186$ & -0.30335 & $18 \%$ & \\
\hline $175->188$ & 0.42930 & $37 \%$ & \\
\hline Excited State 17: & $5.7409 \mathrm{eV}$ & $215.97 \mathrm{~nm}$ & $\mathbf{f}=\mathbf{0 . 0 0 1 3}$ \\
\hline $173->176$ & -0.35478 & $25 \%$ & \\
\hline 174 -> 177 & 0.46524 & $43 \%$ & \\
\hline Excited State 18: & $5.7999 \mathrm{eV}$ & $213.77 \mathrm{~nm}$ & $f=0.1145$ \\
\hline $173->176$ & 0.27777 & $15 \%$ & \\
\hline $174->178$ & 0.23735 & $11 \%$ & \\
\hline Excited State 19: & $5.8129 \mathrm{eV}$ & $213.29 \mathrm{~nm}$ & $\mathbf{f}=\mathbf{0 . 0 2 7 2}$ \\
\hline $173->176$ & -0.22506 & $10 \%$ & \\
\hline $174->178$ & -0.22435 & $10 \%$ & \\
\hline $175->190$ & 0.26265 & $14 \%$ & \\
\hline Excited State 20: & $5.9140 \mathrm{eV}$ & $209.65 \mathrm{~nm}$ & $f=\mathbf{0 . 0 2 5 2}$ \\
\hline 171 -> 176 & -0.24480 & $12 \%$ & \\
\hline 172 -> 176 & 0.34229 & $23 \%$ & \\
\hline $172->177$ & -0.31790 & $20 \%$ & \\
\hline Excited State 21: & $5.9420 \mathrm{eV}$ & $208.66 \mathrm{~nm}$ & $f=0.0016$ \\
\hline $169->176$ & -0.24526 & $12 \%$ & \\
\hline $171->177$ & 0.23081 & $11 \%$ & \\
\hline $173->178$ & 0.22981 & $11 \%$ & \\
\hline $174->178$ & 0.26575 & $14 \%$ & \\
\hline 174 -> 179 & -0.23658 & $11 \%$ & \\
\hline Excited State 22: & $5.9587 \mathrm{eV}$ & $208.07 \mathrm{~nm}$ & $f=0.0524$ \\
\hline $175->187$ & 0.24121 & $12 \%$ & \\
\hline $175->189$ & 0.44665 & $40 \%$ & \\
\hline Excited State 23: & $5.9898 \mathrm{eV}$ & $206.99 \mathrm{~nm}$ & $f=0.0598$ \\
\hline $173->177$ & 0.35869 & $26 \%$ & \\
\hline $174->178$ & -0.34234 & $23 \%$ & \\
\hline Excited State 24: & $6.0123 \mathrm{eV}$ & $206.22 \mathrm{~nm}$ & $f=0.0492$ \\
\hline $175->187$ & 0.22862 & $10 \%$ & \\
\hline 175 -> 189 & -0.24022 & $12 \%$ & \\
\hline $175->190$ & 0.30780 & $19 \%$ & \\
\hline $175->192$ & 0.26237 & $14 \%$ & \\
\hline Excited State 25: & $6.0547 \mathrm{eV}$ & $204.77 \mathrm{~nm}$ & $f=0.0185$ \\
\hline $175->190$ & 0.33401 & $22 \%$ & \\
\hline $175->191$ & 0.36133 & $26 \%$ & \\
\hline Excited State 26: & $6.0705 \mathrm{eV}$ & $204.24 \mathrm{~nm}$ & $\mathbf{f}=\mathbf{0 . 0 0 1 2}$ \\
\hline
\end{tabular}




\begin{tabular}{|c|c|c|c|}
\hline $172->178$ & -0.24089 & $12 \%$ & \\
\hline $173->178$ & 0.38239 & $29 \%$ & \\
\hline $174->178$ & 0.25759 & $13 \%$ & \\
\hline Excited State 27: & $6.1399 \mathrm{eV}$ & $201.93 \mathrm{~nm}$ & $\mathbf{f}=\mathbf{0 . 0 1 0 7}$ \\
\hline 172 -> 179 & -0.22118 & $10 \%$ & \\
\hline $173->179$ & 0.30331 & $18 \%$ & \\
\hline $174->179$ & 0.52663 & $55 \%$ & \\
\hline Excited State 28: & $6.1444 \mathrm{eV}$ & $201.78 \mathrm{~nm}$ & $f=0.0196$ \\
\hline 169 -> 176 & -0.23408 & $11 \%$ & \\
\hline $172->176$ & 0.30774 & $19 \%$ & \\
\hline $172->178$ & 0.22754 & $10 \%$ & \\
\hline Excited State 29: & $6.1564 \mathrm{eV}$ & $201.39 \mathrm{~nm}$ & $f=0.0032$ \\
\hline $175->188$ & -0.24208 & $12 \%$ & \\
\hline 175 -> 193 & -0.30512 & $19 \%$ & \\
\hline 175 -> 194 & 0.41981 & $35 \%$ & \\
\hline
\end{tabular}

Table S22. First 50 excited states of III + B.

\begin{tabular}{|c|c|c|c|c|}
\hline $\begin{array}{c}\text { Excited State } \\
174->175\end{array}$ & 1: & $\begin{array}{l}\mathbf{2 . 8 2 2 9} \mathrm{eV} \\
0.67381\end{array}$ & $\begin{array}{l}\mathbf{4 3 9 . 2 1} \mathbf{n m} \\
91 \%\end{array}$ & $f=0.0110$ \\
\hline $\begin{array}{c}\text { Excited State } \\
174->176\end{array}$ & 2: & $\begin{array}{l}\mathbf{3 . 0 3 0 9} \mathbf{e V} \\
0.64744\end{array}$ & $\begin{array}{l}\mathbf{4 0 9 . 0 7} \mathbf{~ n m} \\
84 \%\end{array}$ & $f=0.0156$ \\
\hline $\begin{array}{c}\text { Excited State } \\
\begin{array}{c}174->177 \\
174->178\end{array}\end{array}$ & 3: & $\begin{array}{l}\mathbf{3 . 2 2 5 5} \mathbf{e V} \\
0.37538 \\
0.58813\end{array}$ & $\begin{array}{l}\mathbf{3 8 4 . 3 8} \mathbf{~ n m} \\
28 \% \\
69 \%\end{array}$ & $f=0.0006$ \\
\hline $\begin{array}{c}\text { Excited State } \\
174->176 \\
174->177 \\
174->178\end{array}$ & 4: & $\begin{array}{l}3.2330 \mathrm{eV} \\
0.21958 \\
0.56606 \\
-0.35890\end{array}$ & $\begin{array}{l}\mathbf{3 8 3 . 5 0} \mathbf{~ n m} \\
10 \% \\
64 \% \\
26 \%\end{array}$ & $f=0.0089$ \\
\hline $\begin{array}{c}\text { Excited State } \\
174->179\end{array}$ & 5: & $\begin{array}{l}4.2155 \mathrm{eV} \\
0.65661\end{array}$ & $\begin{array}{l}\mathbf{2 9 4 . 1 2} \mathbf{n m} \\
86 \%\end{array}$ & $f=0.1844$ \\
\hline $\begin{array}{c}\text { Excited State } \\
\qquad \begin{array}{c}174->180 \\
174->182\end{array}\end{array}$ & 6: & $\begin{array}{l}\mathbf{4 . 4 6 3 4} \mathbf{e V} \\
0.53852 \\
-0.33938\end{array}$ & $\begin{array}{l}\mathbf{2 7 7 . 7 8} \mathbf{~ n m} \\
58 \% \\
23 \%\end{array}$ & $\mathrm{f}=0.4636$ \\
\hline $\begin{array}{c}\text { Excited State } \\
174->180 \\
174->181 \\
174->185\end{array}$ & 7: & $\begin{array}{l}\mathbf{4 . 5 0 7 0} \mathbf{e V} \\
0.32325 \\
0.53653 \\
-0.24312\end{array}$ & $\begin{array}{l}\mathbf{2 7 5 . 0 9} \mathbf{n m} \\
21 \% \\
58 \% \\
12 \%\end{array}$ & $f=0.0635$ \\
\hline 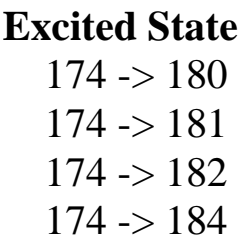 & 8: & $\begin{array}{l}\mathbf{4 . 5 9 2 6} \mathbf{e V} \\
0.25976 \\
-0.29297 \\
0.52251 \\
0.23358\end{array}$ & $\begin{array}{l}\mathbf{2 6 9 . 9 7} \mathbf{n m} \\
13 \% \\
17 \% \\
55 \% \\
11 \%\end{array}$ & $f=0.0464$ \\
\hline
\end{tabular}




\begin{tabular}{|c|c|c|c|}
\hline $\begin{array}{c}\text { Excited State } \\
174->183\end{array}$ & $\begin{array}{l}\mathbf{4 . 8 0 3 1} \mathbf{e V} \\
0.61572\end{array}$ & $\begin{array}{l}\mathbf{2 5 8 . 1 3} \mathbf{n m} \\
76 \%\end{array}$ & $f=0.3093$ \\
\hline Excited State 10: & $4.9159 \mathrm{eV}$ & $252.21 \mathrm{~nm}$ & $f=0.0292$ \\
\hline $174->184$ & 0.61437 & $75 \%$ & \\
\hline Excited State 11: & $4.9384 \mathrm{eV}$ & $251.06 \mathrm{~nm}$ & $f=0.0004$ \\
\hline $174->181$ & 0.24007 & $12 \%$ & \\
\hline $174->185$ & 0.59498 & $71 \%$ & \\
\hline Excited State 12: & $5.0114 \mathrm{eV}$ & $247.40 \mathrm{~nm}$ & $f=0.0461$ \\
\hline $174->186$ & 0.60596 & $73 \%$ & \\
\hline Excited State 13: & $5.0603 \mathrm{eV}$ & $245.01 \mathrm{~nm}$ & $f=0.0122$ \\
\hline $174->187$ & 0.61339 & $75 \%$ & \\
\hline Excited State 14: & $5.0951 \mathrm{eV}$ & $243.34 \mathrm{~nm}$ & $f=0.0170$ \\
\hline 171 -> 175 & 0.27445 & $15 \%$ & \\
\hline $173->175$ & 0.52465 & $55 \%$ & \\
\hline Excited State 15: & $5.1481 \mathrm{eV}$ & $240.83 \mathrm{~nm}$ & $f=0.0295$ \\
\hline $174->188$ & 0.62125 & $77 \%$ & \\
\hline Excited State 16: & $5.1629 \mathrm{eV}$ & $240.15 \mathrm{~nm}$ & $f=0.0084$ \\
\hline 169 -> 178 & -0.28589 & $16 \%$ & \\
\hline 171 -> 176 & 0.23866 & $11 \%$ & \\
\hline $172->175$ & 0.44849 & $40 \%$ & \\
\hline Excited State 17: & $5.2475 \mathrm{eV}$ & $236.27 \mathrm{~nm}$ & $f=0.0092$ \\
\hline $174->189$ & 0.44113 & $39 \%$ & \\
\hline 174 -> 190 & -0.31861 & $20 \%$ & \\
\hline 174 -> 191 & -0.25660 & $13 \%$ & \\
\hline Excited State 18: & $5.2712 \mathrm{eV}$ & $235.21 \mathrm{~nm}$ & $f=0.0030$ \\
\hline $170->175$ & 0.29204 & $17 \%$ & \\
\hline 171 -> 175 & -0.22522 & $10 \%$ & \\
\hline $173->175$ & 0.36952 & $27 \%$ & \\
\hline Excited State 19: & $5.3140 \mathrm{eV}$ & $233.31 \mathrm{~nm}$ & $f=0.0034$ \\
\hline $174->189$ & 0.41539 & $35 \%$ & \\
\hline 174 -> 190 & 0.42751 & $37 \%$ & \\
\hline 174 -> 191 & 0.24773 & $12 \%$ & \\
\hline Excited State 20: & $5.3718 \mathrm{eV}$ & $230.81 \mathrm{~nm}$ & $f=0.0099$ \\
\hline $172->175$ & -0.24410 & $12 \%$ & \\
\hline 173 -> 176 & 0.43682 & $38 \%$ & \\
\hline $174->191$ & 0.25289 & $13 \%$ & \\
\hline Excited State 21: & $5.3822 \mathrm{eV}$ & $230.36 \mathrm{~nm}$ & $f=0.0056$ \\
\hline $172->175$ & 0.23074 & $11 \%$ & \\
\hline $173->176$ & -0.29949 & $18 \%$ & \\
\hline 174 -> 190 & -0.32055 & $21 \%$ & \\
\hline $174->191$ & 0.35109 & $25 \%$ & \\
\hline Excited State 22: & $5.4063 \mathrm{eV}$ & $229.33 \mathrm{~nm}$ & $f=0.0004$ \\
\hline $170->175$ & 0.30383 & $18 \%$ & \\
\hline 172 -> 175 & 0.32558 & $21 \%$ & \\
\hline 172 -> 176 & 0.34953 & $24 \%$ & \\
\hline $173->176$ & 0.23443 & $11 \%$ & \\
\hline
\end{tabular}




\begin{tabular}{|c|c|c|c|}
\hline Excited State 23: & $5.4769 \mathrm{eV}$ & $226.38 \mathrm{~nm}$ & $f=0.0292$ \\
\hline 174 -> 192 & 0.50201 & $50 \%$ & \\
\hline $174->193$ & -0.28402 & $16 \%$ & \\
\hline Excited State 24: & $5.5178 \mathrm{eV}$ & $224.70 \mathrm{~nm}$ & $f=0.0167$ \\
\hline $173->177$ & 0.44510 & $40 \%$ & \\
\hline $174->193$ & -0.27096 & $15 \%$ & \\
\hline 174 -> 194 & -0.18318 & $7 \%$ & \\
\hline Excited State 25: & $5.5206 \mathrm{eV}$ & $224.58 \mathrm{~nm}$ & $f=0.0058$ \\
\hline $173->177$ & 0.31457 & $20 \%$ & \\
\hline $174->193$ & 0.36104 & $26 \%$ & \\
\hline 174 -> 194 & 0.24852 & $12 \%$ & \\
\hline Excited State 26: & $5.5682 \mathrm{eV}$ & $222.67 \mathrm{~nm}$ & $\mathbf{f}=\mathbf{0 . 0 0 4 7}$ \\
\hline $171->175$ & -0.27830 & $15 \%$ & \\
\hline 172 -> 176 & 0.44054 & $39 \%$ & \\
\hline 173 -> 177 & -0.31238 & $20 \%$ & \\
\hline Excited State 27: & $5.5964 \mathrm{eV}$ & $221.54 \mathrm{~nm}$ & $f=0.0041$ \\
\hline $173->178$ & 0.60860 & $74 \%$ & \\
\hline Excited State 28: & $5.6103 \mathrm{eV}$ & $220.99 \mathrm{~nm}$ & $\mathbf{f}=\mathbf{0 . 0 0 3 7}$ \\
\hline $174->193$ & -0.25476 & $13 \%$ & \\
\hline $174->194$ & 0.50773 & $52 \%$ & \\
\hline Excited State 29: & $5.6213 \mathrm{eV}$ & $220.56 \mathrm{~nm}$ & $f=0.0251$ \\
\hline $171->175$ & 0.34748 & $24 \%$ & \\
\hline $172->177$ & 0.44481 & $40 \%$ & \\
\hline Excited State 30: & $5.6691 \mathrm{eV}$ & $218.70 \mathrm{~nm}$ & $f=0.0069$ \\
\hline $174->195$ & -0.36538 & $27 \%$ & \\
\hline $174->196$ & -0.27913 & $16 \%$ & \\
\hline $174->197$ & 0.40407 & $33 \%$ & \\
\hline Excited State 31: & $5.6867 \mathrm{eV}$ & $218.02 \mathrm{~nm}$ & $\mathbf{f}=\mathbf{0 . 0 2 2 2}$ \\
\hline 169 -> 175 & 0.23534 & $11 \%$ & \\
\hline $170->175$ & 0.35938 & $26 \%$ & \\
\hline $170->176$ & -0.35617 & $25 \%$ & \\
\hline Excited State 32: & $5.7189 \mathrm{eV}$ & $216.80 \mathrm{~nm}$ & $f=0.0106$ \\
\hline $174->195$ & 0.44974 & $40 \%$ & \\
\hline $174->197$ & 0.43656 & $38 \%$ & \\
\hline Excited State 33: & $5.7435 \mathrm{eV}$ & $215.87 \mathrm{~nm}$ & $f=0.0010$ \\
\hline $171->176$ & -0.38069 & $29 \%$ & \\
\hline $172->177$ & 0.40234 & $32 \%$ & \\
\hline Excited State 34: & $5.7492 \mathrm{eV}$ & $215.65 \mathrm{~nm}$ & $f=0.0131$ \\
\hline $174->196$ & 0.54308 & $59 \%$ & \\
\hline Excited State 35: & $5.7883 \mathrm{eV}$ & $214.20 \mathrm{~nm}$ & $f=0.0092$ \\
\hline 169 -> 175 & 0.47524 & $45 \%$ & \\
\hline $172->178$ & 0.35237 & $25 \%$ & \\
\hline Excited State 36: & $5.8121 \mathrm{eV}$ & $213.32 \mathrm{~nm}$ & $f=0.0071$ \\
\hline $174->198$ & 0.57711 & $67 \%$ & \\
\hline Excited State 37: & $5.8437 \mathrm{eV}$ & $212.17 \mathrm{~nm}$ & $\mathbf{f}=\mathbf{0 . 0 0 5 7}$ \\
\hline $174->199$ & 0.47097 & $44 \%$ & \\
\hline
\end{tabular}




\begin{tabular}{|c|c|c|c|}
\hline Excited State 38: & $5.8469 \mathrm{eV}$ & $212.05 \mathrm{~nm}$ & $f=0.0101$ \\
\hline 167 -> 175 & 0.40404 & $33 \%$ & \\
\hline $170->176$ & 0.37996 & $29 \%$ & \\
\hline $174->199$ & -0.23967 & $11 \%$ & \\
\hline Excited State 39: & $5.8700 \mathrm{eV}$ & $211.22 \mathrm{~nm}$ & $f=0.0597$ \\
\hline 171 -> 177 & -0.25333 & $13 \%$ & \\
\hline $172->178$ & 0.41660 & $35 \%$ & \\
\hline Excited State 40: & $5.9080 \mathrm{eV}$ & $209.86 \mathrm{~nm}$ & $\mathrm{f}=\mathbf{0 . 0 3 2 4}$ \\
\hline $168->175$ & 0.23332 & $11 \%$ & \\
\hline 169 -> 175 & -0.22442 & $10 \%$ & \\
\hline 171 -> 177 & 0.40918 & $33 \%$ & \\
\hline 172 -> 178 & 0.29218 & $17 \%$ & \\
\hline Excited State 41: & $5.9221 \mathrm{eV}$ & $209.36 \mathrm{~nm}$ & $f=0.0023$ \\
\hline $168->175$ & -0.24105 & $12 \%$ & \\
\hline $170->177$ & 0.49825 & $50 \%$ & \\
\hline $171->177$ & 0.26454 & $14 \%$ & \\
\hline Excited State 42: & $5.9321 \mathrm{eV}$ & $209.01 \mathrm{~nm}$ & $f=0.0057$ \\
\hline $174->200$ & 0.58799 & $69 \%$ & \\
\hline Excited State 43: & $5.9815 \mathrm{eV}$ & $207.28 \mathrm{~nm}$ & $f=0.0016$ \\
\hline 169 -> 176 & 0.47336 & $45 \%$ & \\
\hline 171 -> 178 & 0.42839 & $37 \%$ & \\
\hline Excited State 44: & $6.0170 \mathrm{eV}$ & $206.06 \mathrm{~nm}$ & $\mathrm{f}=\mathbf{0 . 0 5 3 6}$ \\
\hline 167 -> 175 & -0.26944 & $15 \%$ & \\
\hline 167 -> 176 & 0.22150 & $10 \%$ & \\
\hline $170->178$ & 0.50856 & $52 \%$ & \\
\hline Excited State 45: & $6.0421 \mathrm{eV}$ & $205.20 \mathrm{~nm}$ & $f=0.0048$ \\
\hline $174->202$ & 0.62653 & $79 \%$ & \\
\hline Excited State 46: & $6.0560 \mathrm{eV}$ & $204.73 \mathrm{~nm}$ & $\mathrm{f}=\mathbf{0 . 0 4 2 5}$ \\
\hline 167 -> 176 & -0.27016 & $15 \%$ & \\
\hline 168 -> 175 & -0.25774 & $13 \%$ & \\
\hline $170->177$ & -0.23949 & $11 \%$ & \\
\hline $170->178$ & 0.41621 & $35 \%$ & \\
\hline Excited State 47: & $6.0631 \mathrm{eV}$ & $204.49 \mathrm{~nm}$ & $f=0.0029$ \\
\hline 174 -> 201 & 0.61450 & $76 \%$ & \\
\hline Excited State 48: & $6.1232 \mathrm{eV}$ & $202.48 \mathrm{~nm}$ & $f=0.0297$ \\
\hline 169 -> 176 & 0.30664 & $19 \%$ & \\
\hline 169 -> 177 & 0.51930 & $54 \%$ & \\
\hline 171 -> 178 & -0.23489 & $11 \%$ & \\
\hline Excited State 49: & $6.1716 \mathrm{eV}$ & $200.89 \mathrm{~nm}$ & $f=0.0623$ \\
\hline 167 -> 176 & 0.35727 & $26 \%$ & \\
\hline $168->175$ & -0.21942 & $10 \%$ & \\
\hline 168 -> 176 & 0.36827 & $27 \%$ & \\
\hline 168 -> 177 & -0.31897 & $20 \%$ & \\
\hline Excited State 50: & $6.1816 \mathrm{eV}$ & $200.57 \mathrm{~nm}$ & $f=0.0025$ \\
\hline $174->203$ & 0.50812 & $52 \%$ & \\
\hline 174 -> 204 & -0.30264 & $18 \%$ & \\
\hline
\end{tabular}


$174->205 \quad 0.26706 \quad 14 \%$

Table S23. First 50 excited states of III + B calculated at the M06-2X/aug-cc-pVDZ/ IEFPCM(acetonitrile) level of theory.

\begin{tabular}{|c|c|c|c|c|}
\hline Excited State & 1: & $3.7482 \mathrm{eV}$ & $330.79 \mathrm{~nm}$ & $f=0.0296$ \\
\hline $174->175$ & & 0.56290 & $63 \%$ & \\
\hline 174 -> 176 & & 0.34516 & $24 \%$ & \\
\hline $174->177$ & & 0.22293 & $10 \%$ & \\
\hline Excited State & 2: & $3.9316 \mathrm{eV}$ & $315.35 \mathrm{~nm}$ & $\mathbf{f}=\mathbf{0 . 0 0 4 7}$ \\
\hline $174->175$ & & -0.29659 & $18 \%$ & \\
\hline 174 -> 176 & & 0.45408 & $41 \%$ & \\
\hline $174->178$ & & 0.40967 & $34 \%$ & \\
\hline Excited State & 3: & $4.1816 \mathrm{eV}$ & $296.50 \mathrm{~nm}$ & $f=0.0194$ \\
\hline $174->175$ & & 0.26887 & $14 \%$ & \\
\hline 174 -> 176 & & -0.32763 & $21 \%$ & \\
\hline $174->178$ & & 0.55413 & $61 \%$ & \\
\hline Excited State & 4: & $4.2706 \mathrm{eV}$ & $290.32 \mathrm{~nm}$ & $f=0.0102$ \\
\hline $174->176$ & & -0.23229 & $11 \%$ & \\
\hline 174 -> 177 & & 0.63855 & $82 \%$ & \\
\hline Excited State & 5: & $4.3262 \mathrm{eV}$ & $286.59 \mathrm{~nm}$ & $f=0.1118$ \\
\hline 174 -> 179 & & 0.47360 & $45 \%$ & \\
\hline $174->180$ & & 0.25718 & $13 \%$ & \\
\hline 174 -> 182 & & -0.34856 & $24 \%$ & \\
\hline Excited State & 6: & $4.5512 \mathrm{eV}$ & $272.42 \mathrm{~nm}$ & $f=0.2927$ \\
\hline $174->181$ & & 0.46969 & $44 \%$ & \\
\hline 174 -> 184 & & -0.27145 & $15 \%$ & \\
\hline Excited State & 7: & $4.6714 \mathrm{eV}$ & $265.41 \mathrm{~nm}$ & $f=0.1391$ \\
\hline $174->180$ & & 0.28686 & $16 \%$ & \\
\hline 174 -> 182 & & 0.33977 & $23 \%$ & \\
\hline 174 -> 184 & & -0.24590 & $12 \%$ & \\
\hline $174->185$ & & -0.24731 & $12 \%$ & \\
\hline Excited State & 8: & $4.8115 \mathrm{eV}$ & $257.68 \mathrm{~nm}$ & $\mathrm{f}=\mathbf{0 . 4 2 4 8}$ \\
\hline $174->180$ & & 0.38362 & $29 \%$ & \\
\hline $174->183$ & & -0.33931 & $23 \%$ & \\
\hline 174 -> 191 & & -0.22445 & $10 \%$ & \\
\hline Excited State & 9: & $4.9980 \mathrm{eV}$ & $248.07 \mathrm{~nm}$ & $f=0.1811$ \\
\hline 174 -> 179 & & 0.27961 & $16 \%$ & \\
\hline $174->180$ & & -0.24617 & $12 \%$ & \\
\hline $174->182$ & & 0.22671 & $10 \%$ & \\
\hline 174 -> 185 & & -0.22767 & $10 \%$ & \\
\hline 174 -> 188 & & -0.22245 & $10 \%$ & \\
\hline Excited State & 10: & $5.1534 \mathrm{eV}$ & $240.59 \mathrm{~nm}$ & $f=0.0071$ \\
\hline 174 -> 184 & & 0.24292 & $12 \%$ & \\
\hline 174 -> 187 & & 0.40889 & $33 \%$ & \\
\hline Excited State & 11: & $5.1939 \mathrm{eV}$ & $238.71 \mathrm{~nm}$ & $f=0.0218$ \\
\hline
\end{tabular}




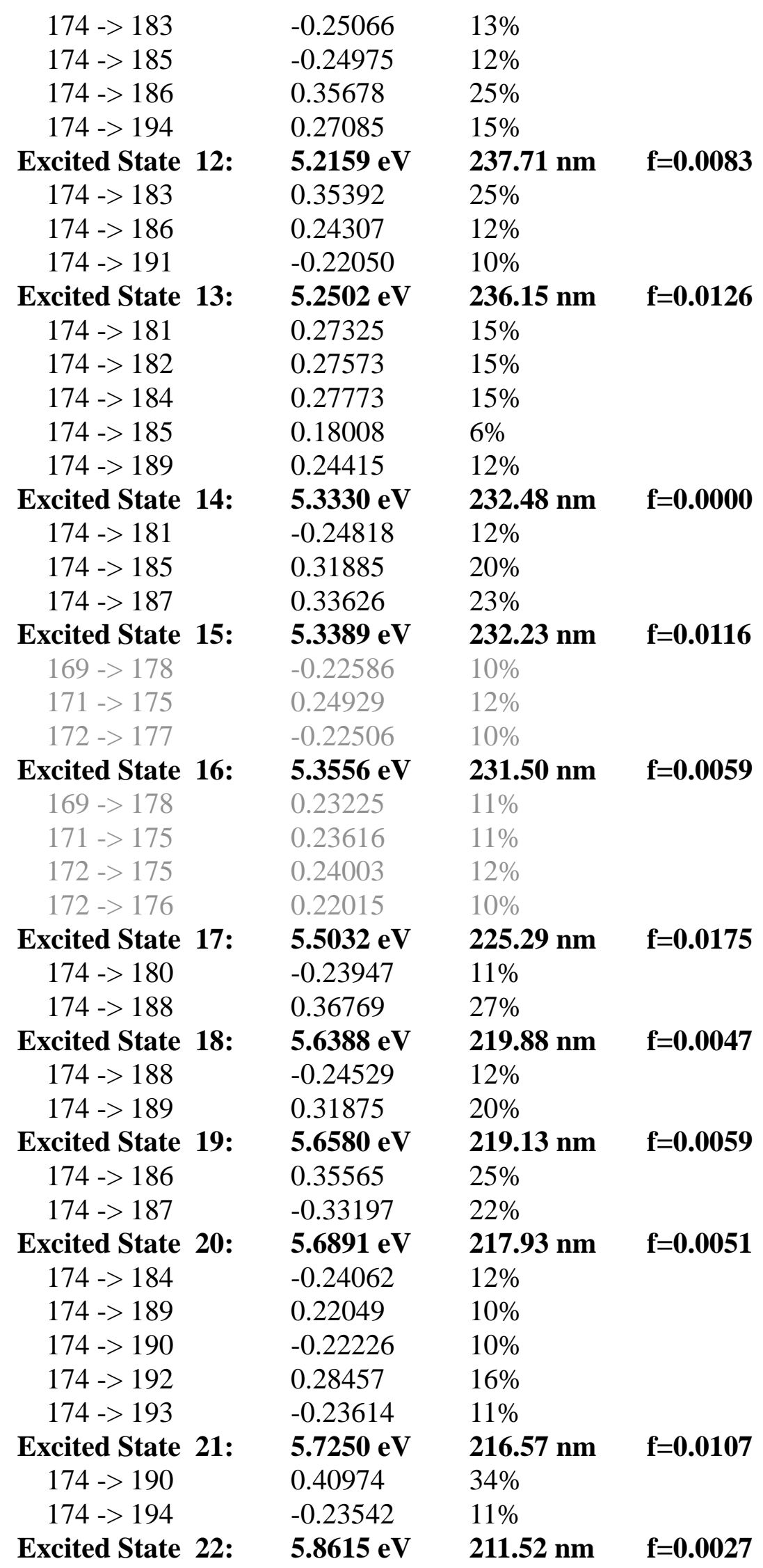




$\begin{array}{lll}174 \text {-> } 191 & 0.28293 & 16 \% \\ 174 \text {-> } 192 & 0.29672 & 18 \% \\ 174 \text {-> } 193 & 0.40129 & 32 \%\end{array}$

\begin{tabular}{|c|c|c|c|}
\hline Excited State 23: & $5.8897 \mathrm{eV}$ & $210.51 \mathrm{~nm}$ & $f=0.0085$ \\
\hline $174->195$ & 0.25838 & $13 \%$ & \\
\hline $174->196$ & 0.25787 & $13 \%$ & \\
\hline $174->197$ & 0.33351 & $22 \%$ & \\
\hline Excited State 24: & $5.9868 \mathrm{eV}$ & $207.10 \mathrm{~nm}$ & $f=0.0092$ \\
\hline $174->195$ & 0.52432 & $55 \%$ & \\
\hline $174->197$ & -0.24135 & $12 \%$ & \\
\hline Excited State 25: & $6.0040 \mathrm{eV}$ & $206.50 \mathrm{~nm}$ & $f=0.0069$ \\
\hline $174->196$ & 0.34658 & $24 \%$ & \\
\hline $174->203$ & -0.22125 & $10 \%$ & \\
\hline Excited State 26: & $6.0129 \mathrm{eV}$ & $206.20 \mathrm{~nm}$ & $\mathbf{f}=\mathbf{0 . 0 0 7 7}$ \\
\hline 169 -> 175 & 0.27801 & $15 \%$ & \\
\hline 172 -> 178 & -0.24366 & $12 \%$ & \\
\hline $173->175$ & 0.23845 & $11 \%$ & \\
\hline
\end{tabular}

\begin{tabular}{|c|c|c|}
\hline Excited State 27: & $6.0594 \mathrm{eV}$ & $204.62 \mathrm{~nm}$ \\
\hline $174->198$ & 0.36281 & $26 \%$ \\
\hline 174 -> 201 & -0.24790 & $12 \%$ \\
\hline
\end{tabular}

Excited State 28: $\quad \mathbf{6 . 0 9 6 1} \mathrm{eV} \quad \mathbf{2 0 3 . 3 8} \mathbf{~ n m} \quad \mathrm{f}=\mathbf{0 . 0 0 1 5}$

$\begin{array}{lll}168->175 & 0.25888 & 13 \% \\ 169->176 & 0.26311 & 14 \% \\ 170->175 & 0.21904 & 10 \% \\ 171->177 & -0.24842 & 12 \%\end{array}$

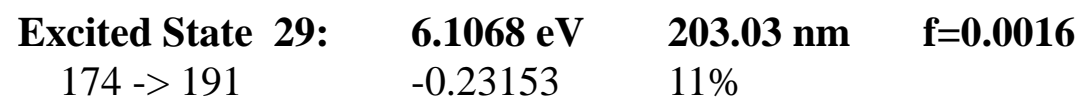

$174->192 \quad 0.29658 \quad 18 \%$

$174->197 \quad 0.28595 \quad 16 \%$

174 -> $199 \quad 0.23271 \quad 11 \%$

Excited State 30: $\quad 6.1673 \mathrm{eV} \quad \mathbf{2 0 1 . 0 3} \mathrm{nm} \quad f=0.0013$

$174->198 \quad-0.22193 \quad 10 \%$

$174->200 \quad 0.37589 \quad 28 \%$

Table S24. First 50 excited states of III + C.

\begin{tabular}{|c|c|c|c|c|}
\hline Excited State & 1: & $2.9678 \mathrm{eV}$ & $417.77 \mathrm{~nm}$ & $f=0.0004$ \\
\hline $179->180$ & & 0.65734 & $86 \%$ & \\
\hline Excited State & 2: & $3.1923 \mathrm{eV}$ & $388.38 \mathrm{~nm}$ & $f=0.0008$ \\
\hline 179 -> 181 & & 0.60165 & $72 \%$ & \\
\hline 179 -> 183 & & 0.24639 & $12 \%$ & \\
\hline Excited State & 3: & $3.3307 \mathrm{eV}$ & $372.25 \mathrm{~nm}$ & $f=0.0065$ \\
\hline 179 -> 183 & & 0.65571 & $86 \%$ & \\
\hline Excited State & 4: & $3.4059 \mathrm{eV}$ & $364.02 \mathrm{~nm}$ & $f=0.0440$ \\
\hline
\end{tabular}




\begin{tabular}{|c|c|c|c|c|}
\hline $179->181$ & & 0.22706 & $10 \%$ & \\
\hline $179->182$ & & 0.66507 & $88 \%$ & \\
\hline Excited State & 5: & $3.9642 \mathrm{eV}$ & $312.76 \mathrm{~nm}$ & $f=0.4766$ \\
\hline 179 -> 184 & & 0.66753 & $89 \%$ & \\
\hline Excited State & 6: & $4.2411 \mathrm{eV}$ & $292.34 \mathrm{~nm}$ & $f=0.2572$ \\
\hline $179->185$ & & 0.63023 & $79 \%$ & \\
\hline Excited State & 7: & $4.4690 \mathrm{eV}$ & $277.43 \mathrm{~nm}$ & $\mathbf{f}=\mathbf{0 . 0 3 3 4}$ \\
\hline $179->186$ & & 0.60974 & $74 \%$ & \\
\hline Excited State & 8: & $4.7626 \mathrm{eV}$ & $260.33 \mathrm{~nm}$ & $f=0.0072$ \\
\hline $179->187$ & & 0.62102 & $77 \%$ & \\
\hline 179 -> 189 & & -0.23362 & $11 \%$ & \\
\hline Excited State & 9: & $4.7689 \mathrm{eV}$ & $259.99 \mathrm{~nm}$ & $\mathbf{f}=\mathbf{0 . 0 0 7 4}$ \\
\hline 179 -> 188 & & 0.62424 & $78 \%$ & \\
\hline Excited State & 10: & $4.9081 \mathrm{eV}$ & $252.61 \mathrm{~nm}$ & $\mathbf{f}=\mathbf{0 . 0 2 7 5}$ \\
\hline 179 -> 186 & & 0.22612 & $10 \%$ & \\
\hline $179->189$ & & 0.60599 & $73 \%$ & \\
\hline Excited State & 11: & $5.0789 \mathrm{eV}$ & $244.12 \mathrm{~nm}$ & $f=0.0075$ \\
\hline 177 -> 180 & & 0.46165 & $43 \%$ & \\
\hline 178 -> 180 & & -0.34848 & $24 \%$ & \\
\hline Excited State & 12: & $5.0931 \mathrm{eV}$ & $243.43 \mathrm{~nm}$ & $f=0.0020$ \\
\hline 177 -> 180 & & 0.24786 & $12 \%$ & \\
\hline $178->180$ & & 0.59349 & $70 \%$ & \\
\hline Excited State & 13: & $5.1280 \mathrm{eV}$ & $241.78 \mathrm{~nm}$ & $\mathbf{f}=\mathbf{0 . 0 0 0 4}$ \\
\hline $179->190$ & & 0.59993 & $72 \%$ & \\
\hline 179 -> 191 & & -0.22902 & $10 \%$ & \\
\hline Excited State & 14: & $5.1873 \mathrm{eV}$ & $239.01 \mathrm{~nm}$ & $f=0.0049$ \\
\hline 173 -> 183 & & -0.27999 & $16 \%$ & \\
\hline 175 -> 181 & & 0.27398 & $15 \%$ & \\
\hline 176 -> 180 & & 0.36259 & $26 \%$ & \\
\hline Excited State & 15: & $5.2026 \mathrm{eV}$ & $238.31 \mathrm{~nm}$ & $f=0.0006$ \\
\hline 179 -> 188 & & -0.23747 & $11 \%$ & \\
\hline 179 -> 191 & & 0.58224 & $68 \%$ & \\
\hline Excited State & 16: & $5.2423 \mathrm{eV}$ & $236.51 \mathrm{~nm}$ & $\mathbf{f}=\mathbf{0 . 0 1 5 0}$ \\
\hline 179 -> 192 & & 0.53797 & $58 \%$ & \\
\hline 179 -> 193 & & -0.23001 & $11 \%$ & \\
\hline Excited State & 17: & $5.2694 \mathrm{eV}$ & $235.29 \mathrm{~nm}$ & $f=0.0074$ \\
\hline 179 -> 192 & & 0.29517 & $17 \%$ & \\
\hline 179 -> 193 & & 0.47171 & $45 \%$ & \\
\hline 179 -> 194 & & -0.33532 & $22 \%$ & \\
\hline Excited State & 18: & $5.2819 \mathrm{eV}$ & $234.73 \mathrm{~nm}$ & $\mathbf{f}=\mathbf{0 . 0 0 3 1}$ \\
\hline 174 -> 180 & & -0.28060 & $16 \%$ & \\
\hline 177 -> 180 & & 0.36746 & $27 \%$ & \\
\hline Excited State & 19: & $5.3244 \mathrm{eV}$ & $232.86 \mathrm{~nm}$ & $\mathbf{f}=\mathbf{0 . 0 0 1 0}$ \\
\hline 178 -> 181 & & 0.65014 & $85 \%$ & \\
\hline Excited State & 20: & $5.3432 \mathrm{eV}$ & $232.04 \mathrm{~nm}$ & $f=0.0215$ \\
\hline 179 -> 193 & & 0.41382 & $34 \%$ & \\
\hline
\end{tabular}




\begin{tabular}{|c|c|c|c|}
\hline 179 -> 194 & 0.48394 & $47 \%$ & \\
\hline Excited State 21: & $5.3869 \mathrm{eV}$ & $230.16 \mathrm{~nm}$ & $f=0.0042$ \\
\hline $176->180$ & 0.43682 & $38 \%$ & \\
\hline $177->181$ & 0.39116 & $31 \%$ & \\
\hline Excited State 22: & $5.4175 \mathrm{eV}$ & $228.86 \mathrm{~nm}$ & $f=0.0042$ \\
\hline 174 -> 180 & -0.34716 & $24 \%$ & \\
\hline $176->181$ & -0.24934 & $12 \%$ & \\
\hline 177 -> 181 & 0.42130 & $35 \%$ & \\
\hline Excited State 23: & $5.4398 \mathrm{eV}$ & $227.92 \mathrm{~nm}$ & $f=0.0013$ \\
\hline 179 -> 195 & -0.29558 & $17 \%$ & \\
\hline 179 -> 196 & 0.51552 & $53 \%$ & \\
\hline 179 -> 199 & 0.22057 & $10 \%$ & \\
\hline Excited State 24: & $5.4687 \mathrm{eV}$ & $226.72 \mathrm{~nm}$ & $f=0.0092$ \\
\hline 178 -> 182 & -0.26978 & $15 \%$ & \\
\hline 178 -> 183 & 0.59196 & $70 \%$ & \\
\hline Excited State 25: & $5.4847 \mathrm{eV}$ & $226.06 \mathrm{~nm}$ & $f=0.0035$ \\
\hline 178 -> 182 & 0.57624 & $66 \%$ & \\
\hline 178 -> 183 & 0.34250 & $23 \%$ & \\
\hline Excited State 26: & $5.5247 \mathrm{eV}$ & $224.42 \mathrm{~nm}$ & $f=0.0063$ \\
\hline 175 -> 180 & 0.23363 & $11 \%$ & \\
\hline 177 -> 182 & 0.51259 & $53 \%$ & \\
\hline Excited State 27: & $5.5453 \mathrm{eV}$ & $223.58 \mathrm{~nm}$ & $f=0.0114$ \\
\hline 177 -> 183 & 0.61732 & $76 \%$ & \\
\hline Excited State 28: & $5.5636 \mathrm{eV}$ & $222.85 \mathrm{~nm}$ & $\mathbf{f}=\mathbf{0 . 0 0 2 7}$ \\
\hline 179 -> 195 & 0.51127 & $52 \%$ & \\
\hline 179 -> 196 & 0.34459 & $24 \%$ & \\
\hline Excited State 29: & $5.5867 \mathrm{eV}$ & $221.93 \mathrm{~nm}$ & $f=0.0022$ \\
\hline 175 -> 180 & -0.38339 & $29 \%$ & \\
\hline $176->181$ & 0.38473 & $30 \%$ & \\
\hline 177 -> 182 & 0.32037 & $21 \%$ & \\
\hline Excited State 30: & $5.6145 \mathrm{eV}$ & $220.83 \mathrm{~nm}$ & $f=0.0510$ \\
\hline 177 -> 185 & -0.23439 & $11 \%$ & \\
\hline 178 -> 184 & 0.53232 & $57 \%$ & \\
\hline Excited State 31: & $5.6365 \mathrm{eV}$ & $219.97 \mathrm{~nm}$ & $f=0.0026$ \\
\hline 175 -> 180 & 0.23778 & $11 \%$ & \\
\hline 176 -> 181 & 0.29090 & $17 \%$ & \\
\hline $176->182$ & 0.28377 & $16 \%$ & \\
\hline 179 -> 199 & -0.25828 & $13 \%$ & \\
\hline Excited State 32: & $5.6377 \mathrm{eV}$ & $219.92 \mathrm{~nm}$ & $f=0.0243$ \\
\hline 179 -> 197 & 0.27484 & $15 \%$ & \\
\hline 179 -> 199 & 0.35697 & $25 \%$ & \\
\hline Excited State 33: & $5.6830 \mathrm{eV}$ & $218.17 \mathrm{~nm}$ & $f=0.0101$ \\
\hline 179 -> 197 & 0.50215 & $50 \%$ & \\
\hline 179 -> 199 & -0.38310 & $29 \%$ & \\
\hline Excited State 34: & $5.7339 \mathrm{eV}$ & $216.23 \mathrm{~nm}$ & $f=0.0116$ \\
\hline 174 -> 180 & -0.21824 & $10 \%$ & \\
\hline
\end{tabular}




\begin{tabular}{|c|c|c|c|}
\hline $175->181$ & -0.27271 & $15 \%$ & \\
\hline 176 -> 181 & -0.22749 & $10 \%$ & \\
\hline 176 -> 182 & 0.45986 & $42 \%$ & \\
\hline Excited State 35: & $5.7418 \mathrm{eV}$ & $215.93 \mathrm{~nm}$ & $f=0.0028$ \\
\hline $179->198$ & 0.56734 & $64 \%$ & \\
\hline Excited State 36: & $5.7501 \mathrm{eV}$ & $215.62 \mathrm{~nm}$ & $f=0.0065$ \\
\hline $171->180$ & 0.25372 & $13 \%$ & \\
\hline 173 -> 180 & -0.23630 & $11 \%$ & \\
\hline $174->180$ & -0.24610 & $12 \%$ & \\
\hline $174->181$ & 0.38515 & $30 \%$ & \\
\hline Excited State 37: & $5.8012 \mathrm{eV}$ & $213.72 \mathrm{~nm}$ & $f=0.0010$ \\
\hline 173 -> 180 & 0.34123 & $23 \%$ & \\
\hline $176->183$ & 0.50205 & $50 \%$ & \\
\hline Excited State 38: & $5.8066 \mathrm{eV}$ & $213.52 \mathrm{~nm}$ & $f=0.0059$ \\
\hline 179 -> 200 & 0.63489 & $81 \%$ & \\
\hline Excited State 39: & $5.8472 \mathrm{eV}$ & $212.04 \mathrm{~nm}$ & $f=0.0249$ \\
\hline $171->180$ & -0.25742 & $13 \%$ & \\
\hline $173->180$ & -0.30746 & $19 \%$ & \\
\hline $176->183$ & 0.34899 & $24 \%$ & \\
\hline Excited State 40: & $5.8544 \mathrm{eV}$ & $211.78 \mathrm{~nm}$ & $f=0.0100$ \\
\hline 179 -> 201 & 0.36493 & $27 \%$ & \\
\hline $179->202$ & 0.46231 & $43 \%$ & \\
\hline Excited State 41: & $5.8757 \mathrm{eV}$ & $211.01 \mathrm{~nm}$ & $f=0.0384$ \\
\hline 171 -> 180 & -0.28458 & $16 \%$ & \\
\hline 174 -> 181 & 0.38447 & $30 \%$ & \\
\hline Excited State 42: & $5.9071 \mathrm{eV}$ & $209.89 \mathrm{~nm}$ & $\mathbf{f}=\mathbf{0 . 0 0 1 3}$ \\
\hline $172->180$ & -0.25231 & $13 \%$ & \\
\hline 175 -> 182 & 0.49648 & $49 \%$ & \\
\hline Excited State 43: & $5.9257 \mathrm{eV}$ & $209.23 \mathrm{~nm}$ & $f=0.0049$ \\
\hline 172 -> 180 & 0.29787 & $18 \%$ & \\
\hline 174 -> 181 & -0.27062 & $15 \%$ & \\
\hline $174->182$ & 0.42370 & $36 \%$ & \\
\hline Excited State 44: & $5.9267 \mathrm{eV}$ & $209.20 \mathrm{~nm}$ & $f=0.0101$ \\
\hline 179 -> 201 & 0.51406 & $53 \%$ & \\
\hline 179 -> 202 & -0.31632 & $20 \%$ & \\
\hline Excited State 45: & $5.9688 \mathrm{eV}$ & $207.72 \mathrm{~nm}$ & $f=0.0089$ \\
\hline 179 -> 203 & 0.55951 & $63 \%$ & \\
\hline Excited State 46: & $5.9770 \mathrm{eV}$ & $207.44 \mathrm{~nm}$ & $f=0.0299$ \\
\hline 173 -> 180 & 0.24755 & $12 \%$ & \\
\hline 173 -> 181 & 0.34447 & $24 \%$ & \\
\hline 175 -> 183 & 0.39074 & $31 \%$ & \\
\hline Excited State 47: & $6.0170 \mathrm{eV}$ & $206.06 \mathrm{~nm}$ & $f=0.0025$ \\
\hline 177 -> 184 & 0.51094 & $52 \%$ & \\
\hline 179 -> 204 & 0.22944 & $11 \%$ & \\
\hline Excited State 48: & $6.0228 \mathrm{eV}$ & $205.86 \mathrm{~nm}$ & $\mathbf{f}=\mathbf{0 . 0 2 3 3}$ \\
\hline 171 -> 180 & 0.23955 & $11 \%$ & \\
\hline
\end{tabular}




\begin{tabular}{|c|c|c|c|}
\hline $174->183$ & 0.58095 & $68 \%$ & \\
\hline Excited State 49: & $6.0775 \mathrm{eV}$ & $204.01 \mathrm{~nm}$ & $f=0.1851$ \\
\hline $171->181$ & -0.27874 & $16 \%$ & \\
\hline $172->180$ & -0.27857 & $16 \%$ & \\
\hline 174 -> 182 & 0.33469 & $22 \%$ & \\
\hline Excited State 50: & $6.0945 \mathrm{eV}$ & $203.44 \mathrm{~nm}$ & $f=0.0499$ \\
\hline 178 -> 185 & -0.29545 & $17 \%$ & \\
\hline 179 -> 204 & 0.44617 & $40 \%$ & \\
\hline
\end{tabular}

Table S25. First 50 excited states of IV + A.

\begin{tabular}{|c|c|c|c|c|}
\hline Excited State & 1: & $4.2821 \mathrm{eV}$ & $289.54 \mathrm{~nm}$ & $f=0.0040$ \\
\hline $82->83$ & & 0.60873 & $74 \%$ & \\
\hline $82->84$ & & -0.35397 & $25 \%$ & \\
\hline Excited State & 2: & $4.2974 \mathrm{eV}$ & $288.51 \mathrm{~nm}$ & $f=0.0080$ \\
\hline $82->83$ & & 0.35119 & $25 \%$ & \\
\hline $82->84$ & & 0.60693 & $74 \%$ & \\
\hline Excited State & 3: & $4.6726 \mathrm{eV}$ & $265.34 \mathrm{~nm}$ & $f=0.0139$ \\
\hline $82->85$ & & 0.62634 & $78 \%$ & \\
\hline $82->87$ & & 0.21940 & $10 \%$ & \\
\hline Excited State & 4: & $4.8144 \mathrm{eV}$ & $257.53 \mathrm{~nm}$ & $f=0.0143$ \\
\hline $82->86$ & & 0.29557 & $17 \%$ & \\
\hline $82->87$ & & 0.44116 & $39 \%$ & \\
\hline $82->88$ & & 0.35829 & $26 \%$ & \\
\hline Excited State & 5: & $4.9990 \mathrm{eV}$ & $248.02 \mathrm{~nm}$ & $f=0.0079$ \\
\hline $82->86$ & & -0.31241 & $20 \%$ & \\
\hline $82->87$ & & 0.45454 & $41 \%$ & \\
\hline $82->88$ & & -0.36806 & $27 \%$ & \\
\hline Excited State & 6: & $5.0482 \mathrm{eV}$ & $245.60 \mathrm{~nm}$ & $f=0.0060$ \\
\hline $82->86$ & & 0.51816 & $54 \%$ & \\
\hline $82->88$ & & -0.38919 & $30 \%$ & \\
\hline Excited State & 7: & $5.1435 \mathrm{eV}$ & $241.05 \mathrm{~nm}$ & $f=0.0052$ \\
\hline $82->89$ & & -0.38840 & $30 \%$ & \\
\hline $82->91$ & & 0.42489 & $36 \%$ & \\
\hline $82->92$ & & -0.24972 & $12 \%$ & \\
\hline Excited State & 8: & $5.3503 \mathrm{eV}$ & $231.74 \mathrm{~nm}$ & $f=0.0906$ \\
\hline $82->89$ & & 0.42686 & $36 \%$ & \\
\hline $82->91$ & & 0.35832 & $26 \%$ & \\
\hline Excited State & 9: & $5.3599 \mathrm{eV}$ & $231.32 \mathrm{~nm}$ & $\mathbf{f}=\mathbf{0 . 0 1 0 7}$ \\
\hline 79 -> 83 & & 0.26510 & $14 \%$ & \\
\hline 79 -> 84 & & -0.28113 & $16 \%$ & \\
\hline $81->83$ & & 0.35546 & $25 \%$ & \\
\hline $81->84$ & & 0.32034 & $21 \%$ & \\
\hline
\end{tabular}




\begin{tabular}{|c|c|c|c|}
\hline Excited State 10: & $5.4244 \mathrm{eV}$ & $228.57 \mathrm{~nm}$ & $f=0.0001$ \\
\hline $82->90$ & 0.64302 & $83 \%$ & \\
\hline Excited State 11: & $5.4368 \mathrm{eV}$ & $228.05 \mathrm{~nm}$ & $f=0.0654$ \\
\hline $82->92$ & -0.38595 & $30 \%$ & \\
\hline $82->93$ & 0.45007 & $41 \%$ & \\
\hline Excited State 12: & $5.5113 \mathrm{eV}$ & $224.96 \mathrm{~nm}$ & $f=0.0063$ \\
\hline $82->92$ & 0.45901 & $42 \%$ & \\
\hline $82->93$ & 0.43090 & $37 \%$ & \\
\hline Excited State 13: & $5.5972 \mathrm{eV}$ & $221.51 \mathrm{~nm}$ & $f=0.0084$ \\
\hline $82->94$ & 0.65861 & $87 \%$ & \\
\hline Excited State 14: & $5.7572 \mathrm{eV}$ & $215.36 \mathrm{~nm}$ & $\mathbf{f}=\mathbf{0 . 0 8 3 9}$ \\
\hline $82->95$ & 0.63407 & $80 \%$ & \\
\hline Excited State 15: & $5.7814 \mathrm{eV}$ & $214.45 \mathrm{~nm}$ & $f=0.1128$ \\
\hline $82->96$ & 0.61202 & $75 \%$ & \\
\hline Excited State 16: & $5.8772 \mathrm{eV}$ & $210.96 \mathrm{~nm}$ & $f=0.0058$ \\
\hline $78->83$ & 0.36715 & $27 \%$ & \\
\hline 78 -> 91 & 0.30452 & $19 \%$ & \\
\hline Excited State 17: & $5.9167 \mathrm{eV}$ & $209.55 \mathrm{~nm}$ & $f=0.0384$ \\
\hline $82->97$ & 0.59409 & $71 \%$ & \\
\hline Excited State 18: & $5.9344 \mathrm{eV}$ & $208.92 \mathrm{~nm}$ & $f=0.0284$ \\
\hline 79 -> 83 & 0.26528 & $14 \%$ & \\
\hline $79->84$ & 0.22295 & $10 \%$ & \\
\hline $81->83$ & -0.35767 & $26 \%$ & \\
\hline $81->84$ & 0.37674 & $28 \%$ & \\
\hline $82->97$ & 0.25483 & $13 \%$ & \\
\hline Excited State 19: & $6.0194 \mathrm{eV}$ & $205.98 \mathrm{~nm}$ & $f=0.0056$ \\
\hline $82->98$ & 0.65464 & $86 \%$ & \\
\hline Excited State 20: & $6.0371 \mathrm{eV}$ & $205.37 \mathrm{~nm}$ & $\mathbf{f}=\mathbf{0 . 0 0 6 7}$ \\
\hline $80->83$ & 0.61108 & $75 \%$ & \\
\hline $80->84$ & -0.26740 & $14 \%$ & \\
\hline Excited State 21: & $6.0784 \mathrm{eV}$ & $203.98 \mathrm{~nm}$ & $f=0.0093$ \\
\hline $80->83$ & 0.25315 & $13 \%$ & \\
\hline $80->84$ & 0.59019 & $70 \%$ & \\
\hline Excited State 22: & $6.0856 \mathrm{eV}$ & $203.73 \mathrm{~nm}$ & $f=0.0054$ \\
\hline $82->99$ & 0.61729 & $76 \%$ & \\
\hline Excited State 23: & $6.1604 \mathrm{eV}$ & $201.26 \mathrm{~nm}$ & $f=0.0003$ \\
\hline $82->100$ & 0.57388 & $66 \%$ & \\
\hline $82->101$ & 0.31422 & $20 \%$ & \\
\hline Excited State 24: & $6.2207 \mathrm{eV}$ & $199.31 \mathrm{~nm}$ & $\mathbf{f}=\mathbf{0 . 0 3 7 1}$ \\
\hline $82->100$ & -0.31621 & $20 \%$ & \\
\hline $82->101$ & 0.59928 & $72 \%$ & \\
\hline Excited State 25: & $6.2404 \mathrm{eV}$ & $198.68 \mathrm{~nm}$ & $f=0.0069$ \\
\hline $81->85$ & 0.60406 & $73 \%$ & \\
\hline $81->88$ & 0.26358 & $14 \%$ & \\
\hline Excited State 26: & $6.3424 \mathrm{eV}$ & $195.48 \mathrm{~nm}$ & $f=0.0345$ \\
\hline
\end{tabular}




\begin{tabular}{|c|c|c|c|}
\hline $80->85$ & 0.50972 & $52 \%$ & \\
\hline Excited State 27: & $6.3655 \mathrm{eV}$ & $194.78 \mathrm{~nm}$ & $f=0.0463$ \\
\hline $80->85$ & 0.32294 & $21 \%$ & \\
\hline $81->87$ & -0.23545 & $11 \%$ & \\
\hline Excited State 28: & $6.3839 \mathrm{eV}$ & $194.21 \mathrm{~nm}$ & $f=0.0155$ \\
\hline $82->103$ & 0.61194 & $75 \%$ & \\
\hline Excited State 29: & $6.4061 \mathrm{eV}$ & $193.54 \mathrm{~nm}$ & $f=0.0026$ \\
\hline $82->102$ & 0.60446 & $73 \%$ & \\
\hline Excited State 30: & $6.4102 \mathrm{eV}$ & $193.42 \mathrm{~nm}$ & $f=0.0457$ \\
\hline $78->83$ & -0.23620 & $11 \%$ & \\
\hline $78->84$ & 0.32254 & $21 \%$ & \\
\hline $79->85$ & 0.40462 & $33 \%$ & \\
\hline Excited State 31: & $6.4335 \mathrm{eV}$ & $192.72 \mathrm{~nm}$ & $f=0.0212$ \\
\hline $78->83$ & -0.23564 & $11 \%$ & \\
\hline $78->84$ & 0.39641 & $31 \%$ & \\
\hline $79->85$ & -0.31486 & $20 \%$ & \\
\hline Excited State 32: & $6.4657 \mathrm{eV}$ & $191.76 \mathrm{~nm}$ & $f=0.0196$ \\
\hline $82->104$ & 0.62420 & $78 \%$ & \\
\hline Excited State 33: & $6.5000 \mathrm{eV}$ & $190.75 \mathrm{~nm}$ & $f=0.1446$ \\
\hline $82->105$ & 0.55973 & $63 \%$ & \\
\hline $82->106$ & -0.23175 & $11 \%$ & \\
\hline Excited State 34: & $6.5273 \mathrm{eV}$ & $189.95 \mathrm{~nm}$ & $f=0.1768$ \\
\hline $79->84$ & 0.33075 & $22 \%$ & \\
\hline $81->83$ & 0.24121 & $12 \%$ & \\
\hline $82->105$ & 0.27131 & $15 \%$ & \\
\hline Excited State 35: & $6.5705 \mathrm{eV}$ & $188.70 \mathrm{~nm}$ & $f=0.0115$ \\
\hline $82->105$ & 0.25132 & $13 \%$ & \\
\hline $82->106$ & 0.44142 & $39 \%$ & \\
\hline $82->107$ & 0.30574 & $19 \%$ & \\
\hline Excited State 36: & $6.5792 \mathrm{eV}$ & $188.45 \mathrm{~nm}$ & $f=0.0635$ \\
\hline $78->83$ & 0.41693 & $35 \%$ & \\
\hline $78->84$ & 0.27463 & $15 \%$ & \\
\hline Excited State 37: & $6.6274 \mathrm{eV}$ & $187.08 \mathrm{~nm}$ & $\mathbf{f}=\mathbf{0 . 0 8 9 2}$ \\
\hline $81->87$ & 0.40168 & $32 \%$ & \\
\hline Excited State 38: & $6.6594 \mathrm{eV}$ & $186.18 \mathrm{~nm}$ & $f=0.0584$ \\
\hline $81 \rightarrow 86$ & 0.51609 & $53 \%$ & \\
\hline Excited State 39: & $6.6801 \mathrm{eV}$ & $185.60 \mathrm{~nm}$ & $f=0.0634$ \\
\hline $80->87$ & -0.22826 & $10 \%$ & \\
\hline $81->85$ & -0.23247 & $11 \%$ & \\
\hline $81->88$ & 0.48071 & $46 \%$ & \\
\hline Excited State 40: & $6.6858 \mathrm{eV}$ & $185.45 \mathrm{~nm}$ & $f=0.0063$ \\
\hline $82->106$ & -0.35938 & $26 \%$ & \\
\hline $82->107$ & 0.55217 & $61 \%$ & \\
\hline Excited State 41: & $6.7095 \mathrm{eV}$ & $184.79 \mathrm{~nm}$ & $f=0.1764$ \\
\hline 80 -> 87 & 0.34386 & $24 \%$ & \\
\hline
\end{tabular}




\begin{tabular}{|c|c|c|c|}
\hline $81->87$ & -0.22330 & $10 \%$ & \\
\hline Excited State 42: & $6.7350 \mathrm{eV}$ & $184.09 \mathrm{~nm}$ & $f=0.0014$ \\
\hline $82->108$ & 0.64253 & $83 \%$ & \\
\hline Excited State 43: & $6.7577 \mathrm{eV}$ & $183.47 \mathrm{~nm}$ & $f=0.0172$ \\
\hline $79->87$ & -0.32563 & $21 \%$ & \\
\hline 81 -> 89 & -0.22512 & $10 \%$ & \\
\hline 81 -> 91 & 0.34057 & $23 \%$ & \\
\hline Excited State 44: & $6.7803 \mathrm{eV}$ & $182.86 \mathrm{~nm}$ & $f=0.0151$ \\
\hline $79->86$ & 0.31863 & $20 \%$ & \\
\hline $80->86$ & 0.32991 & $22 \%$ & \\
\hline Excited State 45: & $6.7918 \mathrm{eV}$ & $182.55 \mathrm{~nm}$ & $f=0.0106$ \\
\hline $78->85$ & 0.38309 & $29 \%$ & \\
\hline $82->109$ & -0.27890 & $16 \%$ & \\
\hline Excited State 46: & $6.8018 \mathrm{eV}$ & $182.28 \mathrm{~nm}$ & $\mathbf{f}=\mathbf{0 . 0 3 0 7}$ \\
\hline $82->109$ & 0.52381 & $55 \%$ & \\
\hline Excited State 47: & $6.8094 \mathrm{eV}$ & $182.08 \mathrm{~nm}$ & $\mathbf{f}=\mathbf{0 . 0 1 3 0}$ \\
\hline $80->88$ & 0.55973 & $63 \%$ & \\
\hline Excited State 48: & $6.8203 \mathrm{eV}$ & $181.79 \mathrm{~nm}$ & $f=0.0410$ \\
\hline $78->85$ & 0.22228 & $10 \%$ & \\
\hline 79 -> 86 & -0.30662 & $19 \%$ & \\
\hline 79 -> 87 & 0.30968 & $19 \%$ & \\
\hline $80->85$ & 0.22615 & $10 \%$ & \\
\hline $80->86$ & 0.22871 & $10 \%$ & \\
\hline Excited State 49: & $6.8749 \mathrm{eV}$ & $180.34 \mathrm{~nm}$ & $f=0.1104$ \\
\hline $79->85$ & 0.24415 & $12 \%$ & \\
\hline $79->87$ & 0.30028 & $18 \%$ & \\
\hline $79->88$ & -0.28156 & $16 \%$ & \\
\hline Excited State 50: & $6.9057 \mathrm{eV}$ & $179.54 \mathrm{~nm}$ & $f=0.0080$ \\
\hline $82->109$ & -0.23684 & $11 \%$ & \\
\hline $82->110$ & 0.59987 & $72 \%$ & \\
\hline
\end{tabular}

Table S26. Excited states > $200 \mathrm{~nm}$ of IV + A calculated at the whPBE0/aug-cc-pVDZ/ IEFPCM(acetonitrile) level of theory.

\begin{tabular}{|c|c|c|c|c|}
\hline Excited State & 1: & $4.6131 \mathrm{eV}$ & $268.76 \mathrm{~nm}$ & $f=0.0182$ \\
\hline $82->83$ & & 0.64740 & $84 \%$ & \\
\hline $82->84$ & & 0.21564 & $9 \%$ & \\
\hline Excited State & 2: & $4.6588 \mathrm{eV}$ & $266.13 \mathrm{~nm}$ & $\mathbf{f}=\mathbf{0 . 0 0 3 7}$ \\
\hline $82->83$ & & -0.22619 & $10 \%$ & \\
\hline $82->84$ & & 0.64868 & $84 \%$ & \\
\hline Excited State & 3: & $4.9080 \mathrm{eV}$ & $252.62 \mathrm{~nm}$ & $f=0.0087$ \\
\hline $82->85$ & & 0.55108 & $61 \%$ & \\
\hline $82->87$ & & -0.32153 & $21 \%$ & \\
\hline
\end{tabular}




\begin{tabular}{|c|c|c|c|c|}
\hline Excited State & 4: & $5.0745 \mathrm{eV}$ & $244.33 \mathrm{~nm}$ & $f=0.0158$ \\
\hline 82 -> 88 & & 0.53958 & $58 \%$ & \\
\hline Excited State & 5: & $5.2800 \mathrm{eV}$ & $234.82 \mathrm{~nm}$ & $f=0.0306$ \\
\hline 82 -> 85 & & 0.22491 & $10 \%$ & \\
\hline 82 -> 86 & & -0.24035 & $12 \%$ & \\
\hline 82 -> 87 & & 0.48845 & $48 \%$ & \\
\hline 82 -> 92 & & -0.22375 & $10 \%$ & \\
\hline Excited State & 6: & $5.3793 \mathrm{eV}$ & $230.48 \mathrm{~nm}$ & $f=0.0326$ \\
\hline 82 -> 86 & & 0.49386 & $49 \%$ & \\
\hline 82 -> 94 & & 0.33374 & $22 \%$ & \\
\hline Excited State & 7: & $5.3915 \mathrm{eV}$ & $229.96 \mathrm{~nm}$ & $f=0.0003$ \\
\hline 79 -> 83 & & -0.36258 & $26 \%$ & \\
\hline 81 -> 84 & & 0.49811 & $50 \%$ & \\
\hline Excited State & 8: & $5.4314 \mathrm{eV}$ & $228.27 \mathrm{~nm}$ & $f=0.0054$ \\
\hline $82->86$ & & 0.26075 & $14 \%$ & \\
\hline $82->88$ & & 0.35063 & $25 \%$ & \\
\hline 82 -> 94 & & -0.24450 & $12 \%$ & \\
\hline Excited State & 9: & $5.5674 \mathrm{eV}$ & $222.70 \mathrm{~nm}$ & $f=0.2163$ \\
\hline 82 -> 92 & & 0.33145 & $22 \%$ & \\
\hline 82 -> 93 & & -0.25345 & $13 \%$ & \\
\hline 82 -> 96 & & 0.22727 & $10 \%$ & \\
\hline 82 -> 98 & & -0.26638 & $14 \%$ & \\
\hline Excited State & 10: & $5.7513 \mathrm{eV}$ & $215.58 \mathrm{~nm}$ & $f=0.0055$ \\
\hline $82->89$ & & 0.38037 & $29 \%$ & \\
\hline 82 -> 90 & & -0.32132 & $21 \%$ & \\
\hline 82 -> 91 & & 0.31404 & $20 \%$ & \\
\hline Excited State & 11: & 5.8089 eV & $213.44 \mathrm{~nm}$ & $f=0.0013$ \\
\hline 82 -> 89 & & 0.27799 & $15 \%$ & \\
\hline 82 -> 90 & & 0.48104 & $46 \%$ & \\
\hline 82 -> 91 & & 0.23094 & $11 \%$ & \\
\hline Excited State & 12: & $5.8432 \mathrm{eV}$ & $212.18 \mathrm{~nm}$ & $f=0.0106$ \\
\hline $82->89$ & & -0.28170 & $16 \%$ & \\
\hline 82 -> 91 & & 0.46555 & $43 \%$ & \\
\hline 82 -> 94 & & 0.27185 & $15 \%$ & \\
\hline Excited State & 13: & $5.8701 \mathrm{eV}$ & $211.21 \mathrm{~nm}$ & $f=0.0129$ \\
\hline 82 -> 92 & & 0.29123 & $17 \%$ & \\
\hline 82 -> 93 & & 0.28205 & $16 \%$ & \\
\hline 82 -> 94 & & 0.26935 & $15 \%$ & \\
\hline 82 -> 95 & & -0.23287 & $11 \%$ & \\
\hline Excited State & 14: & $5.9445 \mathrm{eV}$ & $208.57 \mathrm{~nm}$ & $f=0.0045$ \\
\hline 78 -> 84 & & 0.34000 & $23 \%$ & \\
\hline 78 -> 93 & & 0.27738 & $15 \%$ & \\
\hline 78 -> 94 & & -0.31584 & $20 \%$ & \\
\hline Excited State & 15: & $5.9915 \mathrm{eV}$ & $206.93 \mathrm{~nm}$ & $f=0.0511$ \\
\hline 79 -> 84 & & 0.32259 & $21 \%$ & \\
\hline
\end{tabular}




\begin{tabular}{|c|c|c|c|}
\hline $81->83$ & 0.47396 & $45 \%$ & \\
\hline Excited State 16: & $6.0269 \mathrm{eV}$ & $205.72 \mathrm{~nm}$ & $f=0.1287$ \\
\hline $81->83$ & 0.22005 & $10 \%$ & \\
\hline $82->93$ & 0.29778 & $18 \%$ & \\
\hline $82->98$ & -0.28076 & $16 \%$ & \\
\hline $82->101$ & 0.23271 & $11 \%$ & \\
\hline Excited State 17: & $6.1241 \mathrm{eV}$ & $202.45 \mathrm{~nm}$ & $f=0.0036$ \\
\hline $82->95$ & 0.57452 & $66 \%$ & \\
\hline
\end{tabular}

Table S27. First 50 excited states of (Z) IV + A.

\begin{tabular}{|c|c|c|c|c|}
\hline Excited State & 1: & $4.2667 \mathrm{eV}$ & $290.58 \mathrm{~nm}$ & $f=0.0057$ \\
\hline $82->83$ & & 0.69143 & $96 \%$ & \\
\hline Excited State & 2: & $4.3189 \mathrm{eV}$ & $287.08 \mathrm{~nm}$ & $f=0.0068$ \\
\hline $82->84$ & & 0.69252 & $96 \%$ & \\
\hline Excited State & 3: & $4.6110 \mathrm{eV}$ & $268.89 \mathrm{~nm}$ & $f=0.0085$ \\
\hline $82->85$ & & 0.65036 & $85 \%$ & \\
\hline Excited State & 4: & $4.8586 \mathrm{eV}$ & $255.18 \mathrm{~nm}$ & $f=0.0184$ \\
\hline $82->86$ & & 0.33472 & $22 \%$ & \\
\hline $82->87$ & & 0.44412 & $39 \%$ & \\
\hline $82->88$ & & 0.30988 & $19 \%$ & \\
\hline Excited State & 5: & $5.0179 \mathrm{eV}$ & $247.08 \mathrm{~nm}$ & $f=0.0051$ \\
\hline $82->87$ & & -0.40924 & $33 \%$ & \\
\hline $82->88$ & & 0.50549 & $51 \%$ & \\
\hline Excited State & 6: & $5.0510 \mathrm{eV}$ & $245.47 \mathrm{~nm}$ & $f=0.0276$ \\
\hline $82->86$ & & 0.57645 & $66 \%$ & \\
\hline $82->87$ & & -0.27475 & $15 \%$ & \\
\hline Excited State & 7: & $5.1476 \mathrm{eV}$ & $240.86 \mathrm{~nm}$ & $f=0.0069$ \\
\hline $82->88$ & & 0.27514 & $15 \%$ & \\
\hline $82->89$ & & 0.44303 & $39 \%$ & \\
\hline $82->90$ & & 0.26820 & $14 \%$ & \\
\hline Excited State & 8: & $5.3654 \mathrm{eV}$ & $231.08 \mathrm{~nm}$ & $f=0.0009$ \\
\hline 79 -> 83 & & -0.29786 & $18 \%$ & \\
\hline 79 -> 84 & & -0.32258 & $21 \%$ & \\
\hline 81 -> 83 & & 0.39810 & $32 \%$ & \\
\hline $81->84$ & & -0.33506 & $22 \%$ & \\
\hline Excited State & 9: & $5.3786 \mathrm{eV}$ & $230.51 \mathrm{~nm}$ & $f=0.0021$ \\
\hline $82->89$ & & 0.43193 & $37 \%$ & \\
\hline $82->90$ & & -0.32891 & $22 \%$ & \\
\hline $82->91$ & & -0.32923 & $22 \%$ & \\
\hline $82->92$ & & -0.23399 & $11 \%$ & \\
\hline Excited State & 10: & $5.4371 \mathrm{eV}$ & $228.03 \mathrm{~nm}$ & $f=0.0092$ \\
\hline $82->90$ & & 0.48379 & $47 \%$ & \\
\hline
\end{tabular}




\begin{tabular}{|c|c|c|c|}
\hline $82->91$ & -0.45035 & $41 \%$ & \\
\hline Excited State 11: & $5.4953 \mathrm{eV}$ & $225.62 \mathrm{~nm}$ & $f=\mathbf{0 . 0 0 7 7}$ \\
\hline $82->91$ & -0.29337 & $17 \%$ & \\
\hline $82->92$ & 0.58163 & $68 \%$ & \\
\hline Excited State 12: & $5.5913 \mathrm{eV}$ & $221.75 \mathrm{~nm}$ & $f=0.0019$ \\
\hline $82->93$ & 0.53863 & $58 \%$ & \\
\hline $82->94$ & 0.33776 & $23 \%$ & \\
\hline Excited State 13: & $5.6390 \mathrm{eV}$ & $219.87 \mathrm{~nm}$ & $f=\mathbf{0 . 0 5 8 3}$ \\
\hline $82->93$ & -0.32803 & $22 \%$ & \\
\hline $82->94$ & 0.56969 & $65 \%$ & \\
\hline Excited State 14: & $5.7370 \mathrm{eV}$ & $216.11 \mathrm{~nm}$ & $f=0.3562$ \\
\hline $82->95$ & 0.42658 & $36 \%$ & \\
\hline $82->96$ & 0.51344 & $53 \%$ & \\
\hline Excited State 15: & $5.8159 \mathrm{eV}$ & $213.18 \mathrm{~nm}$ & $f=0.0276$ \\
\hline $82->95$ & 0.51209 & $52 \%$ & \\
\hline $82->96$ & -0.38937 & $30 \%$ & \\
\hline Excited State 16: & $5.8474 \mathrm{eV}$ & $212.03 \mathrm{~nm}$ & $f=0.0034$ \\
\hline $78->83$ & 0.39035 & $30 \%$ & \\
\hline $78->89$ & -0.23362 & $11 \%$ & \\
\hline $78->90$ & -0.22114 & $10 \%$ & \\
\hline Excited State 17: & $5.9387 \mathrm{eV}$ & $208.77 \mathrm{~nm}$ & $f=0.0150$ \\
\hline $79->83$ & 0.27084 & $15 \%$ & \\
\hline $81->83$ & 0.32962 & $22 \%$ & \\
\hline $81->84$ & 0.33871 & $23 \%$ & \\
\hline $82->97$ & 0.34288 & $24 \%$ & \\
\hline Excited State 18: & $5.9520 \mathrm{eV}$ & $208.31 \mathrm{~nm}$ & $f=0.0091$ \\
\hline $82->97$ & 0.57603 & $66 \%$ & \\
\hline Excited State 19: & $5.9868 \mathrm{eV}$ & $207.10 \mathrm{~nm}$ & $f=0.0031$ \\
\hline $82->98$ & 0.66292 & $88 \%$ & \\
\hline Excited State 20: & $6.0126 \mathrm{eV}$ & $206.21 \mathrm{~nm}$ & $f=0.0141$ \\
\hline $80->83$ & 0.61985 & $77 \%$ & \\
\hline $80->84$ & 0.20950 & $9 \%$ & \\
\hline Excited State 21: & $6.0743 \mathrm{eV}$ & $204.11 \mathrm{~nm}$ & $f=0.0104$ \\
\hline $80->84$ & 0.64696 & $84 \%$ & \\
\hline Excited State 22: & $6.1101 \mathrm{eV}$ & $202.92 \mathrm{~nm}$ & $f=0.0009$ \\
\hline $82->99$ & 0.67178 & $90 \%$ & \\
\hline Excited State 23: & $6.2241 \mathrm{eV}$ & $199.20 \mathrm{~nm}$ & $f=0.0232$ \\
\hline $82->100$ & 0.66897 & $90 \%$ & \\
\hline Excited State 24: & $6.2555 \mathrm{eV}$ & $198.20 \mathrm{~nm}$ & $f=0.0014$ \\
\hline 82 -> 101 & 0.66449 & $88 \%$ & \\
\hline Excited State 25: & $6.2628 \mathrm{eV}$ & $197.97 \mathrm{~nm}$ & $f=0.0075$ \\
\hline $81->85$ & 0.59021 & $70 \%$ & \\
\hline $81->88$ & 0.23251 & $11 \%$ & \\
\hline Excited State 26: & $6.3378 \mathrm{eV}$ & $195.63 \mathrm{~nm}$ & $f=0.0118$ \\
\hline $80->85$ & 0.61330 & $75 \%$ & \\
\hline
\end{tabular}




\begin{tabular}{|c|c|c|c|}
\hline $80->87$ & 0.22581 & $10 \%$ & \\
\hline Excited State 27: & $6.3720 \mathrm{eV}$ & $194.58 \mathrm{~nm}$ & $f=0.0424$ \\
\hline $78->83$ & 0.28748 & $17 \%$ & \\
\hline $78->84$ & 0.40865 & $33 \%$ & \\
\hline Excited State 28: & $6.3831 \mathrm{eV}$ & $194.24 \mathrm{~nm}$ & $f=0.0224$ \\
\hline $82->102$ & 0.60110 & $72 \%$ & \\
\hline $82->103$ & -0.28296 & $16 \%$ & \\
\hline Excited State 29: & $6.3998 \mathrm{eV}$ & $193.73 \mathrm{~nm}$ & $f=0.0626$ \\
\hline $78->84$ & 0.32653 & $21 \%$ & \\
\hline $79->84$ & -0.23875 & $11 \%$ & \\
\hline $79->85$ & 0.35856 & $26 \%$ & \\
\hline Excited State 30: & $6.4228 \mathrm{eV}$ & $193.04 \mathrm{~nm}$ & $f=0.0061$ \\
\hline $79->85$ & -0.22418 & $10 \%$ & \\
\hline $82->102$ & 0.26022 & $14 \%$ & \\
\hline $82->103$ & 0.45410 & $41 \%$ & \\
\hline $82->104$ & 0.34062 & $23 \%$ & \\
\hline Excited State 31: & $6.4604 \mathrm{eV}$ & $191.91 \mathrm{~nm}$ & $f=0.0250$ \\
\hline $82->103$ & -0.35703 & $25 \%$ & \\
\hline $82->104$ & 0.41779 & $35 \%$ & \\
\hline Excited State 32: & $6.4641 \mathrm{eV}$ & $191.80 \mathrm{~nm}$ & $f=0.0267$ \\
\hline $79->85$ & 0.24917 & $12 \%$ & \\
\hline $82->104$ & 0.35396 & $25 \%$ & \\
\hline $82->105$ & 0.24833 & $12 \%$ & \\
\hline Excited State 33: & $6.4731 \mathrm{eV}$ & $191.54 \mathrm{~nm}$ & $\mathbf{f}=\mathbf{0 . 0 2 3 7}$ \\
\hline $82->105$ & 0.53572 & $57 \%$ & \\
\hline $82->106$ & 0.28666 & $16 \%$ & \\
\hline Excited State 34: & $6.5322 \mathrm{eV}$ & $189.81 \mathrm{~nm}$ & $f=0.0842$ \\
\hline $78->83$ & -0.28715 & $16 \%$ & \\
\hline $78->84$ & 0.36233 & $26 \%$ & \\
\hline Excited State 35: & $6.5549 \mathrm{eV}$ & $189.15 \mathrm{~nm}$ & $f=0.2113$ \\
\hline $78->83$ & -0.28485 & $16 \%$ & \\
\hline $79->83$ & 0.23306 & $11 \%$ & \\
\hline $79->84$ & -0.23627 & $11 \%$ & \\
\hline $82->106$ & 0.29780 & $18 \%$ & \\
\hline Excited State 36: & $6.5705 \mathrm{eV}$ & $188.70 \mathrm{~nm}$ & $f=0.1288$ \\
\hline $82->105$ & -0.29735 & $18 \%$ & \\
\hline $82->106$ & 0.48380 & $47 \%$ & \\
\hline Excited State 37: & $6.6517 \mathrm{eV}$ & $186.40 \mathrm{~nm}$ & $f=0.0710$ \\
\hline $80->86$ & 0.25889 & $13 \%$ & \\
\hline $81->86$ & 0.23092 & $11 \%$ & \\
\hline $81->87$ & 0.31391 & $20 \%$ & \\
\hline Excited State 38: & $6.7027 \mathrm{eV}$ & $184.98 \mathrm{~nm}$ & $f=0.0061$ \\
\hline $81 \rightarrow 86$ & -0.27914 & $16 \%$ & \\
\hline $81->87$ & 0.46798 & $44 \%$ & \\
\hline $81->88$ & 0.24684 & $12 \%$ & \\
\hline
\end{tabular}




\begin{tabular}{|c|c|c|c|}
\hline Excited State 39: & $6.7079 \mathrm{eV}$ & $184.83 \mathrm{~nm}$ & $f=0.1850$ \\
\hline $80->86$ & 0.42511 & $36 \%$ & \\
\hline $81->86$ & -0.24607 & $12 \%$ & \\
\hline Excited State 40: & $6.7206 \mathrm{eV}$ & $184.48 \mathrm{~nm}$ & $f=0.0394$ \\
\hline $78->85$ & 0.23677 & $11 \%$ & \\
\hline $81->87$ & -0.22228 & $10 \%$ & \\
\hline $81->88$ & 0.46282 & $43 \%$ & \\
\hline Excited State 41: & $6.7697 \mathrm{eV}$ & $183.15 \mathrm{~nm}$ & $f=0.0118$ \\
\hline $78->85$ & 0.46631 & $43 \%$ & \\
\hline $81->88$ & -0.27580 & $15 \%$ & \\
\hline Excited State 42: & $6.7778 \mathrm{eV}$ & $182.93 \mathrm{~nm}$ & $f=0.0016$ \\
\hline $82->107$ & 0.50499 & $51 \%$ & \\
\hline $82->108$ & 0.39903 & $32 \%$ & \\
\hline Excited State 43: & $6.7886 \mathrm{eV}$ & $182.63 \mathrm{~nm}$ & $f=0.0181$ \\
\hline $80->87$ & 0.53708 & $58 \%$ & \\
\hline Excited State 44: & $6.8016 \mathrm{eV}$ & $182.29 \mathrm{~nm}$ & $\mathbf{f}=\mathbf{0 . 0 3 5 7}$ \\
\hline 79 -> 86 & 0.34254 & $23 \%$ & \\
\hline 79 -> 89 & -0.23504 & $11 \%$ & \\
\hline 81 -> 90 & -0.23422 & $11 \%$ & \\
\hline Excited State 45: & $6.8154 \mathrm{eV}$ & $181.92 \mathrm{~nm}$ & $f=0.0083$ \\
\hline $82->107$ & -0.42839 & $37 \%$ & \\
\hline $82->108$ & 0.45258 & $41 \%$ & \\
\hline Excited State 46: & $6.8335 \mathrm{eV}$ & $181.44 \mathrm{~nm}$ & $f=0.0080$ \\
\hline $80->88$ & 0.59085 & $70 \%$ & \\
\hline Excited State 47: & $6.8461 \mathrm{eV}$ & $181.10 \mathrm{~nm}$ & $f=0.0368$ \\
\hline 79 -> 87 & 0.58961 & $70 \%$ & \\
\hline Excited State 48: & $6.8516 \mathrm{eV}$ & $180.96 \mathrm{~nm}$ & $\mathbf{f}=\mathbf{0 . 0 0 1 2}$ \\
\hline $82->109$ & 0.61898 & $77 \%$ & \\
\hline Excited State 49: & $6.8701 \mathrm{eV}$ & $180.47 \mathrm{~nm}$ & $\mathbf{f}=\mathbf{0 . 1 0 7 7}$ \\
\hline $79->85$ & -0.26806 & $14 \%$ & \\
\hline 79 -> 86 & -0.28651 & $16 \%$ & \\
\hline 79 -> 88 & 0.29859 & $18 \%$ & \\
\hline 81 -> 90 & -0.26419 & $14 \%$ & \\
\hline Excited State 50: & $6.9070 \mathrm{eV}$ & $179.51 \mathrm{~nm}$ & $f=0.0111$ \\
\hline $82->110$ & 0.62729 & $79 \%$ & \\
\hline
\end{tabular}

Table S28. Excited states $>190 \mathrm{~nm}$ of $\mathbf{I V}+\mathbf{B}$.

\begin{tabular}{|c|c|c|c|c|}
\hline Excited State & 1: & $4.0873 \mathrm{eV}$ & $303.34 \mathrm{~nm}$ & $f=0.0155$ \\
\hline 83 & & 0.6 & $96 \%$ & \\
\hline Excited State & o. & $4.1015 \mathrm{eV}$ & $302.29 \mathrm{~nm}$ & $f=0.0308$ \\
\hline $81->82$ & & 0.69185 & $96 \%$ & \\
\hline Excited State & 3: & $4.4542 \mathrm{eV}$ & $278.35 \mathrm{~nm}$ & $f=0.099$ \\
\hline
\end{tabular}




\begin{tabular}{|c|c|c|c|c|}
\hline $81->84$ & & -0.29146 & $17 \%$ & \\
\hline $81->85$ & & 0.54102 & $59 \%$ & \\
\hline $81->86$ & & 0.28180 & $16 \%$ & \\
\hline Excited State & 4: & $4.4727 \mathrm{eV}$ & $277.20 \mathrm{~nm}$ & $f=0.4662$ \\
\hline $81->84$ & & 0.56770 & $64 \%$ & \\
\hline $81->85$ & & 0.32849 & $22 \%$ & \\
\hline Excited State & 5: & $4.6617 \mathrm{eV}$ & $265.97 \mathrm{~nm}$ & $f=0.1911$ \\
\hline $81->84$ & & 0.21969 & $10 \%$ & \\
\hline $81->86$ & & 0.57544 & $66 \%$ & \\
\hline $81->88$ & & 0.25179 & $13 \%$ & \\
\hline Excited State & 6: & $4.8568 \mathrm{eV}$ & $255.28 \mathrm{~nm}$ & $\mathbf{f}=\mathbf{0 . 0 2 3 5}$ \\
\hline $81->87$ & & 0.61062 & $75 \%$ & \\
\hline Excited State & 7: & $4.8789 \mathrm{eV}$ & $254.13 \mathrm{~nm}$ & $f=0.1153$ \\
\hline $81->88$ & & 0.55799 & $62 \%$ & \\
\hline Excited State & 8: & $4.9607 \mathrm{eV}$ & $249.94 \mathrm{~nm}$ & $f=0.1756$ \\
\hline 81 -> 89 & & 0.46960 & $44 \%$ & \\
\hline $81->90$ & & 0.35397 & $25 \%$ & \\
\hline $81->92$ & & 0.29831 & $18 \%$ & \\
\hline Excited State & 9: & $5.1146 \mathrm{eV}$ & $242.41 \mathrm{~nm}$ & $f=0.0280$ \\
\hline $81->89$ & & -0.45003 & $41 \%$ & \\
\hline $81->90$ & & 0.45812 & $42 \%$ & \\
\hline Excited State & 10: & $5.1976 \mathrm{eV}$ & $238.54 \mathrm{~nm}$ & $f=0.0145$ \\
\hline $81->90$ & & -0.22776 & $10 \%$ & \\
\hline 81 -> 91 & & -0.27103 & $15 \%$ & \\
\hline 81 -> 92 & & 0.38243 & $29 \%$ & \\
\hline $81->93$ & & -0.32900 & $22 \%$ & \\
\hline Excited State & 11: & $5.2403 \mathrm{eV}$ & $236.60 \mathrm{~nm}$ & $\mathbf{f}=\mathbf{0 . 0 2 3 2}$ \\
\hline $81->90$ & & -0.25857 & $13 \%$ & \\
\hline $81->91$ & & 0.51695 & $53 \%$ & \\
\hline $81->92$ & & 0.31914 & $20 \%$ & \\
\hline Excited State & 12: & $5.3020 \mathrm{eV}$ & $233.84 \mathrm{~nm}$ & $\mathbf{f}=\mathbf{0 . 0 0 7 2}$ \\
\hline $81->91$ & & -0.28297 & $16 \%$ & \\
\hline $81->92$ & & 0.25513 & $13 \%$ & \\
\hline $81->93$ & & 0.51338 & $53 \%$ & \\
\hline Excited State & 13: & $5.3597 \mathrm{eV}$ & $231.33 \mathrm{~nm}$ & $\mathbf{f}=\mathbf{0 . 0 0 0 1}$ \\
\hline $78->83$ & & -0.41734 & $35 \%$ & \\
\hline $80->82$ & & 0.50536 & $51 \%$ & \\
\hline Excited State & 14: & $5.4124 \mathrm{eV}$ & $229.08 \mathrm{~nm}$ & $f=0.0045$ \\
\hline $81->94$ & & 0.60794 & $74 \%$ & \\
\hline Excited State & 15: & $5.5405 \mathrm{eV}$ & $223.78 \mathrm{~nm}$ & $\mathbf{f}=\mathbf{0 . 0 0 2 7}$ \\
\hline $81->95$ & & 0.63437 & $80 \%$ & \\
\hline Excited State & 16: & $5.6257 \mathrm{eV}$ & $220.39 \mathrm{~nm}$ & $f=0.0018$ \\
\hline $81->96$ & & 0.65968 & $87 \%$ & \\
\hline Excited State & 17: & $5.6856 \mathrm{eV}$ & $218.07 \mathrm{~nm}$ & $f=0.0075$ \\
\hline 81 -> 97 & & -0.32435 & $21 \%$ & \\
\hline $81->98$ & & 0.51867 & $54 \%$ & \\
\hline
\end{tabular}




\begin{tabular}{|c|c|c|c|}
\hline Excited State 18: & $5.7413 \mathrm{eV}$ & $215.95 \mathrm{~nm}$ & $f=0.0037$ \\
\hline $81->97$ & 0.56061 & $63 \%$ & \\
\hline $81->98$ & 0.30356 & $18 \%$ & \\
\hline Excited State 19: & $5.8643 \mathrm{eV}$ & $211.42 \mathrm{~nm}$ & $f=0.0039$ \\
\hline $81->99$ & 0.63157 & $80 \%$ & \\
\hline Excited State 20: & $5.8700 \mathrm{eV}$ & $211.22 \mathrm{~nm}$ & $f=0.0052$ \\
\hline $77->82$ & 0.39051 & $30 \%$ & \\
\hline $77->89$ & -0.23677 & $11 \%$ & \\
\hline 77 -> 90 & -0.27401 & $15 \%$ & \\
\hline Excited State 21: & $5.9259 \mathrm{eV}$ & $209.22 \mathrm{~nm}$ & $f=0.0199$ \\
\hline $78->82$ & 0.38372 & $29 \%$ & \\
\hline $80->83$ & 0.55780 & $62 \%$ & \\
\hline Excited State 22: & $6.0056 \mathrm{eV}$ & $206.45 \mathrm{~nm}$ & $f=0.0008$ \\
\hline $81->100$ & 0.66169 & $88 \%$ & \\
\hline Excited State 23: & $6.0293 \mathrm{eV}$ & $205.64 \mathrm{~nm}$ & $f=0.0051$ \\
\hline $79->82$ & 0.26830 & $14 \%$ & \\
\hline $79->83$ & 0.62229 & $77 \%$ & \\
\hline Excited State 24: & $6.0610 \mathrm{eV}$ & $204.56 \mathrm{~nm}$ & $f=0.0204$ \\
\hline $79->82$ & 0.62853 & $79 \%$ & \\
\hline $79->83$ & -0.25591 & $13 \%$ & \\
\hline Excited State 25: & $6.1158 \mathrm{eV}$ & $202.73 \mathrm{~nm}$ & $f=0.0039$ \\
\hline $81->101$ & 0.67004 & $90 \%$ & \\
\hline Excited State 26: & $6.1839 \mathrm{eV}$ & $200.50 \mathrm{~nm}$ & $f=0.0018$ \\
\hline $81->102$ & 0.45968 & $42 \%$ & \\
\hline $81->103$ & 0.41716 & $35 \%$ & \\
\hline Excited State 27: & $6.1996 \mathrm{eV}$ & $199.99 \mathrm{~nm}$ & $f=0.0136$ \\
\hline $80->82$ & -0.27103 & $15 \%$ & \\
\hline $80->84$ & 0.47652 & $45 \%$ & \\
\hline Excited State 28: & $6.2037 \mathrm{eV}$ & $199.85 \mathrm{~nm}$ & $f=0.0047$ \\
\hline $81->102$ & -0.35503 & $25 \%$ & \\
\hline $81->103$ & 0.47711 & $46 \%$ & \\
\hline $81->104$ & -0.31170 & $19 \%$ & \\
\hline Excited State 29: & $6.2766 \mathrm{eV}$ & $197.54 \mathrm{~nm}$ & $f=0.0067$ \\
\hline $81->102$ & -0.24082 & $12 \%$ & \\
\hline $81->104$ & 0.50503 & $51 \%$ & \\
\hline $81->105$ & -0.34579 & $24 \%$ & \\
\hline Excited State 30: & $6.2995 \mathrm{eV}$ & $196.82 \mathrm{~nm}$ & $f=0.0070$ \\
\hline $80->85$ & 0.57864 & $67 \%$ & \\
\hline $80->87$ & 0.24905 & $12 \%$ & \\
\hline Excited State 31: & $6.3275 \mathrm{eV}$ & $195.94 \mathrm{~nm}$ & $f=0.0068$ \\
\hline $81->104$ & 0.31566 & $20 \%$ & \\
\hline $81->105$ & 0.51129 & $52 \%$ & \\
\hline Excited State 32: & $6.3462 \mathrm{eV}$ & $195.37 \mathrm{~nm}$ & $f=0.0248$ \\
\hline 79 -> 84 & 0.47845 & $46 \%$ & \\
\hline $79->85$ & -0.35405 & $25 \%$ & \\
\hline Fyoitod Stot & 2710 & & 0 \\
\hline
\end{tabular}




$\begin{array}{lll}77->83 & -0.22798 & 10 \% \\ 78->82 & -0.22594 & 10 \% \\ 78->83 & 0.25816 & 13 \% \\ 78->84 & 0.27618 & 15 \% \\ 78->85 & -0.18924 & 7 \% \\ 79->84 & 0.24606 & 12 \%\end{array}$

Excited State 34: $\quad 6.3932 \mathrm{eV} \quad 193.93 \mathrm{~nm} \quad \mathrm{f}=\mathbf{0 . 0 0 1 4}$ $81-105 \quad-0.22263 \quad 10 \%$

$81 \rightarrow 106 \quad 0.57959 \quad 67 \%$

$81->107 \quad-0.22753 \quad 10 \%$

Excited State 35: $\quad 6.4115 \mathrm{eV} \quad \mathbf{1 9 3 . 3 8} \mathrm{nm} \quad f=0.0335$

77 -> 83

78 -> 85

Excited State 36:

$$
\begin{aligned}
& 77 \text {-> } 83 \\
& 79 \text {-> } 84 \\
& 79 \text {-> } 85
\end{aligned}
$$

Excited State 37:

$$
78 \rightarrow 85
$$$$
81->107
$$

Excited State 38:

$$
78->84
$$$$
81->107
$$

Excited State 39:

78 -> 84

$80->84$

$80->86$
$0.49379 \quad 49 \%$

$-0.23013 \quad 11 \%$

$$
6.4221 \mathrm{eV}
$$

$193.06 \mathrm{~nm} f=0.0075$

$-0.27693$

0.33973

0.42662

$6.4587 \mathrm{eV}$

0.43283

$-0.28220$

$6.4719 \mathrm{eV}$

0.23193

0.45773

$6.5067 \mathrm{eV}$

$-0.23879$

0.31879

0.26200
$15 \%$

$23 \%$

$36 \%$

$191.97 \mathrm{~nm} f=0.0176$

$37 \%$

$16 \%$

$191.57 \mathrm{~nm} \quad f=0.0137$

$11 \%$

$42 \%$

$190.55 \mathrm{~nm} f=0.0855$

$11 \%$

$20 \%$

$14 \%$ 


\section{References}

(1) Gaussian 16, Revision C.01, Frisch, M. J.; Trucks, G. W.; Schlegel, H. B.; Scuseria, G. E.; Robb, M. A.; Cheeseman, J. R.; Scalmani, G.; Barone, V.; Petersson, G. A.; Nakatsuji, H.; Li, X.; Caricato, M.; Marenich, A. V.; Bloino, J.; Janesko, B. G.; Gomperts, R.; Mennucci, B.; Hratchian, H. P.; Ortiz, J. V.; Izmaylov, A. F.; Sonnenberg, J. L.; Williams-Young, D.; Ding, F.; Lipparini, F.; Egidi, F.; Goings, J.; Peng, B.; Petrone, A.; Henderson, T.; Ranasinghe, D.; Zakrzewski, V. G.; Gao, J.; Rega, N.; Zheng, G.; Liang, W.; Hada, M.; Ehara, M.; Toyota, K.; Fukuda, R.; Hasegawa, J.; Ishida, M.; Nakajima, T.; Honda, Y.; Kitao, O.; Nakai, H.; Vreven, T.; Throssell, K.; Montgomery, J. A., Jr.; Peralta, J. E.; Ogliaro, F.; Bearpark, M. J.; Heyd, J. J.; Brothers, E. N.; Kudin, K. N.; Staroverov, V. N.; Keith, T. A.; Kobayashi, R.; Normand, J.; Raghavachari, K.; Rendell, A. P.; Burant, J. C.; Iyengar, S. S.; Tomasi, J.; Cossi, M.; Millam, J. M.; Klene, M.; Adamo, C.; Cammi, R.; Ochterski, J. W.; Martin, R. L.; Morokuma, K.; Farkas, O.; Foresman, J. B.; Fox, D. J. Gaussian, Inc., Wallingford CT, 2016.

(2) Mennucci, B.; Cammi, R.; Tomasi, J. Excited States and Solvatochromic Shifts within a Nonequilibrium Solvation Approach: A New Formulation of the Integral Equation Formalism Method at the Self-Consistent Field, Configuration Interaction, and Multiconfiguration SelfConsistent Field Level. J. Chem. Phys. 1998, 109, 2798-2807.

(3) Hanwell, M.D.; Curtis, D.E.; Lonie, D.C.; Vandermeersch, T.; Zurek, E.; Hutchison, G.R. Avogadro: An advanced semantic chemical editor, visualization, and analysis platform. $J$. Cheminformatics 2012, 4 (17).

(4) Halgren, T.A. MMFF VI. MMFF94s option for energy minimization studies. J. Comput. Chem. 1999, 20 (7), 720-729.

(5) Zhao, Y.; Truhlar, D. The M06 suite of density functionals for main group thermochemistry, thermochemical kinetics, noncovalent interactions, excited states, and transition elements: two new functionals and systematic testing of four M06-class functionals and 12 other functionals. Theor. Chem. Acc. 2008, 120, 215-241.

(6) Ditchfield, R., Hehre, W. J., \& Pople, J. A. Self-Consistent Molecular-Orbital Methods. IX. An Extended Gaussian-Type Basis for Molecular-Orbital Studies of Organic Molecules. $J$. Chem. Phys. 1971, 54 (2), 724-728.

(7) (a) Becke, A. Density-functional thermochemistry. III. The role of exact exchange. J. Chem. Phys. 1993, 98, 5648-5652. (b) Lee, C.; Yang, W.; Parr, R. Development of the ColleSalvetti correlation-energy formula into a functional of the electron density. Phys. Rev. B 1988, 37, 785-789.

(8) (a) Perdew, J.; Burke, K.; Ernzerhof, M. Generalized Gradient Approximation Made Simple. Phys. Rev. Lett. 1996, 77, 3865-3868. (b) Adamo, C. Toward reliable density functional methods without adjustable parameters: The PBE0 model. J. Chem. Phys. 1999, 110, 6158-6169.

(9) Zhao, Y.; Truhlar, D. Density Functional for Spectroscopy: No Long-Range SelfInteraction Error, Good Performance for Rydberg and Charge-Transfer States, and Better Performance on Average than B3LYP for Ground States. J. Phys. Chem. A. 2006, 110 (49), 13126-13130.

(10) Yanai, T.; Tew, D.; Handy, N. A new hybrid exchange-correlation functional using the Coulomb-attenuating method (CAM-B3LYP). Chem. Phys. Lett. 2004, 393, 51-57. 
(11) Henderson, T.M.; Izmaylov, A.F.; Scalmani, G.; Scuseria, G.E. Can short-range hybrids describe long-range-dependent properties? J. Chem. Phys. 2009, 131, 044108.

(12) Chai, J.D.; Head-Gordon, M. Long-range corrected hybrid density functionals with damped atom-atom dispersion corrections. Phys. Chem. Chem. Phys. 2008, 10, 6615-6620.

(13) (a) Shao, Y.; Mei, Y.; Sundholm, D.; Kaila, V.R.I. Benchmarking the Performance of Time-Dependent Density Functional Theory Methods on Biochromophores. J. Chem. Theory Comput. 2020, 16 (1), 587-600. (b) Tao, Y.; Zhang, L.; Zou, W.; Kraka, E. Equilibrium Geometries, Adiabatic Excitation Energies and Intrinsic $\mathrm{C}=\mathrm{C} / \mathrm{C}-\mathrm{H}$ Bond Strengths of Ethylene in Lowest Singlet Excited States Described by TDDFT. Symmetry 2020, 12, 1545.

(14) Dunning, T. Gaussian basis sets for use in correlated molecular calculations. I. The atoms boron through neon and hydrogen. J. Chem. Phys. 1989, 90, 1007-23.

(15) Kendall, R.; Dunning, T.; Harrison, R. Electron affinities of the first-row atoms revisited. Systematic basis sets and wave functions. J. Chem. Phys. 1992, 96, 6796-806.

(16) Gauss View, Version 6, Dennington, Roy; Keith, Todd A.; Millam, John M. Semichem Inc., Shawnee Mission, KS, 2016.

(17) Momma, K.; Izumi, F. VESTA 3 for three-dimensional visualization of crystal, volumetric and morphology data. J. Appl. Crystallogr. 2011, 44, 1272-1276.

(18) Silvi, M.; Arceo, E.; Jurberg, I. D.; Cassani, C.; Melchiorre, P. Enantioselective Organocatalytic Alkylation of Aldehydes and Enals Driven by the Direct Photoexcitation of Enamines, J. Am. Chem. Soc. 2015, 137, 6120-6123. 